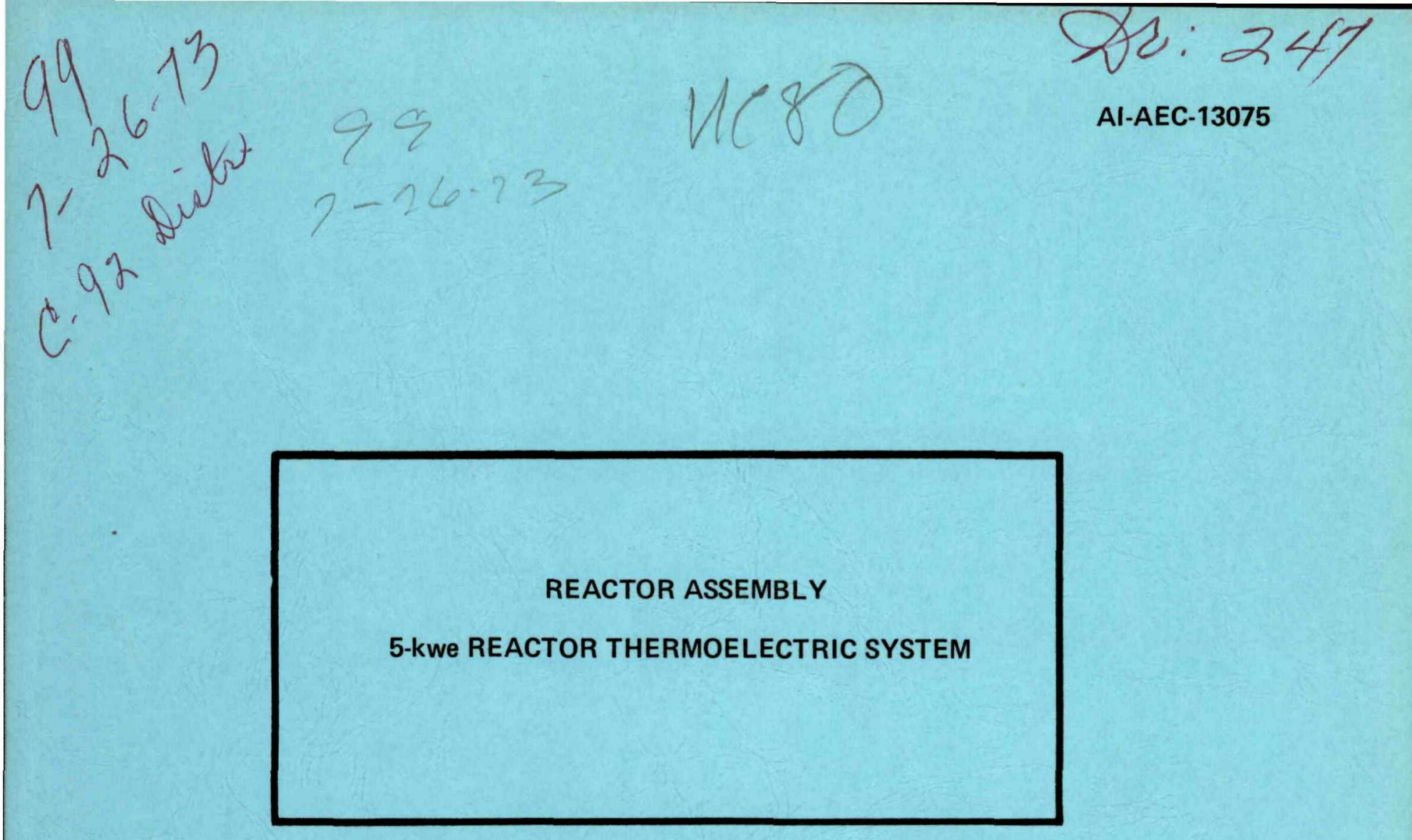

AEC Research and Development Report

Atomics International Division

Rockwell International

AI-AEC-13075

\title{
5-kwe REACTOR THERMOELECTRIC SYSTEM
}

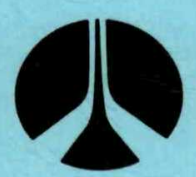

(2) 


\section{DISCLAIMER}

This report was prepared as an account of work sponsored by an agency of the United States Government. Neither the United States Government nor any agency Thereof, nor any of their employees, makes any warranty, express or implied, or assumes any legal liability or responsibility for the accuracy, completeness, or usefulness of any information, apparatus, product, or process disclosed, or represents that its use would not infringe privately owned rights. Reference herein to any specific commercial product, process, or service by trade name, trademark, manufacturer, or otherwise does not necessarily constitute or imply its endorsement, recommendation, or favoring by the United States Government or any agency thereof. The views and opinions of authors expressed herein do not necessarily state or reflect those of the United States Government or any agency thereof. 


\section{DISCLAIMER}

Portions of this document may be illegible in electronic image products. Images are produced from the best available original document. 


\section{NOTICE}

This report was prepared as an account of work sponsored by the United States Government. Neither the United States nor the United States Atomic Energy Commission, nor any of their employees, nor any of their contractors, subcontractors, or their employees, makes any warranty, express or implied, or assumes any legal liability or responsibility for the accuracy, completeness or usefulness of any information, apparatus, product or process disclosed, or represents that its use would not infringe privately owned rights. 
REACTOR ASSEMBLY

5-kwe REACTOR THERMOELECTRIC SYSTEM

H. ROOD

Editor

Contributors

D. BOST

J. V. FACHA

L. D. FELTEN

P. H. HORTON

R. T. THEXTON

R. J. TUTTLE 


\section{DISTRIBUTION}

This report has been distributed according to the category "Systems for Nuclear Auxiliary Power (SNAP) Reactor - SNAP Program," as given in the Standard Distribution for Classified Scientific and Technical Reports, M-3679. 


\section{CONTENTS}

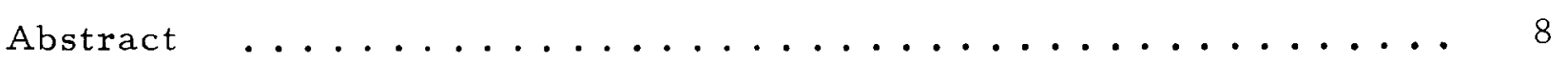

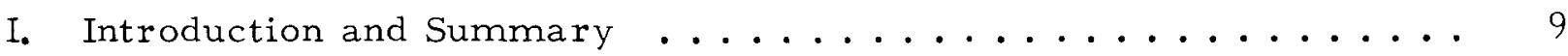

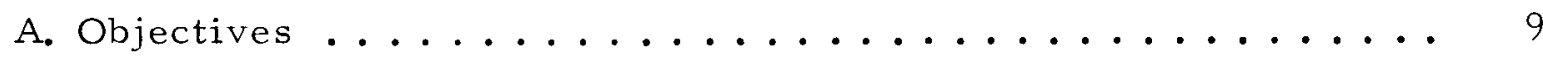

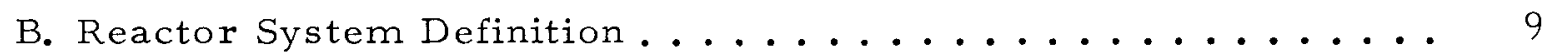

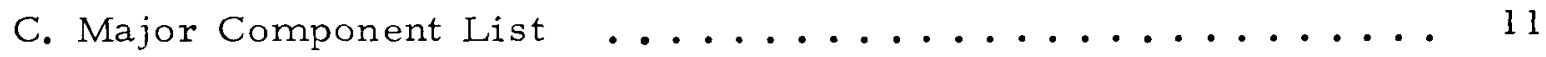

D. Reactor System Design Summary ................... 13

E. Reactor System Performance Summary . . . . . . . . . . 13

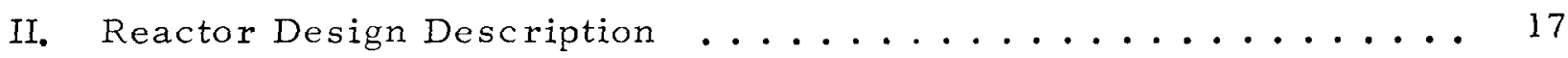

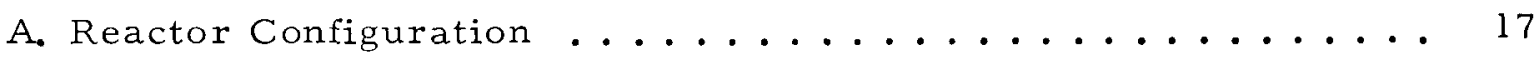

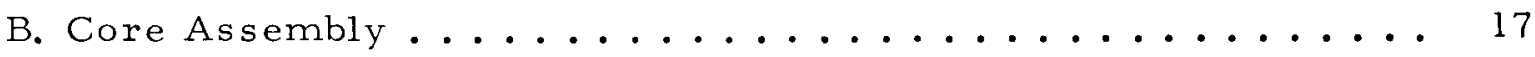

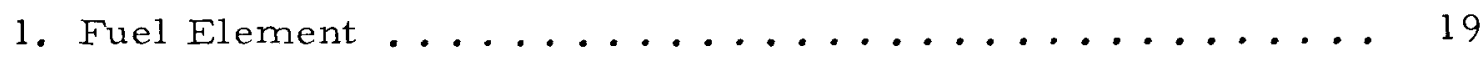

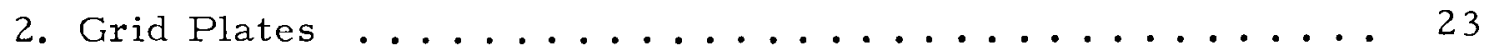

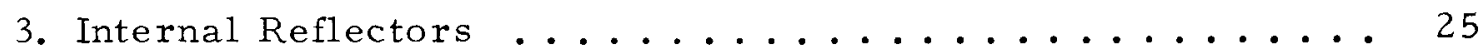

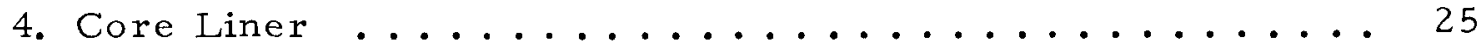

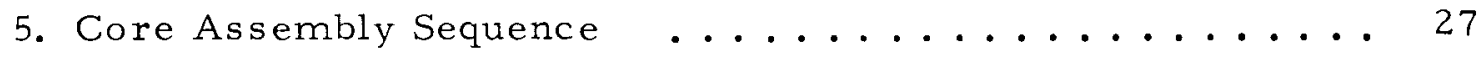

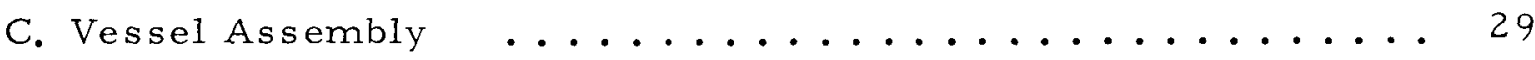

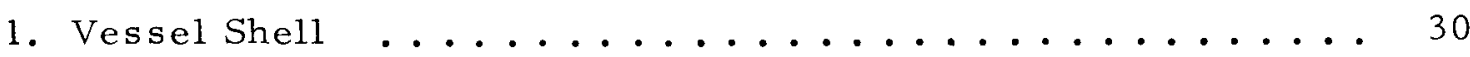

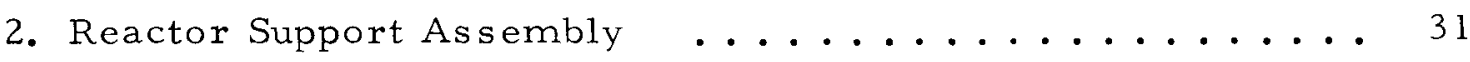

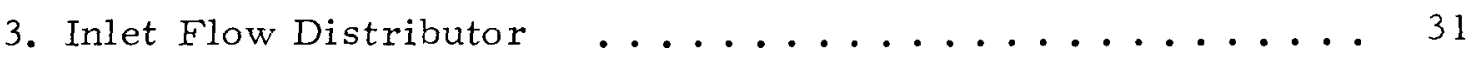

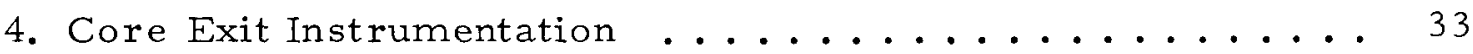

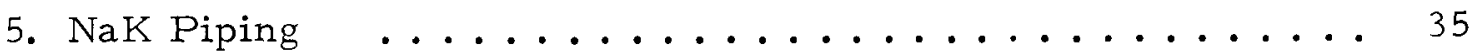

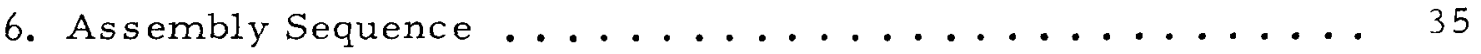

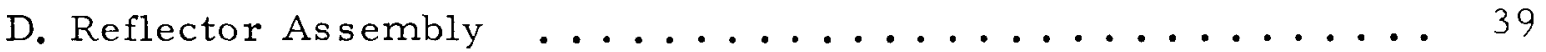

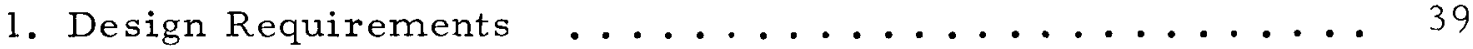

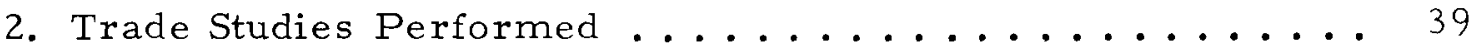

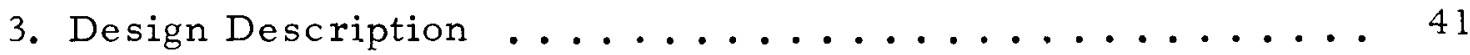

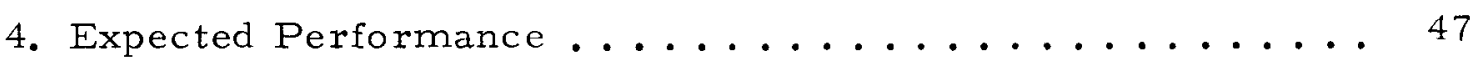

III. Thermal and Hydraulic Design and Performance ......... 53

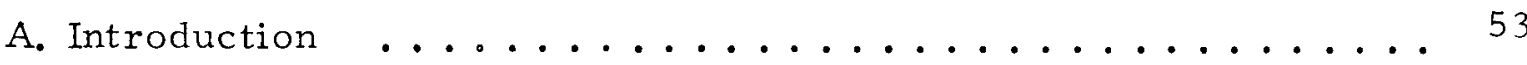

B. Plenum and Core Hydraulics ................ 53

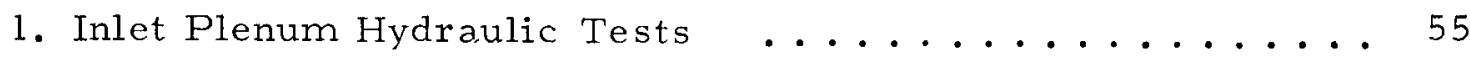

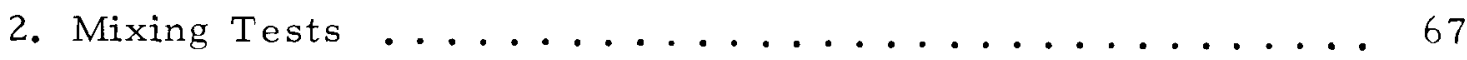

AI- AEC - 13075 
3. Hydraulic Performance ..................... 75

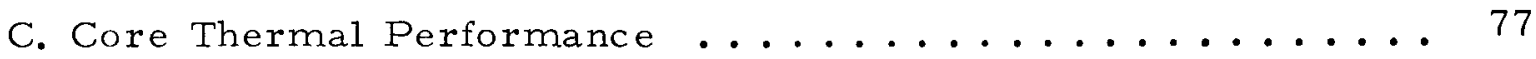

D. Thermal Transient Behavior ................ 83

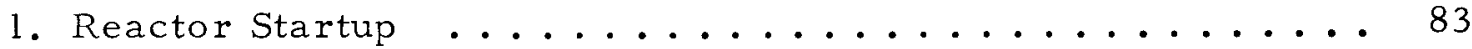

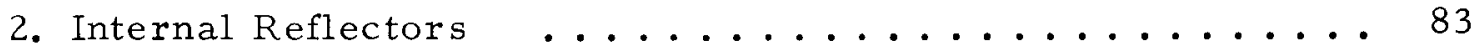

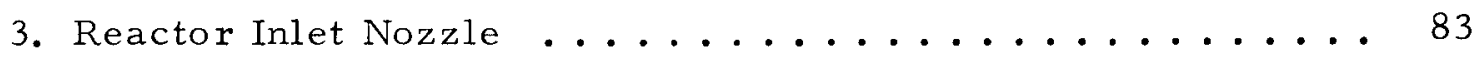

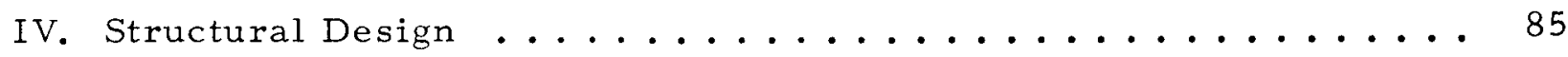

A. Reactor Vessel Structural Design Status .......... 85

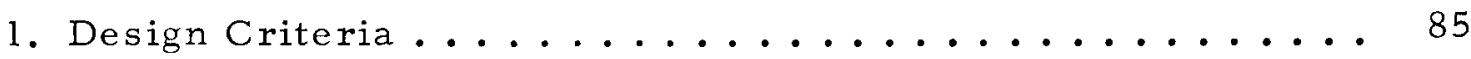

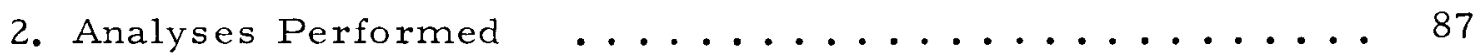

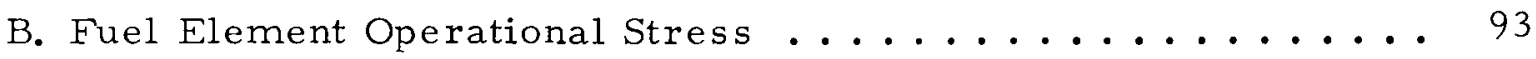

C. Grid Plate Launch Stresses ..................... 97

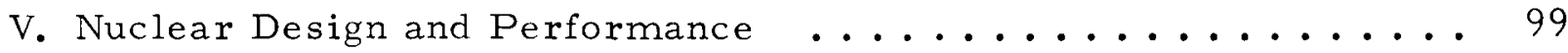

A. Introduction $\ldots \ldots \ldots \ldots . \ldots \ldots$

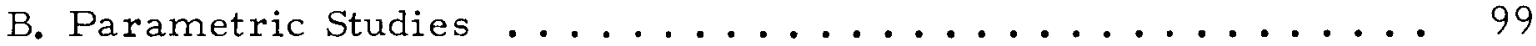

C. Nuclear Characteristics of the Selected Design .........101

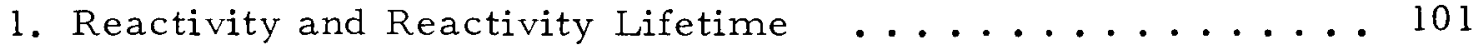

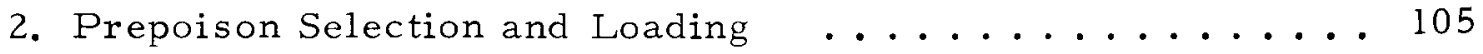

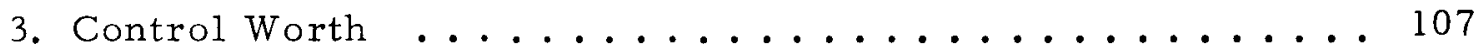

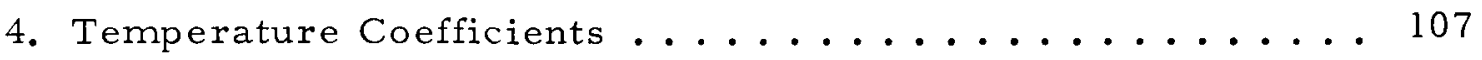

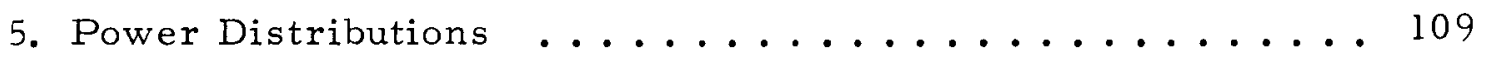

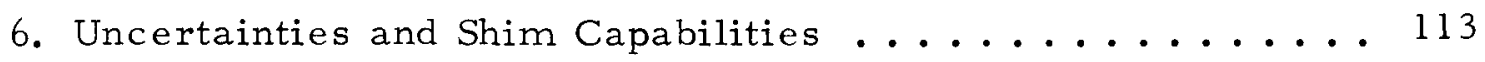

D. Methods of Nuclear Analysis Used ............... 114

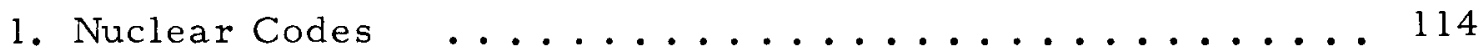

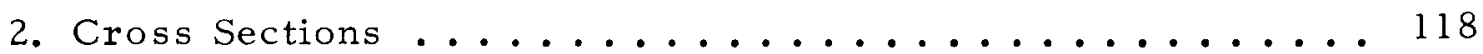

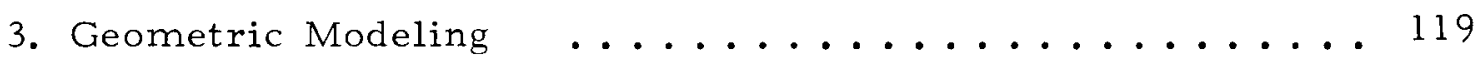

VI. Reactor Performance Margins ................. 121

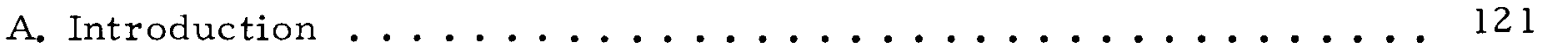

B. Reactivity Lifetime Margins ................. 12l

C. Fuel Element Performance Margins .............. 123

D. Automatic Control System Reliability ............ 124

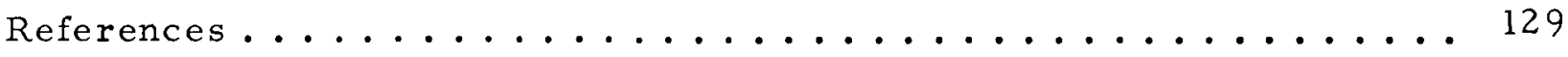

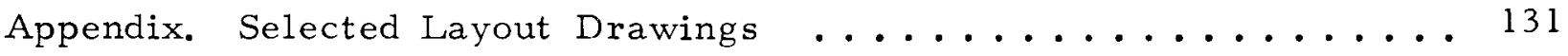

AI- AEC - 13075 


\section{TABLES}

Page

1. Reactor Core Design Summary ................... 12

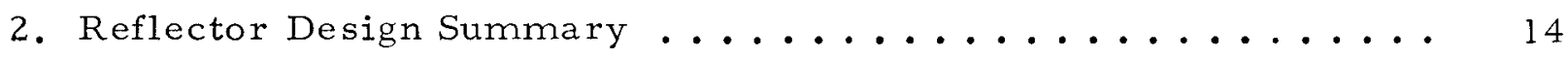

3. Reactor Instrumentation Summary .................. 15

4. Core Thermal Performance Summary .................. 15

5. Core Nuclear Performance Summary ............... 16

6. Control System Performance Summary .............. 16

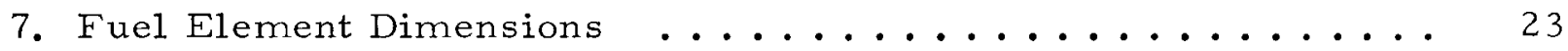

8. Operational Requirements of the Reflector System for the $1 . \ldots \ldots 40$

9. Reflector Environmental Requirements ............... 40

10. Nomenclature for Mixing Equations ............. 70

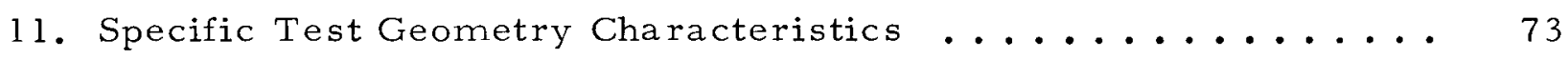

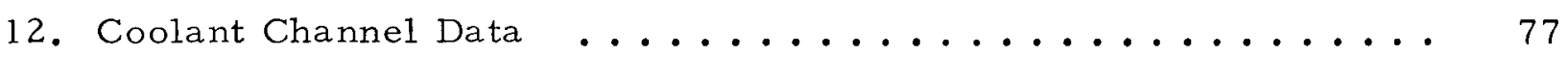

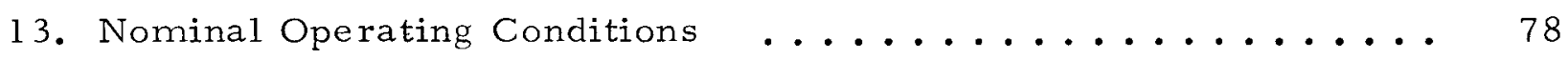

14. Hot Channel Factors, Center Element, Design Conditions .... 79

15. Hot Channel Factors, Center Element, BOL .......... 80

16. Hot Channel Factors, Center Element, EOL .......... 81

17. Reactor Vessel Structural Design Data . . . . . . . . . . . 87

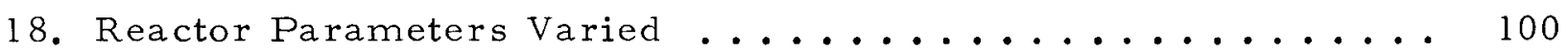

19. Number of Fuel Elements Trade Study .............. 100

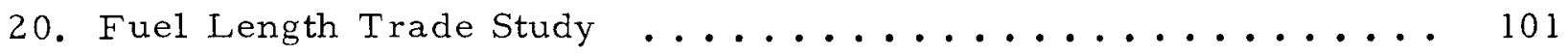

21. Summary of Parametric Studies, Weight Sensitive Coefficients . . 102

22. Reactor Design Summary .................... 102

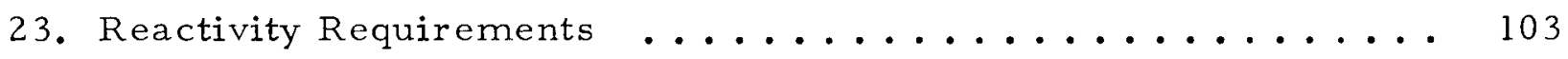

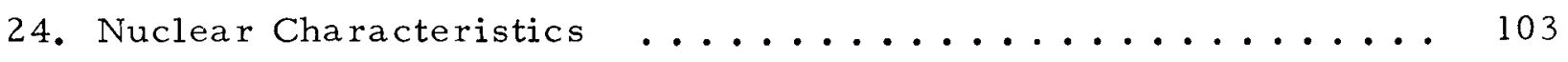

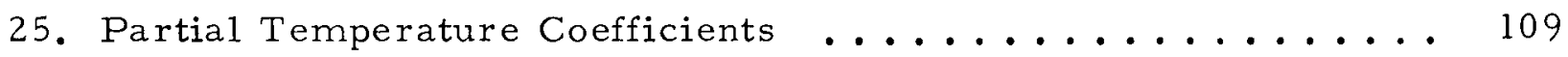

26. Comparison of Calculated and Experimental Reactivities of

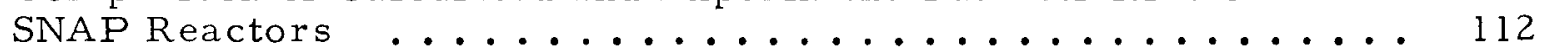

27. Reactivity Lifetime Uncertainties ................ 114

AI-AEC-13075 
1. 5-kwe Reactor Conceptual Design ................ 10

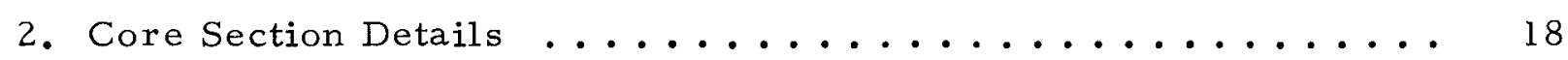

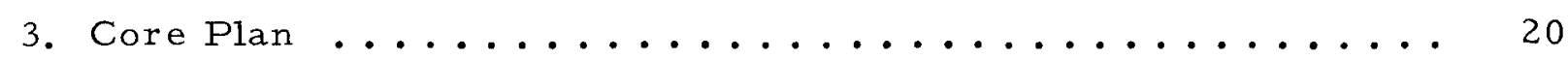

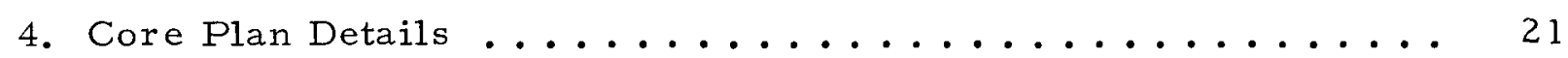

5. Fuel Element Cross Section (Neutral Element Identical

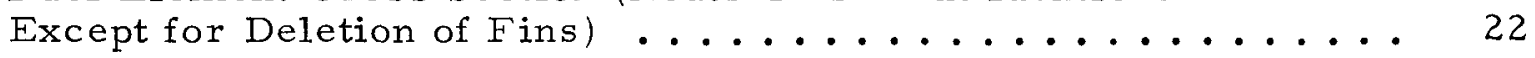

6. Fuel Bundle As sembly Sequence ................. 26

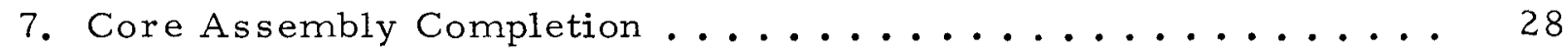

8. In-Channel Thermocouple Installation ............. 28

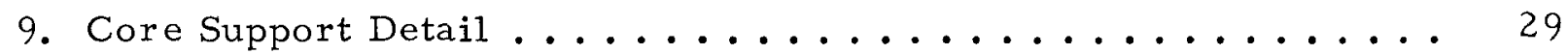

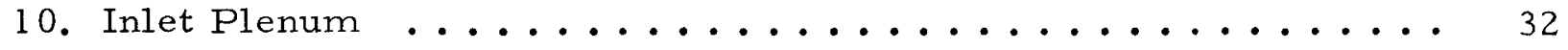

11. Core Exit Instrumentation Assembly ................ 33

12. Reflector Control Verification Test .............. 34

13. Install Channel Exit Thermocouple Assembly . . . . . . . . . 36

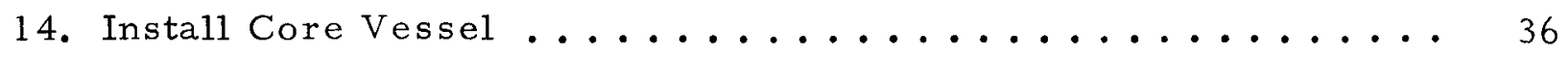

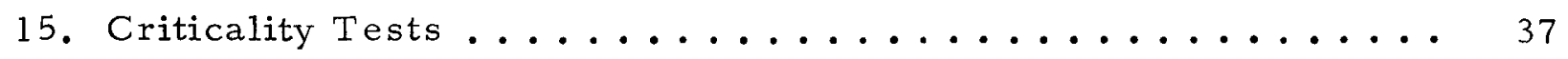

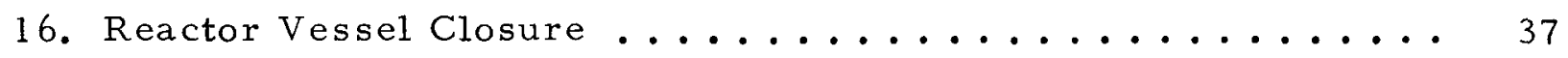

17. Sliding Reflector Control Drive ................. . . 42

18. Backup Shutdown-Restart Mechanism .............. . 46

19. Alumina vs Carbon-Graphite Friction ............. 48

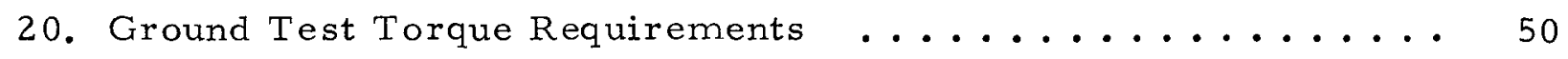

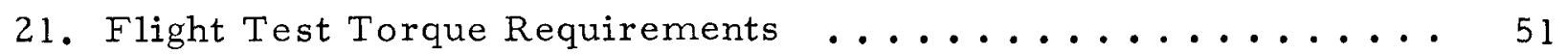

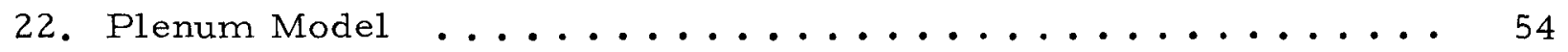

23. Potential Flow Lines at Top of Inlet Plenum 1-1/2-in. Inlet Line Height ................... 56

24. Horizontal Velocity Vectors at Top of Inlet Plenum $1-1 / 2-i n$. Inlet Line Height $\ldots \ldots \ldots \ldots$

25. Potential Flow Lines at Top of Inlet Plenum -

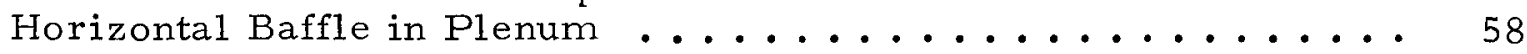

26. Horizontal Velocity Vectors at Top of Inlet Plenum -

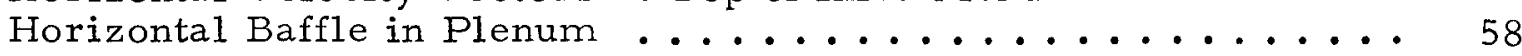

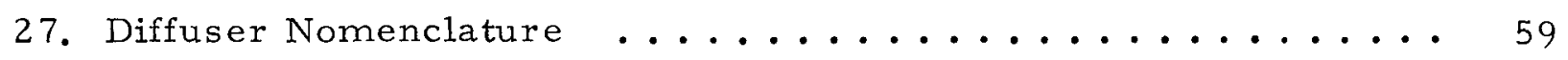




\section{FIGURES}

Page

28. Flow Regimes in Sträight-Wall, Two-Dimensional Diffusers .... 60

29. Hydraulic Test Data, Initial Tests . . . . . . . . . . . . . 62

30. Quarter Section of Configuration I Baffle . . . . . . . . . . 64

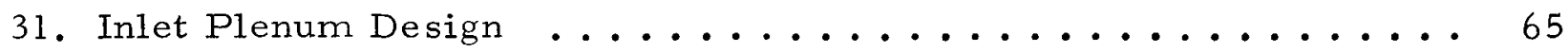

32. Hydraulic Test Data, Final Configuration . . . . . . . . . . . 66

33. Hydraulic Test Grid Pressure Variation, Base Case

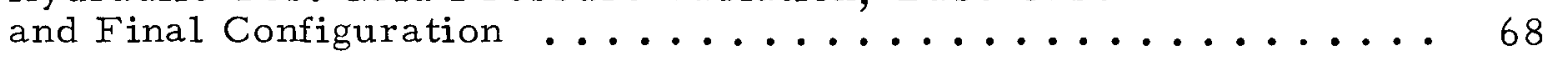

34. 19-Element Mixing Test Bundle, RLN Fins, Triple Injection ... . 69

35. Mixing Equation Nomenclature ................ 72

36. Theoretical-Experimental Comparison, 30-mil Fin Data ..... 74

37. Flow Channels at Edge of Core .................. 76

38. Reference Startup Transient ...................... 82

39. Stress Categories and Limits of Stress Intensity, $\mathrm{T}<800^{\circ} \mathrm{F} \ldots 84$

40. Stress Categories and Limits of Stress Intensity, $\mathrm{T}>800^{\circ} \mathrm{F} \ldots 86$

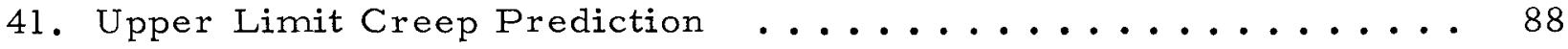

42. Outlet Plenum Head Finite Element Analysis ........... . . 90

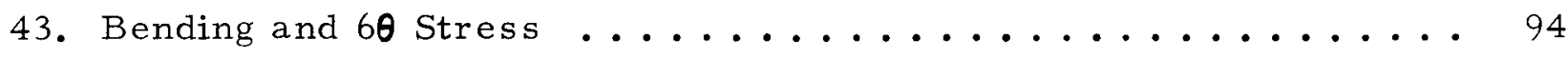

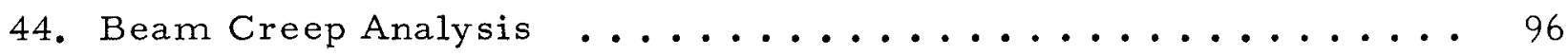

45. Reactivity vs Time, 5-kwe Reactor, Design-To Conditions . . . . 104

46. BOL Power Contours, Segments in Normal Position ........ 108

47. EOL Power Contours, Segments Fully Closed ........... 110

48. Peak Power Per Element Relative to Core Average ......... 111

49. 5-kwe System, Extended Life Characteristics . . . . . . . . 122

50. Reactor Lifetime Capability with One Stuck Control Segment . . . . 122

51. Functional Block Diagram, Automatic Controller ......... 125 


\begin{abstract}
This report summarizes the reactor as sembly engineering performed for the 5-kwe reactor. Areas pertaining to the reactor as a whole are emphasized such as the nuclear effects, plenum hydraulics and in-core coolant mixing, mechanical and structural design of the reactor, vessel design, and core assembly procedure. Also included is a discussion of reactor performance margins, and selected reactor layout drawings.
\end{abstract}




\section{INTRODUCTION AND SUIMMARY}

\section{A. OBJECTIVES}

The overall objective of the $\mathrm{ZrH}$ reactor program was the development and demonstration of reliable long-life unmanned reactor thermoelectric space power systems in the 1 - to 10 -kwe range. To achieve this objective, the 5-kwe Reactor Thermoelectric System was designed. It was planned to test the system in an existing AEC facility at AI's Santa Susana Laboratory. The specific objectives of the 5 -kwe system were to achieve:

1) Five-year life

2) Five-kwe net unconditioned power at the power system-spacecraft mating plane in a space environment at end of life

3) Compatibility with unmanned type spacecraft and launch vehicles such as Titan class boost vehicles

4) Radiation dose at the payload mating plane of $10^{6}$ rads, gamma, and $10^{12}$ nvt, neutrons, average

5) Use of $\mathrm{ZrH}$ reactor and $\mathrm{PbTe}$ compact thermoelectric tubular module technology

6) Automatic startup and control capability

7) Compatibility with existing ground test facilities.

\section{B. REACTOR SYSTEM DEFINITION}

The $\mathrm{ZrH}$ Reactor System is designed to be the heat source for the 5-kwe thermoelectric system. The reactor system will be flight qualifiable as well as capable of operation in the ground test environment. As a flight system, minimum overall system weight will be obtained.

The reactor will be controlled by movement of the external beryllium reflector to regulate the neutron leakage from the core. The flight control system $^{(1)}$ will furnish the electrical power to the control motors. The reactor system shall be capable of fully automatic startup from room temperature to final operating conditions. The reactor operating conditions will be adjustable by means of discrete reflector steps.

$$
\text { AI-AEC- } 13075
$$




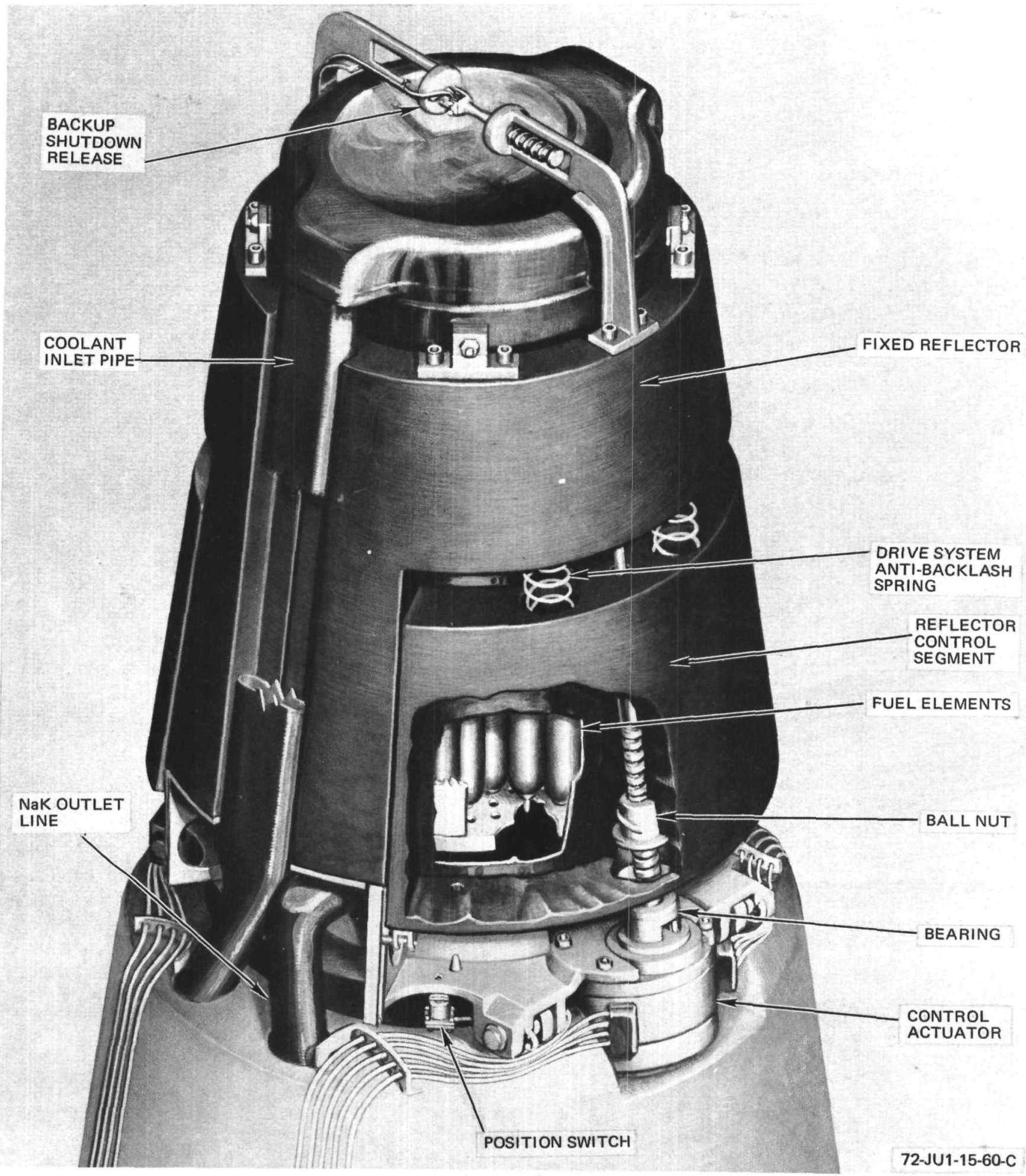

Figure 1. 5-kwe Reactor Conceptual Design

AI-AEC- 13075 
The primary scram function will be accomplished by withdrawal of the reflector control elements to their least reactive position using the normal control actuators. This will be accomplished at a rate sufficient to safeguard the reactor from damage under conditions of a startup accident.

On the ground system, a backup shutdown system will be provided. This shall consist of allowing the control reflector to pivot away from the reactor vessel utilizing spring energy. In the flight system, this shutdown method will not be reversible. The ground test reactor system will include means to reset the backup shut down system.

The reactor system is shown in concept in Figure 1.

C. MAJOR COMPONENT LIST

The reactor system (Refer to Dwg. R-N652200001) "* shall consist of the following major components:

Core Assembly (Dwg. R-N652210001)

Grid Plates

Internal Reflectors (Dwg. R-N652210002)

Fuel Element Assembly (Dwg. R-N652240031)

Core Liner

Vessel and Piping Assembly

Core Vessel

Inlet and Outlet Pipes

In-Core Instrumentation Assembly

Flow Control Baffles

Reflector and Drive Assembly (Dwg. R-N652220032)

Fixed Reflector

Control Sector and Guide

Bearings

Drive Screw and Nut

Control Drum Actuator and Gear Assembly (Dwg. R-N652220095)

Reflector Support Plate

*All Layout drawings referenced here are included in the Appendix.

AI-AEC- 13075 
TABLE 1

REACTOR CORE DESIGN SUMMARY

\begin{tabular}{|c|c|}
\hline Number of Elements & 85 \\
\hline Lattice Pitch (in.) & 1.025 \\
\hline Core Vessel OD (in.) & 10.60 \\
\hline Active Fuel Length (in.) & 16 \\
\hline Fuel Rod Diameter (in.) & 0.938 in. \\
\hline Cladding Material & Hastelloy $\mathrm{X}$ \\
\hline Cladding Thickness, Average (mils) & 25 \\
\hline Hydrogen Barrier Material & $S C B$ \\
\hline $\mathrm{H}_{2}$ Barrier Thickness (in.) & 0.0025 \\
\hline $\begin{array}{l}\text { Fuel-to-Barrier Gap, Diametral, } \\
\text { Cold (in.) }\end{array}$ & 0.012 \\
\hline Fin Type & Right-Left-Neutral \\
\hline Number of Fins Per Element & 3 \\
\hline Spiral Pitch (in.) & 5.0 \\
\hline Fin Height (mils) & $50 \pm 0.10$ \\
\hline Fuel Element Spacing (mils) & 20 \\
\hline Element Backfill Gas & Helium \\
\hline Backfill Pressure, Cold (psia) & 3 \\
\hline Internal Reflectors & BeO, Type 316 Stainless Steel \\
\hline Grid Plate Material & Type 316 Stainless Steel \\
\hline Core Vessel Material & Type 316 Stainless Steel \\
\hline Coolant Inlet and Outlet Lines & 2 each \\
\hline Line Size, Inlet (in.) & 0.75 by 2.62 , outside, Oblong round \\
\hline Wall Thickness, Inlet (mils) & 84 \\
\hline Line Size, Outlet (in.) & 1.0 by 2.0 , outside, Oblong round \\
\hline Wall Thickness, Outlet (mils) & 50 \\
\hline
\end{tabular}

AI-AEC- 13075 
Flight Shutdown Device

Anti-Backlash and Reflector Pivot Springs

Position Switch

Backup Shutdown. Reset Assembly (Ground System only, Dwg. R-N652220033).

This report is oriented primarily toward the vessel and piping assembly and the reflector and drive assembly. Also included are all nuclear effects and the bulk thermal and hydraulic effects associated with the reactor as an assembly. The specific fuel element design details and effects of thermal-hydraulicstress interaction of elements with their neighbors is covered in Reference 2.

D. REACTOR SYSTEM DESIGN SUMMARY

The reactor system design summary is divided into the subareas of core, reflector, and instrumentation. These are summarized in Tables 1, 2, and 3.

\section{E. REACTOR SYSTEM PERFORMANCE SUMMARY}

The reactor system performance characteristics are subdivided into core thermal performance, core nuclear performance, and control system performance. These are summarized in Tables 4,5 , and 6. 
TABLE 2

REFLECTOR DESIGN SUMMARY

\begin{tabular}{|c|c|}
\hline \multicolumn{2}{|l|}{ Reflector } \\
\hline Control Type & Sliding Sector \\
\hline Material & Anodized $\mathrm{Be}$ \\
\hline Number of Sectors & Two \\
\hline Axial Stroke (in.) & 4 \\
\hline Sector Angle $\left(^{\circ}\right)$ & $235^{\circ}$ \\
\hline Midplane Thickness (in.) & 2.4 \\
\hline \multicolumn{2}{|l|}{ Actuator } \\
\hline Motor Type & Redesigned S8DR \\
\hline Diameter (in.) & 5.125 \\
\hline Length (in.) & 4.0 \\
\hline \multicolumn{2}{|l|}{ Bearings } \\
\hline Ball Material & P5 Carbon Graphite \\
\hline Shaft Material & $\mathrm{Al}_{2} \mathrm{O}_{3}$ on Inconel 718 \\
\hline Socket Material & $\mathrm{Al}_{2} \mathrm{O}_{3}$ on Inconel 750 \\
\hline \multicolumn{2}{|l|}{ Ball Screw } \\
\hline Nut and Screw Material & Inconel 718 \\
\hline Ball Material & $\mathrm{WC}-6 \mathrm{Co}$ \\
\hline Lubricant & $\mathrm{MoS}_{2}$ \\
\hline Pitch Diameter (in.) & 0.75 \\
\hline Lead (in.) & 0.75 \\
\hline Number of Ball Circuits & Two \\
\hline \multicolumn{2}{|l|}{ Miscellaneous Components } \\
\hline Position Switch & Modified S8DR \\
\hline Cabling & $\begin{array}{l}\text { Stainless-Steel-Sheathed Clad } \\
\text { Copper }\end{array}$ \\
\hline End of Life Shutdown & Modified S-10A EABRD \\
\hline
\end{tabular}


TABLE 3

REACTOR INSTRUMENTATION SUMMARY

\begin{tabular}{l|l}
\hline \hline Outlet Channel Temperature Thermocouples & 15 \\
Outlet NaK Line Thermocouples & 2 each \\
Inlet NaK Lines Thermocouples & 2 each \\
Control Reflector Thermocouples & 6 maximum \\
Control Sector Full Out Position Switch & 1 each \\
In-Channel Thermocouples & 6 \\
\hline
\end{tabular}

TABLE 4

CORE THERMAL PERFORMANCE SUMMARY

\begin{tabular}{l|l|l}
\hline \hline & EOL & BOL ${ }^{\dagger}$ \\
\hline Thermal Power to Coolant (kwt) & 99.4 & 91.0 \\
Outlet Temperature $\left({ }^{\circ} \mathrm{F}\right)$ & 1200 & 1135 \\
Core Temperature Rise $\left({ }^{\circ} \mathrm{F}\right)$ & 95 & 87 \\
Peak Fuel Temperature $\left({ }^{\circ} \mathrm{F}\right)$ & 1280 & 1225 \\
Peak Cross Element $\Delta \mathrm{T}\left({ }^{\circ} \mathrm{F}\right)$ & & \\
$\quad$ Nominal Geometry & 16.3 & 17.5 \\
Cluster and Asymmetry & 36.0 & 36.7 \\
NaK Flow Rate (lb/hr) & 17,000 & 17,000 \\
NaK System Pressure (psi) & & \\
Core Pressure Drop & 0.16 & \\
Fuel Bundle & 0.21 & \\
Nozzle to Nozzle & 0.01 & \\
Pressure Gradient at Inlet Grid (psi) & 5 & \\
Reactor Design Lifetime (yr) & 5.7 & \\
Coolant Velocity in Piping (fps) & 6600 & \\
Core Average Velocity (fps) & \\
Reynolds Number - Core Average & \\
\hline
\end{tabular}

$* E O L=$ End of life

$\dagger \mathrm{BOL}=$ Beginning of life

AI-AEC- 13075 
TABLE 5

CORE NUCLEAR PERFORMANCE SUMMARY

\begin{tabular}{l|l}
\hline Fuel Uranium Content (wt \%) & 10.5 \\
Burnable Poison Mix & $100 \%$ Nat-Gd \\
Total Poison Loading (\$) & 3.00 \\
Cold, Clean Excess Reactivity (\$) & 7.74 \\
Short-Term Reactivity Losses (\$) & 2.50 \\
Long-Term Reactivity Losses (\$) & 4.74 \\
Total Reactivity Requirements & 7.24 \\
EOL Reactivity Margin (\$) & 0.50 \\
Available Control Worth (\$) & 7.74 \\
Minimum Shutdown Margin & 3.00 \\
Isothermal Temperature & $-0.18 \notin /^{\circ} \mathrm{F}$ \\
Coefficient & \\
Prompt Temperature & $-0.07 \notin /^{\circ} \mathrm{F}$ \\
\hline
\end{tabular}

TABLE 6

CONTROL SYSTEM PERFORMANCE SUMMARY

\begin{tabular}{l|l}
\hline \hline Normal Operation & \\
Reactivity Step Size ( $\not)$ & 0.5 \\
Actuator Step Size ( $\left.{ }^{\circ}\right)$ & 7.2 \\
Sector Step Size (mils) & 5.4 \\
Actuator Torque Requirement (oz. -in.) & 78 \\
Scram Performance & \\
Scram Mode & Actuator Drive \\
Scram Rate ( $\not /$ sec) & 30 \\
Actuator Torque Requirement (oz. -in.) & Reflector Tilt-Out \\
Backup Shutdown & Pneumatic \\
Backup Shutdown Reset & \\
\hline
\end{tabular}




\section{REACTOR DESIGN DESCRIPTION}

\section{A. REACTOR CONFIGURATION}

The reactor designed for integration into a 5-kwe reactor thermoelectric power system is illustrated by Figure l. It consists of: (1) a core 10.5 in. in liameter by $16 \mathrm{in.}$ long (fuel-length) made up of $85 \mathrm{l}$-in.-diameter fuel elements packed in a triangular array, plus twelve internal reflector segments (stainlesssteel-clad $\mathrm{BeO}$ ) to fill the void spaces between the periphery of the fuel element array and the circular reactor vessel; (2) inlet and outlet grid plates plus a core liner to support the fuel elements within the vessel and properly control the flow through the fuel element array; (3) the reactor vessel which is the containment for the $\mathrm{NaK}$ coolant and serves as the basic structure of the reactor assembly; and (4) the reflector-control assembly, a tapered beryllium reflector assembled in two identical halves, with axially sliding control segments, and associated drives and actuators. The reflector mounting hardware allows the reflector halves to rotate $15^{\circ}$ outward for end-of-life shutdown.

The NaK coolant is fed to the reactor through the two pipes which traverse the reflector through grooves in the outer face at the split line between the two halves. Flow is directed within the inlet plenum by vanes and baffling to produce a flat pressure profile over the inlet grid plate. After passing through the core, the flow exits from the outlet plenum through two nozzles oriented $15^{\circ}$ off the reflector split-line axis.

A unique aspect of this reactor, relative to all previous SNAP reactors, is the tapered reflector with sliding control segments. All previous SNAP reactors used rotating drums for control. The primary advantage of this new design is the minimization of the diameter of the neutron shield required to shadow the payload.

\section{B. CORE ASSEMBLY}

The core is designed as a unitized assembly of the 85 fuel elements, inlet and outlet grid plates, fuel element locking rods, internal reflectors, and a 


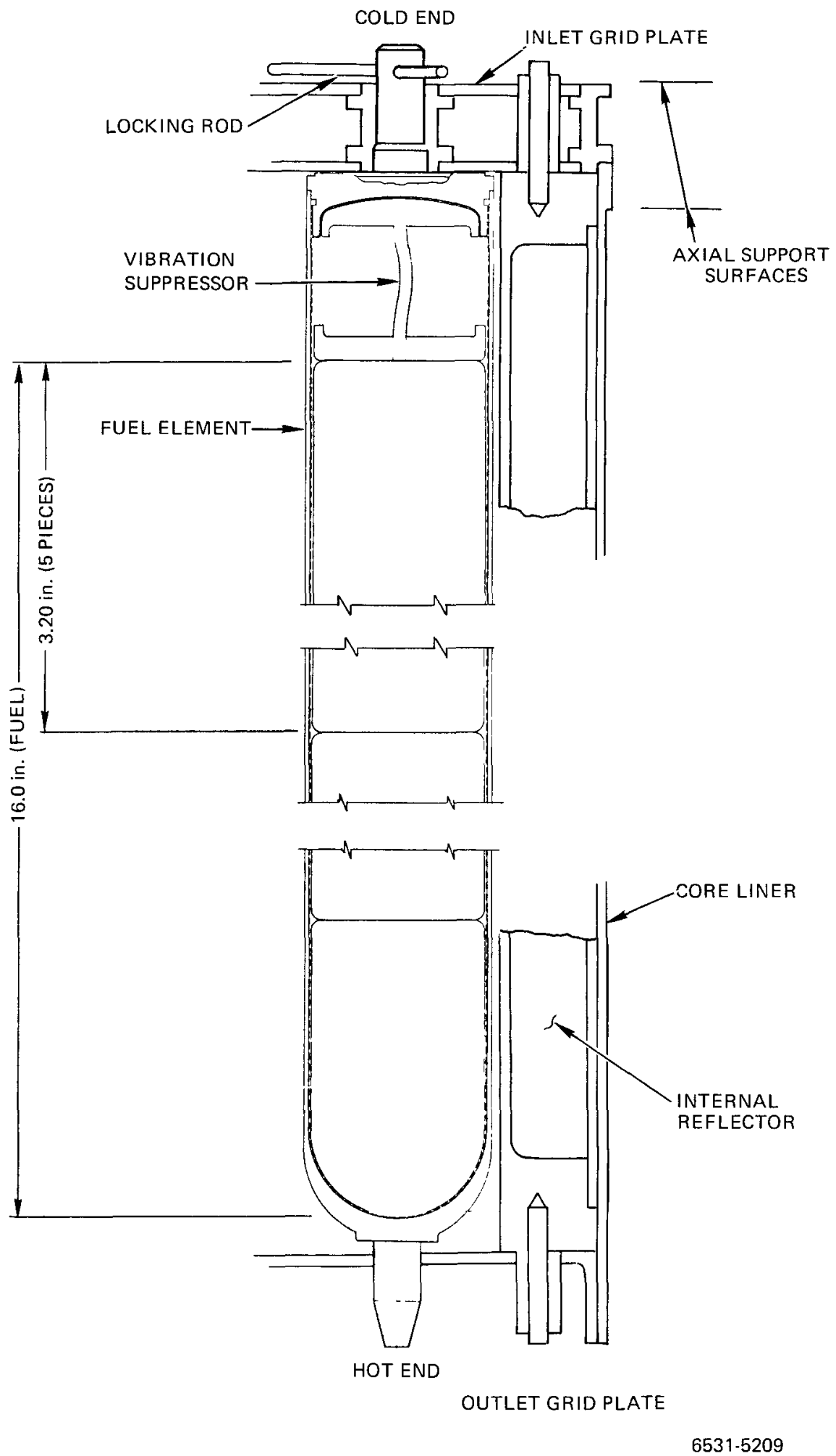

Figure 2. Core Section Details

AI-AEC- 13075 
core liner. The unit is bench assembled, with poison splines in the coolant channels to insure subcriticality, and then inserted into the reactor vessel. Figure 2 illustrates the component arrangement.

Of the 85 fuel elements in a core assembly; 27 are finned in a left-hand direction, 27 in a right-hand direction, and 31 are unfinned (neutral). The elements are arrayed in a triangular lattice as shown on Figure 3. Figure 4 shows the details of the array and the basic dimensional data for the core.

\section{Fuel Element}

Each fuel element consists of a segmented ( 5 piece) fuel rod of hydrided $10 \%$ uranium-zirconium alloy sealed within a Hastelloy-X cladding. A burnable poison is included as a vapor-deposited coating of gadolinium oxide applied to the radial surface of the fuel slugs. A ceramic coating on the inside surfaces of the cladding is the primary hydrogen retention barrier. Basic dimensional data for the fuel element are tabulated in Table 7.

The finned elements have three fins spaced $120^{\circ}$ apart which spiral through three turns on a 5 -in. pitch. The fins, 0.12 in. wide, are formed by hobbing a heavy wall starting tube. The hobbing leaves a fin height of $0.050 \mathrm{in}$. and then 6 flats are milled to a fin height of 0.010 in., giving a cross section as shown by Figure 5 .

A vibration suppressor is installed between the fuel and the cold end cap as illustrated on Figure 2. This device, which resembles a collar button, prevents axial movement of the fuel rod under dynamic loadings incurred during launch. It is designed to yield by collapse of the prekinked column to accommodate axial fuel growth during reactor operation, without overstressing the cladding tube.

The hot end cap is basically a spherical head closure, butt welded to the cladding tube. The end pins have a $15^{\circ}$ chamfer to provide a lead-in for the grid plate during core assembly. The pin diameter on all finned elements and on the twelve outer neutral elements is sized for a 0.020-in. (nominal) diametral clearance in the grid plate hole; and on the inner neutral elements, the pin is sized for a close fit $(0.002$ to 0.005 in diametral clearance). The basis for this feature of the design is discussed in Section V.

AI-AEC- 13075 


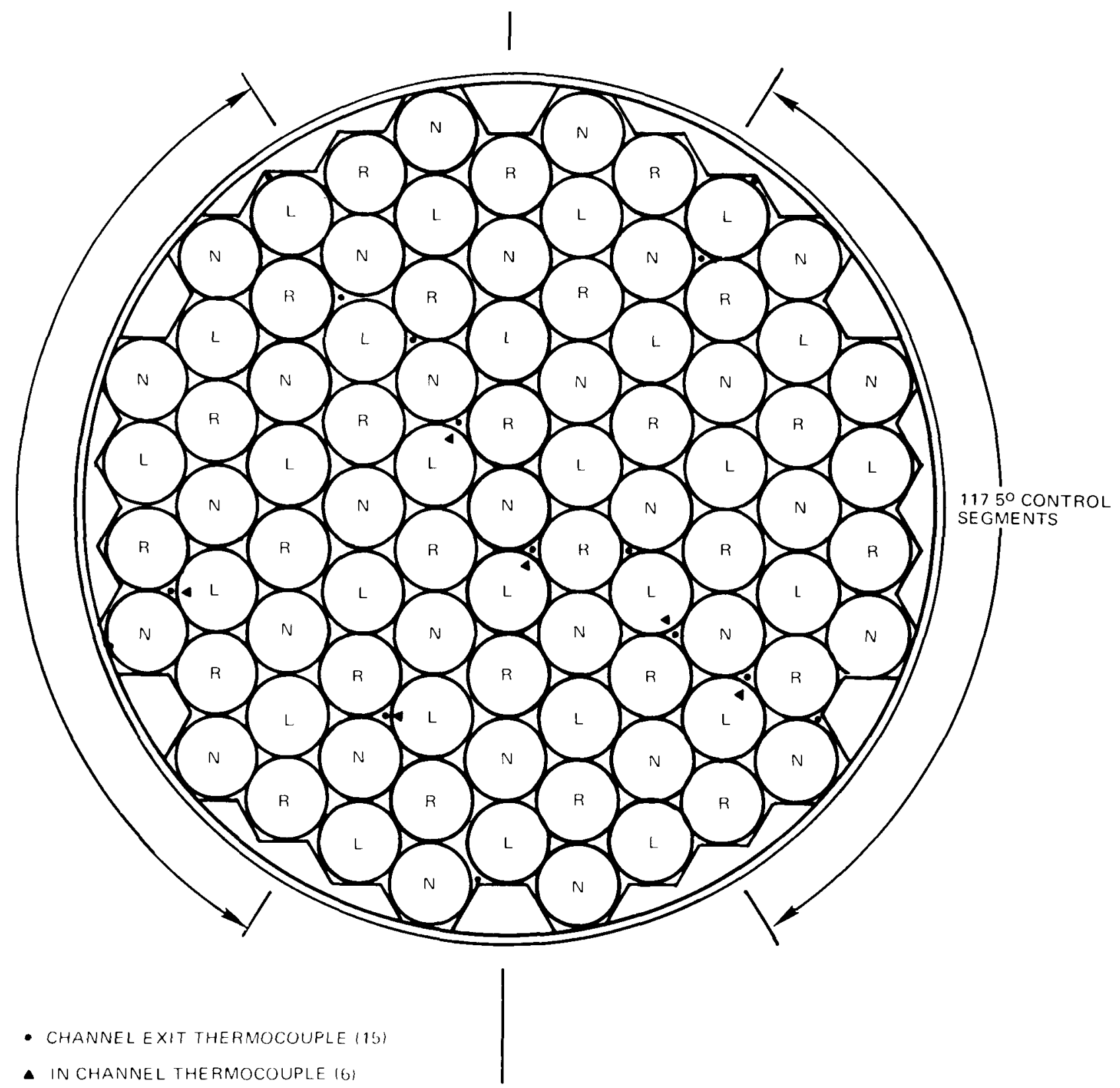

653140134

Figure 3. Core Plan

AI-AEC- 13075 


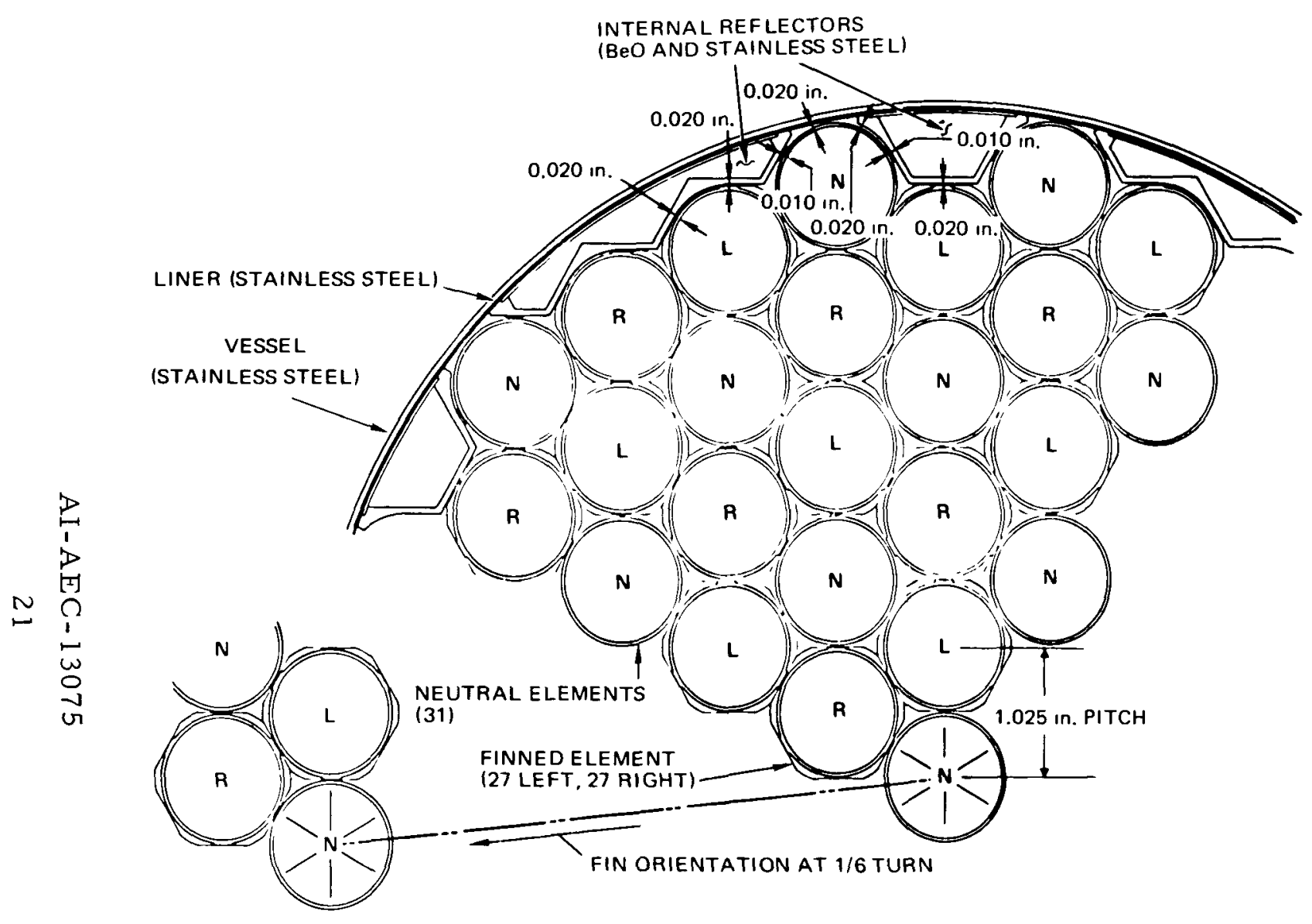

\begin{tabular}{|ll|}
\hline \multicolumn{2}{|c|}{ BASIC DATA } \\
85 ELEMENTS: & $1.025 \mathrm{in}$. PITCH \\
LINER ID: & $10.450 \mathrm{in}$. \\
LINER THICKNESS: & $0.015 \mathrm{in} .(\times 2)$ \\
CLEARANCE: & $0.010 \mathrm{in} .(\times 2)$ \\
VESSEL ID: & $10.500 \mathrm{in}$. \\
VESSEL WALL. & $0.050 \mathrm{in} .(\times 2)$ \\
VESSEL OD: & $10.600 \mathrm{in}$. \\
FUEL LENGTH: & $16.00 \mathrm{in}$. \\
FUEL ELEMENT SPACING \\
CLAD-CLAD: & $0.020 \mathrm{in}$. \\
FIN-CLAD & $0.010 \mathrm{in}$. \\
CLADDING TO INTERNAL \\
REFLECTOR & AS SHOWN \\
\hline \multicolumn{2}{r}{} \\
\hline
\end{tabular}

72-JU6-12-10C

Figure 4. Core Plan Details 


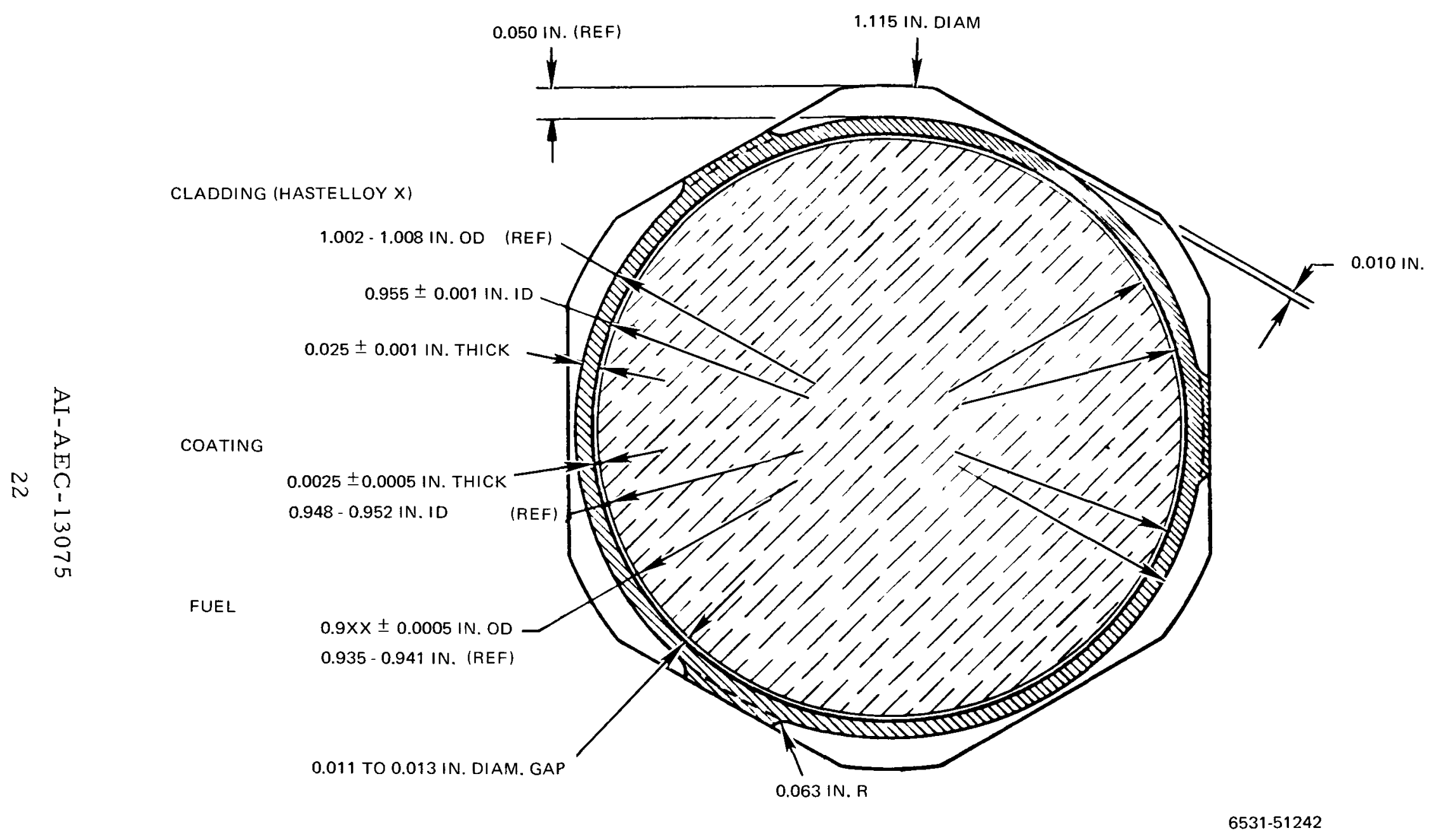

Figure 5. Fuel Element Cross Section (Neutral Element Identical Except for Deletion of Fins) 


\begin{tabular}{|c|c|c|c|}
\hline & Limit & Mean & Limit \\
\hline Pitch 1.025 & & 1.025 & \\
\hline Spacing (in.) & & 0.020 & \\
\hline Cladding OD (in.) & 1.002 & 1.005 & 1.008 \\
\hline Cladding Wall* $0.025 \pm 0.001$ (in.) & 0.024 & 0.025 & 0.026 \\
\hline$\times 2$ & 0.048 & 0.050 & 0.052 \\
\hline Cladding ID ${ }^{*} 0.955 \pm 0.001 \mathrm{in}$ & 0.954 & 0.955 & 0.956 \\
\hline Glass $(t)^{*} 0.0025 \pm 0.0005$ (in.) & 0.002 & 0.0025 & 0.003 \\
\hline $\mathrm{X} 2$ & 0.004 & 0.005 & 0.006 \\
\hline Glass ID & 0.948 & 0.950 & 0.952 \\
\hline Gap (Diameter) 0.011 to 0.013 (in.) & 0.011 & 0.012 & 0.013 \\
\hline Fuel $\mathrm{OD}^{\dagger} .9 \mathrm{XX} \pm .0005$ (in.) & 0.935 & 0.938 & 0.941 \\
\hline Fuel Length, Nominal ${ }^{*}$ (in.) & & 16.0 & \\
\hline Straightness, TIR* & & 0.012 & \\
\hline
\end{tabular}

*Specified dimensions - all others are reference.

$\dagger$ Fuel OD ground and/or selected to give 0.011 to 0.013 in. -diameter gap.

The cold end cap is a flat head closure with an interference fit between the coated tube ID and the coated OD of the engaging socket portion of the cap. After the cap is inserted, the engaged section of the cap and tube is heated to the softening temperature of the ceramic to blend the coating into a continuous hydrogen barrier. The cold end pins are all sized for a close fit $(0.002$ to 0.005 in. diametral clearance) engagement in the grid plate holes. This close fit engagement is limited to a 0.125-in. length engagement adjacent to the end surface of the cap. The remainder is reduced in diameter to facilitate assembly of finned elements adjacent to finned elements as described in Section IIIB- 5 .

\section{Grid Plates}

As illustrated on Figure 2 the inlet grid plate is the basic structural element of the core assembly. The fuel elements are secured to the grid plate 
by the locking rods which are threaded through holes in the fuel element and pins. Each locking rod secures a complete row of elements across the core and thereby also performs a fuel element orientation function, to maintain the correct relationship between the flatted fins and the cladding OD of adjacent elements.

The inlet grid plate is designed as a grazed sandwich structure made up of two facing sheets $0.062 \mathrm{in}$. thick, an outer rim, and 85 spacer posts located at the fuel element axis positions. The spacer posts and the outer rim act as shear transfer elements and thereby cause the two facing sheets to function as though they are integral parts of a solid plate. This sandwich, with a 0.376 -in. separation between the facing sheets has a strength equivalent to a 0.38 -in-thick solid plate and a stiffness equivalent to a 0.41 -in. -thick solid plate. The sandwich plate approach thereby produces a significant weight saving.

The outlet grid plate provides only lateral spacing and support for the fuel elements. This plate is, therefore, of minimum thickness (0.062 in.). An integral rim at the outer edge ( 0.062 thick by $0.25 \mathrm{in}$. long) is included in the design to give the plate flatness stability and to provide a larger engagement with the core liner.

Both grid plates are fabricated from Type 316 stainless steel, and the upper grid plate assembly is furnace brazed using a nickel-base braze alloy. The fuel element positioning holes are precision located (within 0.001 in. of true position) and reamed to a tolerance of \pm 0.0005 . The coolant passage holes are $0.25 \mathrm{in.}$ in diameter except for twelve of the outer boundary channel holes are $0.190 \mathrm{in.}$ in diameter due to space limitations. Each plate also has twelve 0.0170-in. -diameter holes near the periphery for engagement of internal reflector positioning pins.

The use of the brazed sandwich structural grid plate is based on experience on almost identical designs in the SNAP $10 A$ and SNAP 2 DRM reactors. This covers fabrication of over twenty grid plate assemblies and experimental tests which verify the strength and deflection characteristics of the concept. ${ }^{(3)}$

AI-AEC- 13075 


\section{Internal Reflectors}

As shown on Figures 3 and 4, twelve internal reflector segments fill the spaces between the noncircular boundary of the fuel element array and the cylindrical core liner. These consist of BeO shapes contained in sealed stainlesssteel enclosures. The surfaces which face the boundary fuel elements are configured to provide flow rates in individual boundary channels which minimizes the possible temperature difference across the boundary fuel elements.

Fast neutron irradiation of $\mathrm{BeO}$ causes material swelling and helium generation which produces a pressure buildup within the stainless-steel container. The design therefore includes a 1.5-in. axial gas space to limit the pressure at EOL to 18 psi, equal to the NaK coolant pressure if both NaK volume accumulator bellows fail. The internal reflectors, initially evacuated, therefore have a negative internal pressure throughout reactor lifetime.

Each internal reflector is held in position by a pin at each end which engages the grid plates. Because reflector location relative to the boundary elements is critical in establishing the boundary channel flow areas, these pins are custom located during the core assembly sequence as described in Section II-B-5.

\section{Core Liner}

The core liner is a 0.015-in. thick, stainless-steel cylinder closely fitted around the internal reflectors. Its primary function is to limit core bypass flow to a very low value (less than $0.5 \%$ ), in order to minimize the bowing stresses induced in the boundary fuel elements by cross element temperature differentials, but still allowing a generous clearance for insertion of the unitized core assembly into the reactor vessel.

The liner has an external support flange at the core inlet end which fits between a step in the reactor vessel ID and the grid plate. The clamping pressure induced by the weld shrinkage, when the vessel closure weld is made, prevents coolant leakage from the core inlet area into the clearance between the liner and the reactor vessel. The outlet grid plate fits into the liner and is secured axially by a weld to the liner.

The clearance between the liner and the reactor vessel is open to the outlet plenum. The liner therefore operates under a low internal pressure, starting at zero at the outlet end and increasing almost linearly to the core pressure drop (0.19 psi) at the inlet end.

AI- AEC - 13075 

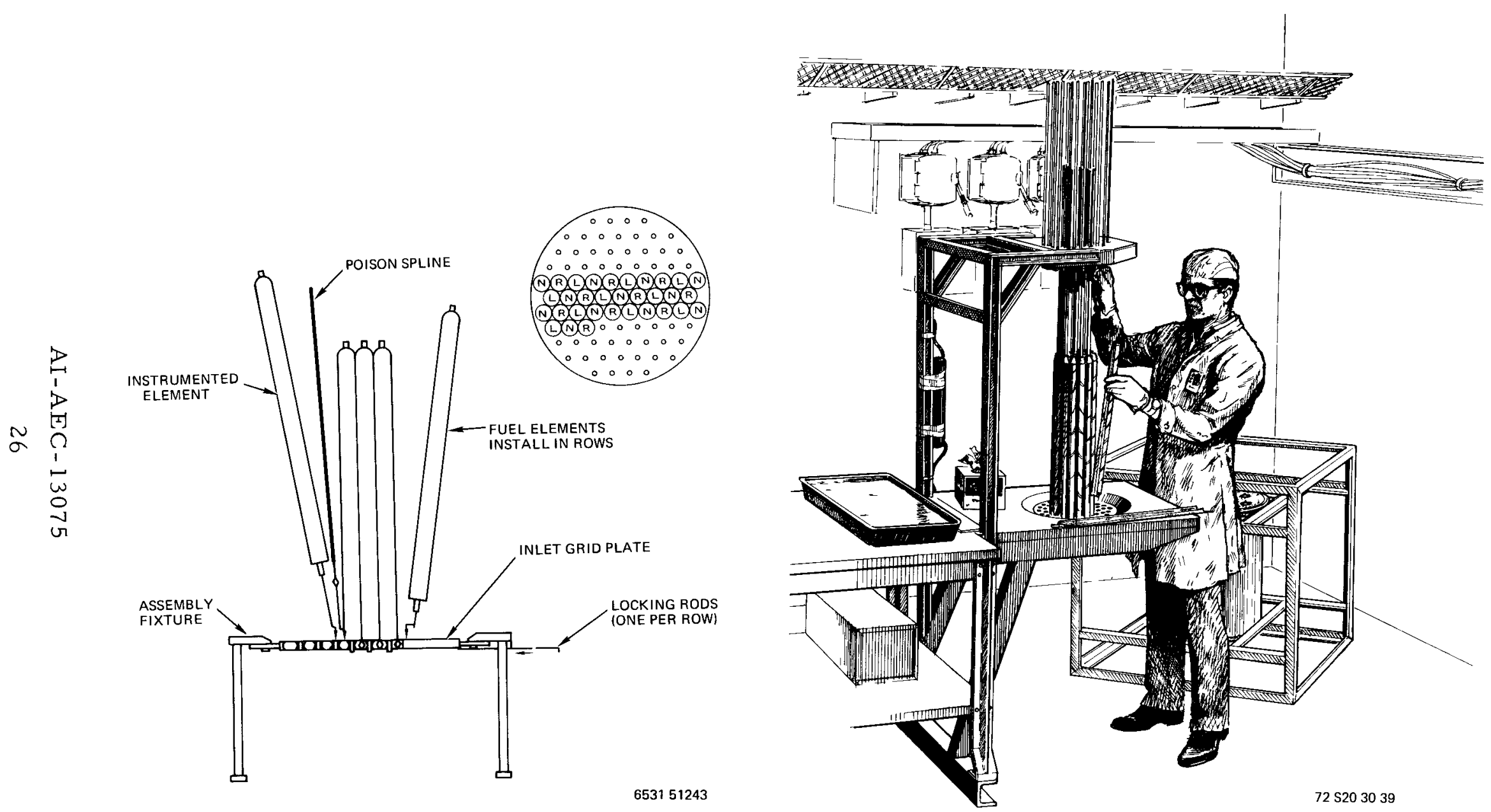

Figure 6. Fuel Bundle Assembly Sequence 


\section{Core Assembly Sequence}

Two basic approaches to the core as sembly have been used on SNAP reactors. On the SNAP 2 and $10 A$ reactors, the fuel elements were inserted into the core vessel one at a time, replacing dummy lucite elements, with multiplication measurements made at intervals until the assembly was completed. The SNAP 8ER and DR cores were assembled outside of the core vessel, "bench assembled," with poison splines inserted into the tri-cusp spaces between elements as the buildup progressed.

In the 5-kwe reactor core, the fins on adjacent fuel elements overlap, preventing axial insertion of finned elements. The bench assembly approach is, therefore, mandatory and the mechanical design of the core assembly is heavily influenced by this.

Prior to beginning the actual core assembly, a customized matching of the internal reflectors to the grid plates must be performed. This involves assembling the grid plates with a set of master boundary elements, which serve as high accuracy positioning fixtures for the internal reflectors, and then match drilling the holes for the reflector positioning pins. The internal reflectors are clamped into position against the master elements, and 0.12-in.-diameter holes for the locating pins are drilled and reamed into the internal reflectors, through drill bushings in the 0.188-in.-diameter holes in the grid plates.

The procedure described above positions the internal reflectors relative to the boundary elements such that the tolerance accumulations which cause deviations in the boundary flow channel areas are minimized. The only deviations in boundary flow area are those due to variations in the fuel elements (cladding OD and straightness, plus end pin eccentricity), end pin clearance, and any bowing of the reflectors or fuel elements that occurs during operation.

Figures 6, 7, and 8 illustrate the sequence proposed for assembly of the core. As shown on Figure 6, the sequence starts with the inlet grid plate mounted in a support stand. The fuel elements are inserted sequentially in rows, starting with the center row or an edge row. As each row is completed, the locking rod is inserted so that the orientation of the elements is maintained. Poison splines, 0.080-in. -diameter, stainless-steel tubes fitted with compacted $\mathrm{B}_{4} \mathrm{C}$, are inserted into each coolant channel as the build-up progresses. Although the bare core has a shutdown margin of approximately $\$ 16$, the poison splines are used to eliminate

AI-AEC- 13075 


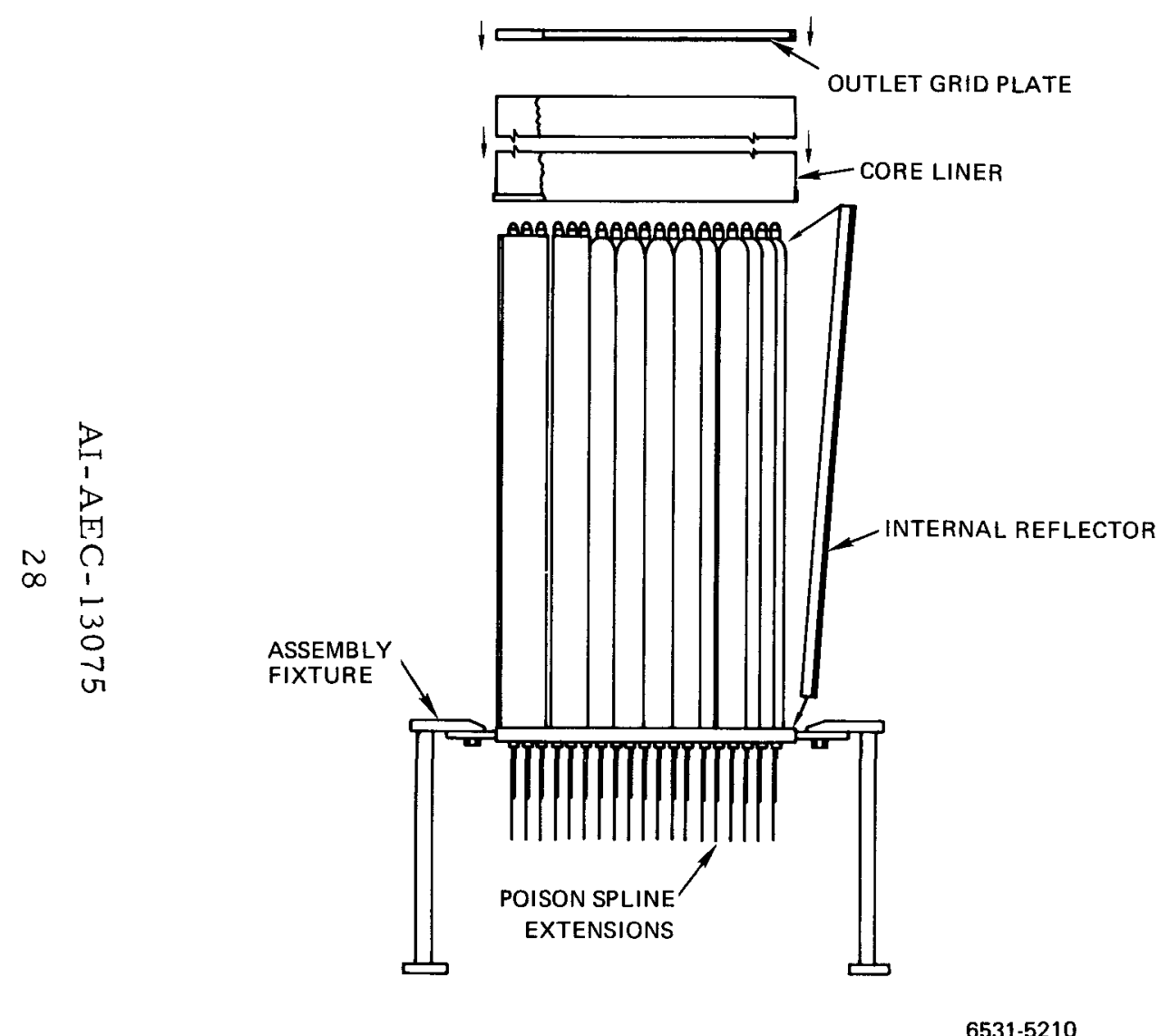

Figure 7. Core Assembly Completion
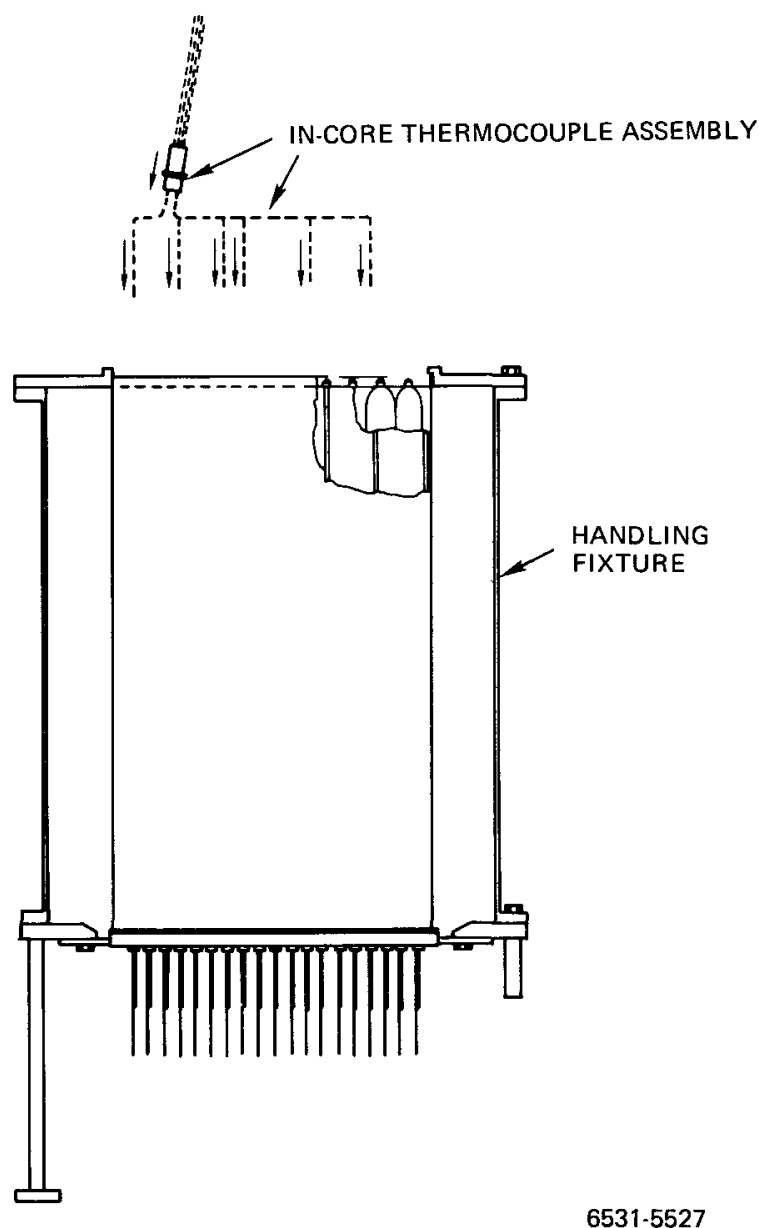

Figure 8. In-Channel Thermocouple Installation 
any possibility of accidental criticality during core assembly and subsequent handling. Completion of the core assembly is illustrated on Figures 7 and 8.

\section{VESSEL ASSEMBLY}

The reactor vessel provides containment for the $\mathrm{NaK}$ coolant and also acts as the basic structural element of the reactor, supporting the core internally and the reflector control assembly externally. All reactor mechanical loadings are carried through a support skirt extended from the vessel and into the neutron shield assembly by a bolted flange connection.

The core is supported within the vessel at the inlet grid plate as shown by Figure 9. The stack-up of the core liner flange, inlet grid plate, and flow distributor rests on a step in the vessel ID. The closure head has a step which engages the forward end of the flow distributor. Shrinkage of the weld between the closure head and the vessel exerts a clamping action on the stack-up and produces a rigid assembly.

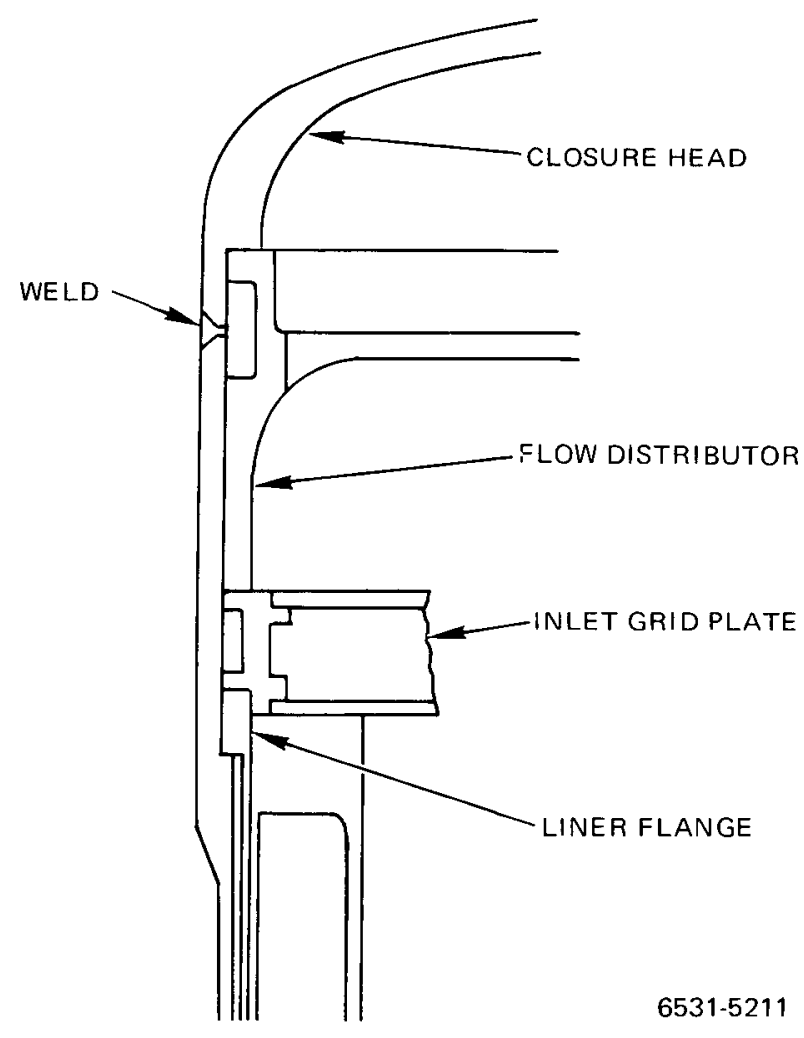

Figure 9. Core Support Detail 
Each of the reflector-control assembly halves is supported on pivot hinges which are part of the reactor support flange. All axial loads are reacted through these hinges. The forward ends of the reflector control assemblies are clamped against the reactor vessel by a spring-loaded tie between the halves.

The components that make up the vessel assembly are described as follows:

\section{Vessel Shell}

The vessel is a thin-wall cylindrical shell with an integrally formed bottom which is concave inward. The inside diameter is $10.500 \mathrm{in}$. and the overall height is $21 \mathrm{in.}$ The wall thickness is $0.125 \mathrm{in}$. for the plenum areas and 0.050 in. at the core sidewall area. A 0.060-in. step in the inside radius just below the inlet grid plate provides a surface for supporting the core as described previously.

The closed end of the vessel, which forms the outlet plenum, has two oval nozzles for 1 -in. high by 2 -in. wide by $0.050-i n$. thick outlet piping elbows. These are located $180^{\circ}$ apart on an axis that is $15^{\circ}$ counterclockwise (looking aft) from the system $Y$ axis.

The procedure proposed for fabricating the vessel shell is identical to that used for the SNAP $10 A$ and SNAP 2DRM reactor vessels. (4) A stainless-steel sheet is deep drawn into a shell form which has the complete inside shape and is slightly larger than the final inside diameter. By proper selection of the starting sheet thickness, the bottom plenum area will be very near the final 0.125 in. thickness and the side wall thickness will increase in a uniform taper. After annealing and cleaning, all surfaces are inspected for defects using a penetrant method.

The vessel blank is then put on a constant diameter steel spin chuck and spun to the final inside diameter using applied heat as required. After trimming the open end to length, the form is removed from the spin chuck and stress relieved. It is then installed on an expanding lathe mandrel and the outer surfaces are machined to arrive at the finished vessel wall thickness.

The inlet piping adapter ring is an extension to the open end of the shell. It includes the two balcony projections to which the inlet piping attaches. The adapter ring is machined from a ring forging and then welded to the vessel.

AI-AEC- 13075 
The completed vessel shell is given a 0.0004-in. thick nickel flash plating and baked to remove any volatiles from the plating. The nickel flash is applied to promote wetting in a subsequent brazing operation and also to protect the vessel from corrosion. Although the vessel material is very corrosion resistant at this time, it will later be subjected to temperatures of 1000 to $1200^{\circ} \mathrm{F}$ for extended periods during reflector assembly acceptance tests and NPU NaK loading and acceptance tests. This temperature will cause some carbide precipitation and sensitize the material to corrosion by a moist air environment.

\section{Reactor Support Assembly}

The reactor support is a welded assembly of the support cylinder and the base flange with integral reflector support fittings. The vessel end is configured for a furnace braze attachment at the vessel knuckle and approximately 0.38 in. up the sidewall of the vessel. This end has an internal flange with threaded holes for attachment of the center gamma shield. The support cylinder and base flange are cutouts as required for the control segment actuators which extend partially under the vessel. This assembly is attached to the vessel shell by furnace brazing (vacuum or hydrogen atmosphere) with a nickle base braze alloy.

The braze attachment of the reactor support base to the vessel shell was successively demonstrated on the S2DRM reactor.

\section{Inlet Flow Distributor}

The purpose of the inlet flow distributor, shown on Figure 10, is to produce a uniform pressure over the inlet grid plate. The distributor assembly consists of a flat baffle, located 0.94 in. above the grid plate surface, with a 4 -in. wide opening across the center of the plenum. The flow spreading vanes are welded to the upper surface of the baffle.

As shown on Figure 9, the flow distributor includes a circumferential rim, with cut-outs in front of the inlet pipes, which functions as a spacer in the core support arrangement.

The method proposed for fabrication is to machine the baffle plate, with its rim integral, from plate stock or a forged biscuit and then attach the flow spreading vanes, cut from sheet stock, by welding or furnace brazing.

AI-AEC- 13075 


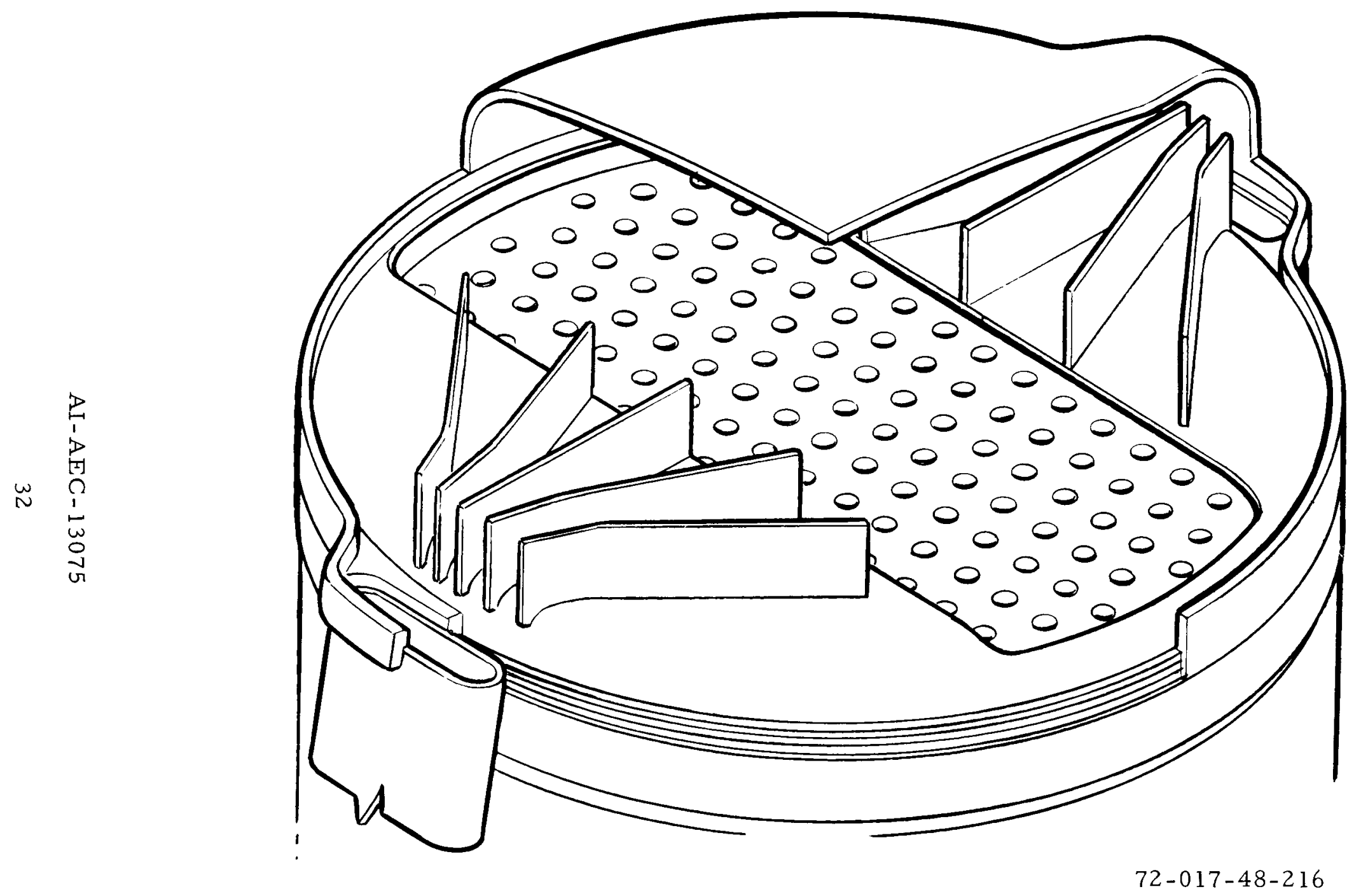

Figure 10. Inlet Plenum 


\section{Core Exit Instrumentation}

Fifteen thermocouples are provided for measurement of coolant temperatures at the exits of selected core channels. This is to be accomplished by centering the sensing ends of the thermocouples over the grid plate exit holes at an axial position of 0.06 to 0.12 in. away from the surface of the grid plate.

The instrument as sembly, illustrated by Figure 11, is completely as sembled prior to being installed in the vessel. The installation requires only one weld, that between the feedthrough and the vessel shell.

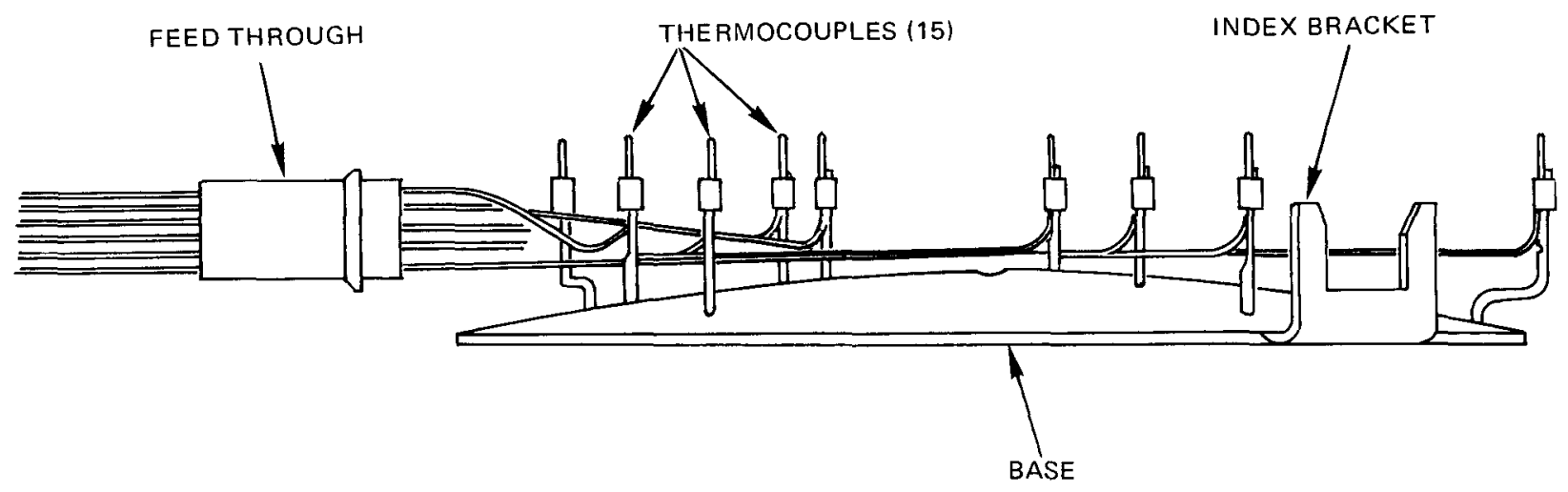

Figure 11. Core Exit Instrumentation Assembly

The thermocouples are chromel-alumel, magnesium oxide insulated in a 0.06-in.-diameter, stainless-steel sheath. The feedthrough for penetration of the $\mathrm{NaK}$ containment is a doubly-sealed, nickel-alloy-brazed design developed a number of years ago for in-pile experiments containing NaK. The design has been completely successful in this application and has more recently been used in other liquid metal (Na) systems. A key aspect of the design is the use of induction heating in a short brazing cycle to prevent the degradation of the thermocouple material physical properties caused by long times at the brazing temperature (above $1900^{\circ} \mathrm{F}$ ) required for the nickel alloy brazes.

The sensing ends of the thermocouples are secured to the positioning posts projecting from the base (see Figure 11) by sleeves which are slipped over the thermocouple and the ends of the post, crimped, and then tack welded to the posts. 


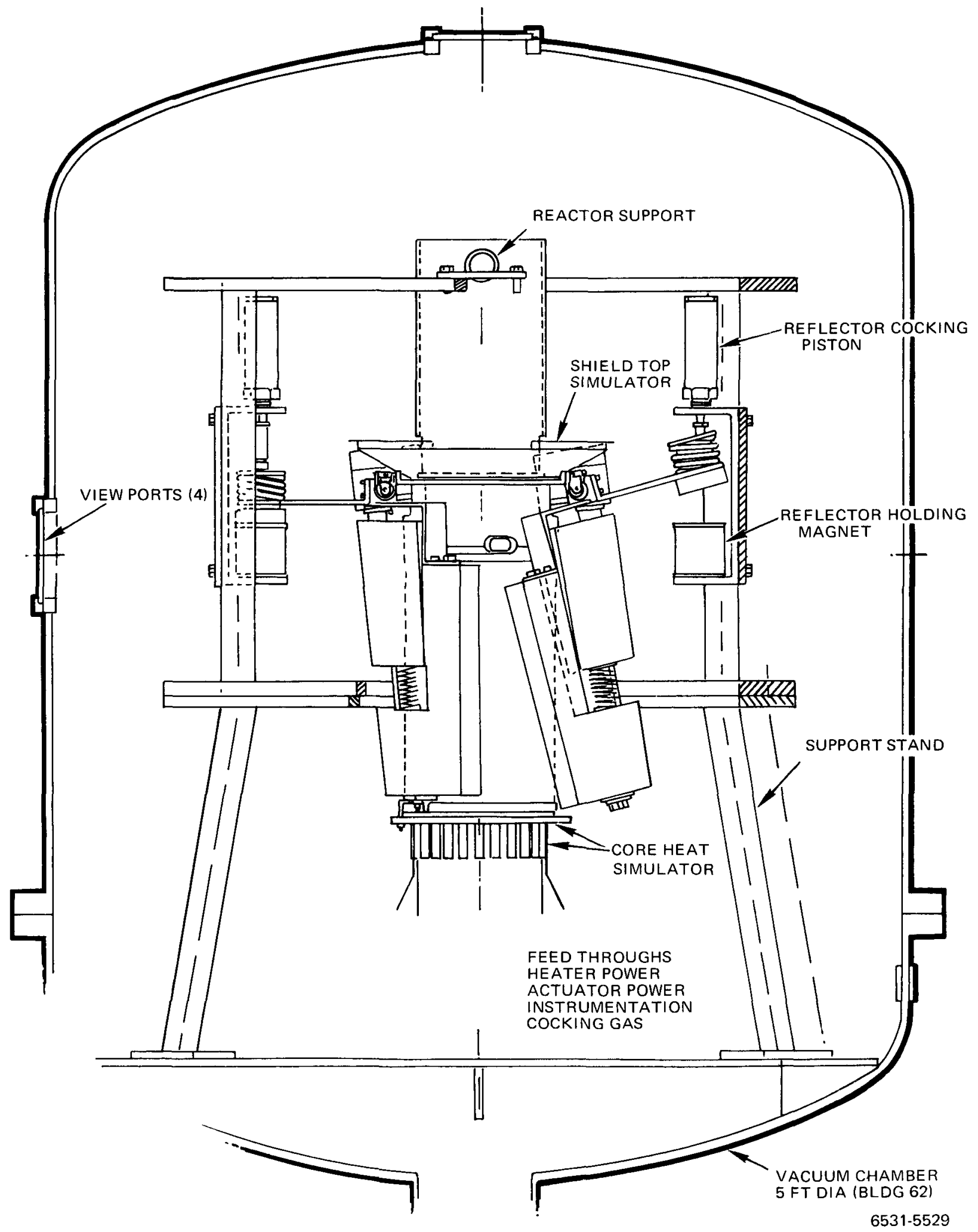

Figure 12. Reflector Control Verification Test 
The index bracket (see Figure 11) engages a bracket extended down from the rim of the outlet grid plate to maintain the orientation of the instrumentation relative to the core.

\section{NaK Piping}

The NaK piping down to the reactor mating plane area is assembled as part of the reactor assembly. The reactor inlet pipes traverse the reflector at the split line. To keep the pipes within the shield shadow cone, which coincides with the outer surface of the beryllium reflector, grooves are provided in the outer surface of the reflector for the pipes. The pipes are made oval $(0.75 \mathrm{in}$. by 2.52 in. outside), to minimize the depth of the grooves in the reflector, and have a wall thickness of 0.083 in. to withstand the 32 -psi internal pressure.

The inlet pipe connections to the reactor vessel are slip-in socket weld joints which must be made from inside the pipe due to inadequate space between the pipe and the vessel shell. This weld will require a custom designed automatic weld head and some weld development. Just below the bottom of the reflector, the inlet pipes make a transition to 1.50 in. OD round for mating to the pipes that traverse the neutron shield.

A volume accumulator feed line, 0.37-in. OD by $0.020-\mathrm{in}$. wall, is routed through one of the reactor inlet pipes into the upper plenum area. The purpose of this line is to prevent the NaK level from dropping below the forward end of the fuel elements when the system is subjected to the accelerations of launch. $\mathrm{NaK}$ coverage of the fuel elements provides viscous damping of the vibration and shock loadings that occur during launch.

\section{Assembly Sequence}

The basic steps involved in the reactor assembly are illustrated by Figures 12 through 16. The first step in the sequence is to mate the reflector control assemblies to the reactor vessel. This involves fit-up adjustments to establish the correct clearances between the reflector and the vessel. This assembly is then put into the reflector-control verification test installation illustrated by Figure 12. A complete operational checkout of the reflector-control assembly, including the ground test backup shutdown mechanism, is then performed in vacuum with electrical heaters used to induce the component temperatures anticipated during nuclear operation. When this test is successfully completed, the 


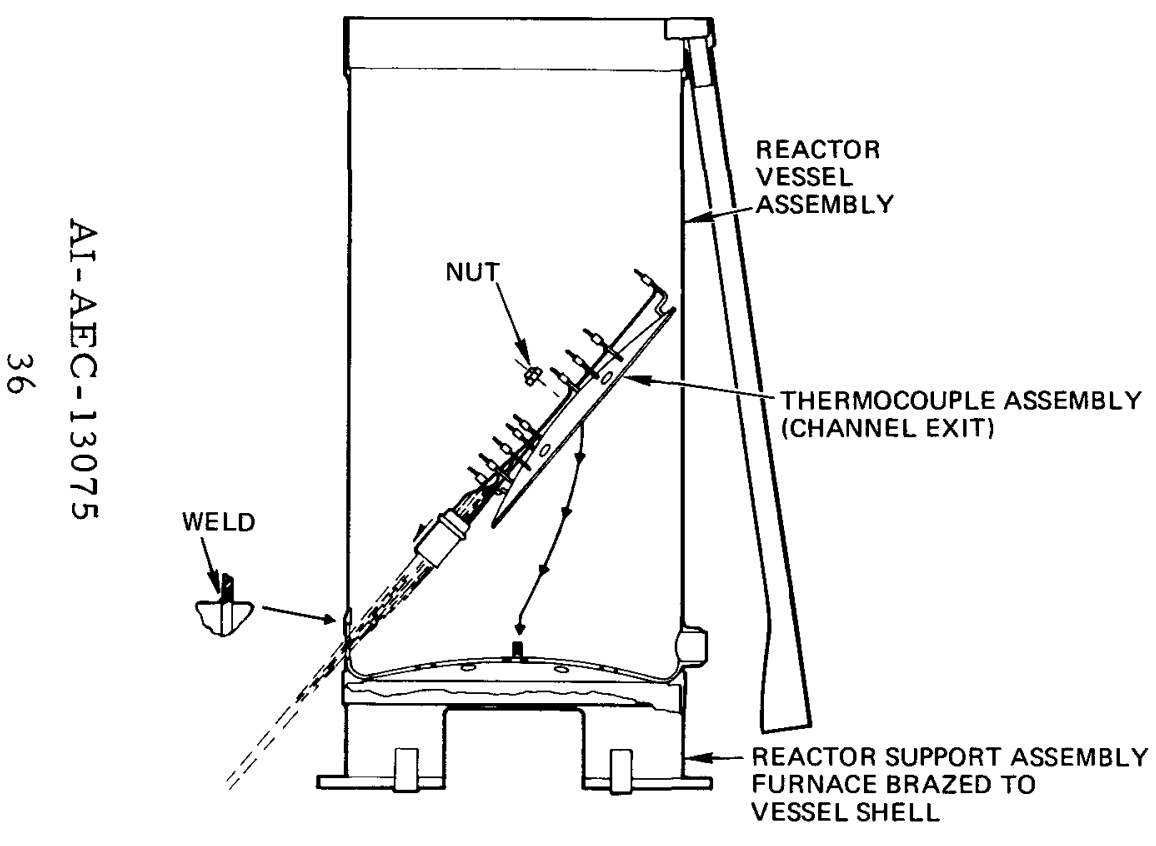

$6531-5530$

Figure 13. Install Channel Exit

Thermocouple Assembly

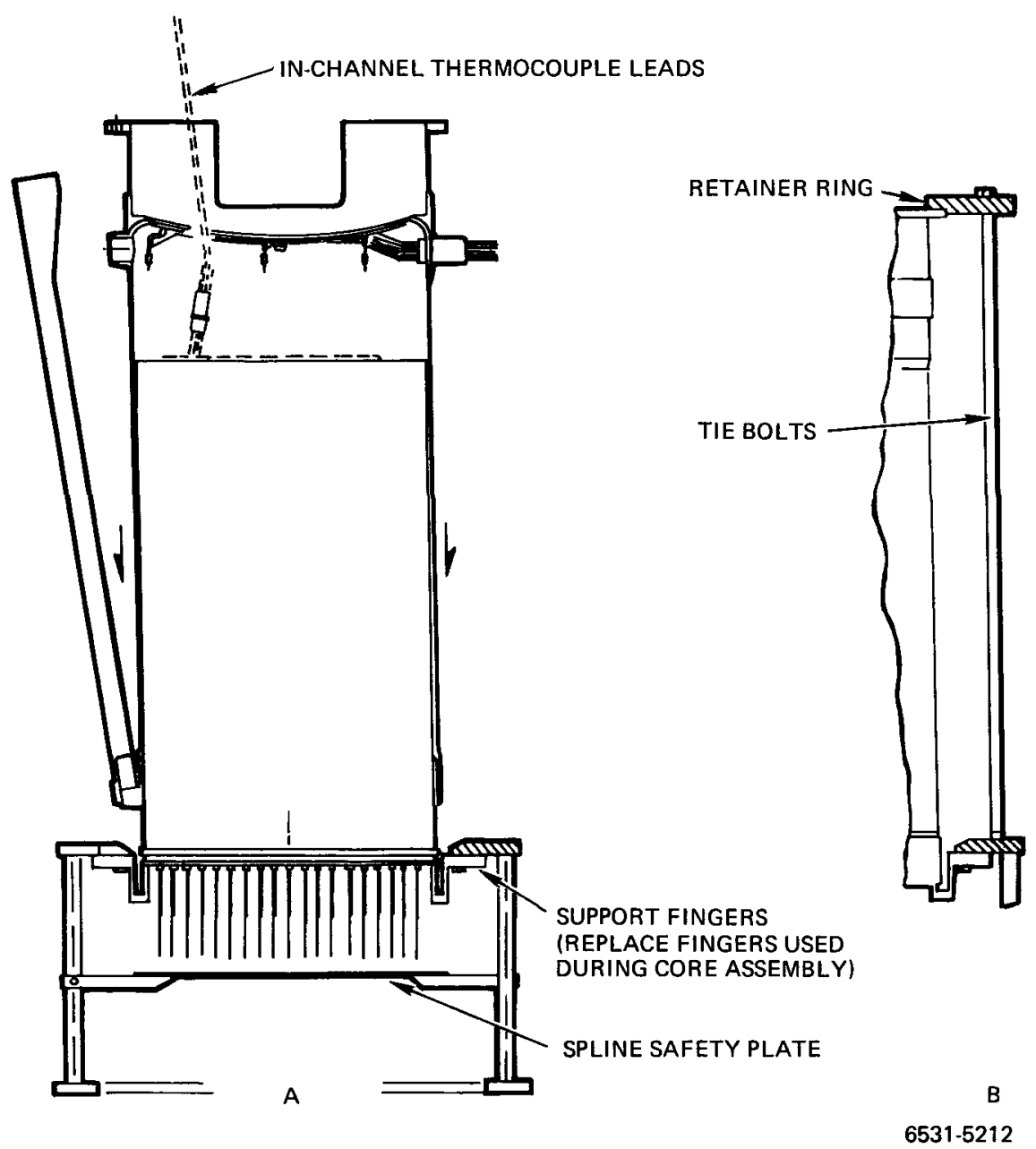

Figure 14. Install Core Vessel 


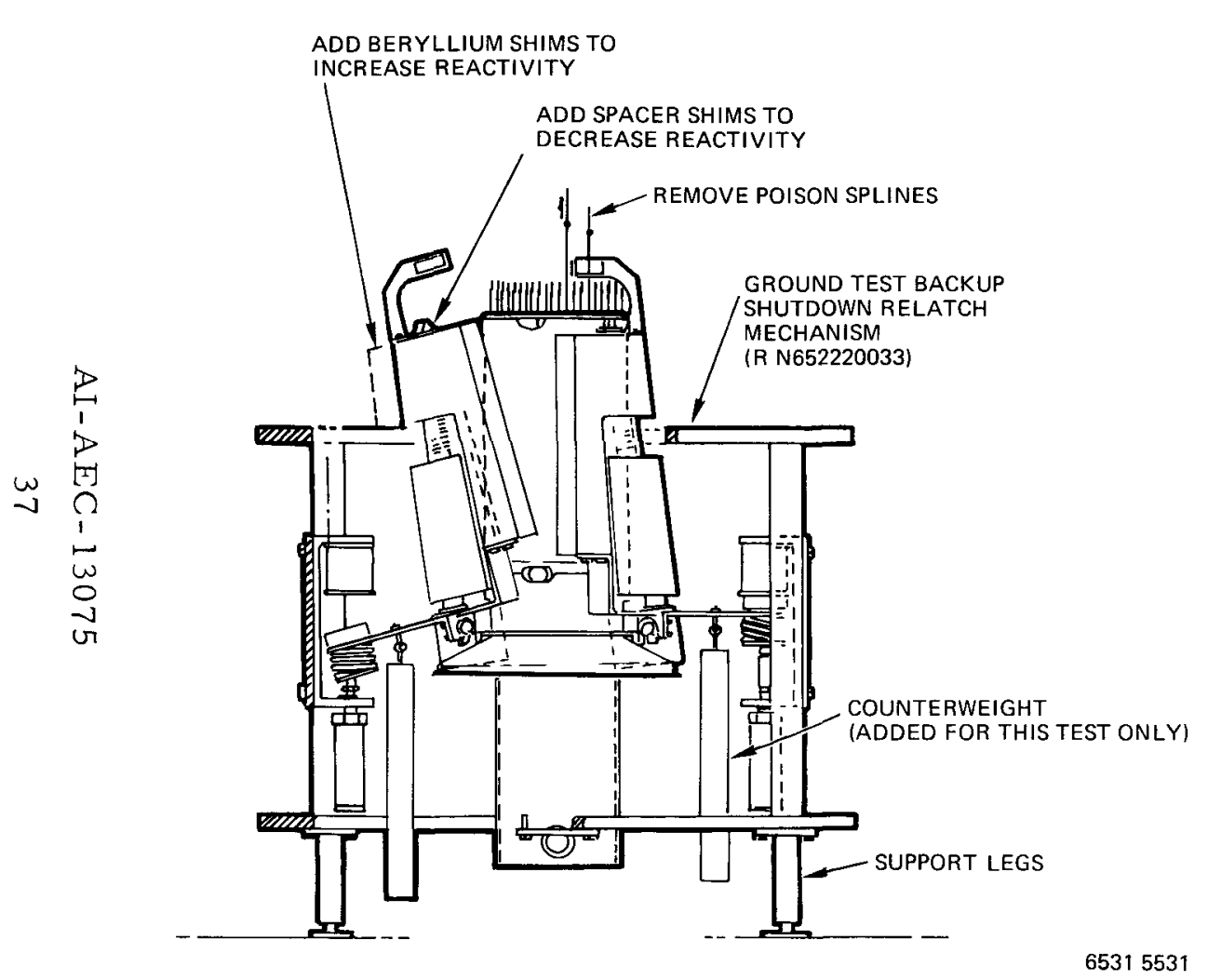

Figure 15. Criticality Tests

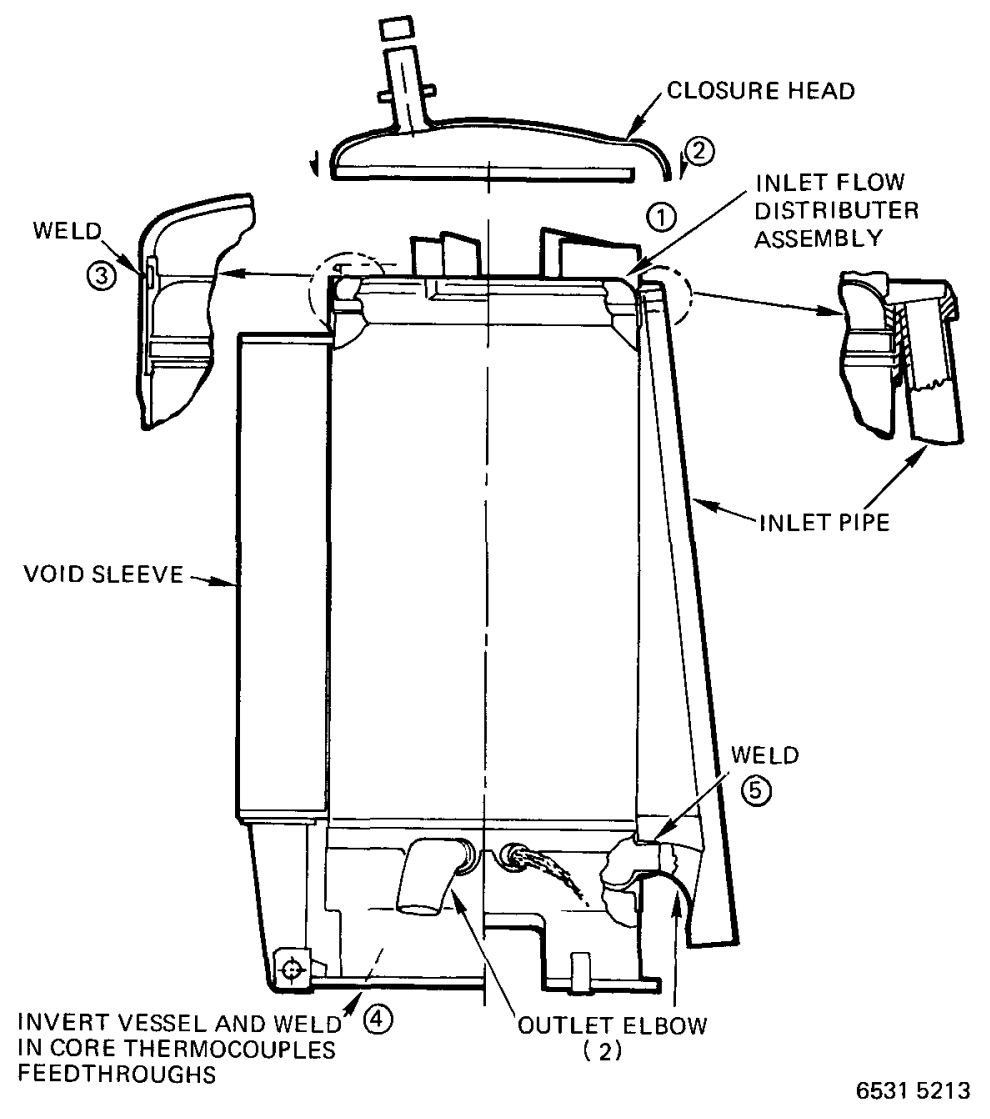

Figure 16. Reactor Vessel Closure 
reflector is removed and the vessel is prepared for core installation. This involves the installation of the core channel exit instrumentation as illustrated by Figure 13.

Installation of the core assembly into the reactor vessel is accomplished by slipping the vessel over the core as illustrated by Figure 14A. This approach is proposed because it eliminates any handling of the core assembly. In addition, the possibility of any damage occuring during this mating is significantly less when the moving component is the $25-1 \mathrm{~b}$ vessel instead of the $240-1 \mathrm{~b}$ core assembly. After the vessel is secured, as illustrated by Figure 14B, it can be inverted and prepared for the criticality tests.

The installation for the criticality tests is illustrated by Figure 15. The system is located in the power test vault, and the controls and instrumentation are connected to the reactor control room through jumper cables to the vault terminal panels. All controls, including the ground test backup shutdown system, are active during the tests.

The initial approach to critical is accomplished by a stepwise removal of the poison splines from the core coolant passages. Each step involves manual removal of a group of splines, while the control segments are at full-out. The cell is vacated and sealed, and then the control sector $\mathrm{s}^{*}$ are driven full-in while the neutron multiplication is measured.

After criticality is reached, and the initial reactivity and control worth measurements are completed, the reactivity adjustments are made. Reactivity is reduced by shimming up the reflector to vessel spacing pads which tilts the reflector halves outward from the vessel. Reactivity can be increased by adding beryllium shim blocks to the outer surfaces of the fixed reflector.

When all reactivity adjustments and measurements have been completed, the reflector-control assemblies are removed and a void sleeve is installed around the reactor to prevent accidental criticality during subsequent handling.

The operations involved in the reactor vessel closure are illustrated on Fibure 16. This will include qualification of welding operators and procedures for each weld configuration, weld surface inspections, weld internal inspections by radiographic and/or ultrasonic methods, and helium leak test of the entire NaK containment boundary.

*The words "sector" and "segment" are used interchangeably in this report.

$$
\text { AI - AEC - } 13075
$$


Sealing of the fill and drain tube extending from the closure head is accomplished as a final operation in the NPU system NaK loading sequence. This involves a double pinch of the tube, cutoff and weld at the outboard pinch, and then installation of a backup seal cap over the tube.

The void sleeve will be kept in place around the reactor vessel until the power system is assembled and ready for $\mathrm{NaK}$ loading and thermal acceptance tests. The void sleeve will then be removed and the reflector - control assemblies installed so that wet critical determinations and control segment calibrations can be performed as part of the thermal acceptance tests.

\section{REFLECTOR ASSEMBLY}

The reflector assembly for the 5-kwe reactor is tapered at $8.5^{\circ}$ from $\sim 1.2$ in. thickness at the top of the reactor to $\sim 3.6 \mathrm{in}$. thickness at the bottom of the reactor. Two segments of the reflector assembly, each subtending $117.5^{\circ}$ of the total $360^{\circ}$ of the reflector, slide vertically to provide reactivity control. Lowering the segments results in a 4 -in. -high window at the core midplane, through which increased neutron leakage occurs.

1. Design Requirements

a. Operational

The operational requirements of the 5 -kwe reflector system are listed in Table 8.

b. Environmental

The environmental design conditions are listed in Table 9.

2. Trade Studies Performed

a. Selection of Reflector Configuration

In selecting the reflector configuration, several designs were considered. These included tapered and untapered reflectors, using either rotating drum control or sliding segment control. As a result of trade studies comparing the four options, ${ }^{(5)}$ the sliding segment, tapered reflector concept was selected, primarily on the basis of minimum weight. Other studies of control system reliability indicated that the optimum number of segments is two.

AI- AEC - 13075 
TABLE 8

OPERATIONAL REQUIREMENTS OF REFLECTOR SYSTEM FOR THE 5-kwe REACTOR

\begin{tabular}{|c|c|}
\hline Item & Function \\
\hline Control Reflector Sector & 0 to $4 \mathrm{in}$. vertical movement ( 2 sectors) \\
\hline Control Motion & $\begin{array}{l}\sim 0.005 \mathrm{in} . \text { /step (1 electrical revolution } \\
\text { of actuator phases) }\end{array}$ \\
\hline Control Stepping Rate & $\begin{array}{l}\text { l step/sec or slower (alternate reflector } \\
\text { sectors) }\end{array}$ \\
\hline Drive Train Backlash & $<0.005$ in. axial and $<4.0^{\circ}$ rotational \\
\hline \multicolumn{2}{|l|}{ Control Sector } \\
\hline Counter Balance & $\begin{array}{l}\text { Control sector weight counter balanced } \\
\text { to prevent inward movement in the event } \\
\text { of actuator malfunction }\end{array}$ \\
\hline \multicolumn{2}{|l|}{ Flight Safety } \\
\hline Launch & $\begin{array}{l}\text { Control Section locked in shutdown (out) } \\
\text { position }\end{array}$ \\
\hline End of Life (EOL) & $\begin{array}{l}\text { Reflector assemblies rotatable away from } \\
\text { core vessel to achieve shutdown }\end{array}$ \\
\hline \multicolumn{2}{|l|}{ Ground Test Safety } \\
\hline Normal Scram & $\begin{array}{l}\text { Simultaneous withdrawal of both reflector } \\
\text { sectors at } 5 \text { steps/sec rate }\end{array}$ \\
\hline Backup Shutdown & $\begin{array}{l}\text { EOL reflector assembly rotation with } \\
\text { stored energy. Reflector as semblies } \\
\text { repositionable for restart }\end{array}$ \\
\hline
\end{tabular}

TABLE 9

REFLECTOR ENVIRONMENTAL REQUIREMENTS

\begin{tabular}{|c|c|}
\hline Item & Function \\
\hline \multicolumn{2}{|l|}{ Environmental-Ground Test } \\
\hline Temperature $\left({ }^{\circ} \mathrm{F}\right)$ & 50 to 875 \\
\hline Pressure & $\begin{array}{l}\text { Sea level ambient (low temperature } \\
\text { operational checkout only) } \\
10^{-5} \text { torr or less (high temperature } \\
\text { operation) }\end{array}$ \\
\hline Acceleration (g) & I gravity (toward the inlet end) \\
\hline Shock and Vibration & Handling only \\
\hline Irradiation (nvt) & $1 \times 10^{20}$ \\
\hline \multicolumn{2}{|l|}{$\begin{array}{l}\text { Environmental-Launch } \\
\text { (Non Operating) }\end{array}$} \\
\hline Temperature $\left({ }^{\circ} \mathrm{F}\right)$ & 50 to 130 \\
\hline Pressure & Sea level ambient to $10^{-8}$ torr or less \\
\hline Acceleration $(\mathrm{g})$ & $\begin{array}{l}\text { Any combination of } 7.5 \text { axial and } 2.0 \\
\text { lateral or } 1.0 \text { axial and } 1.25 \text { lateral, or } \\
16.25 \text { axial and } 0.625 \text { lateral }\end{array}$ \\
\hline Shock and Vibration & $\begin{array}{l}\text { To be determined (effects expected to } \\
\text { be less than that of acceleration) }\end{array}$ \\
\hline \multicolumn{2}{|l|}{$\begin{array}{l}\text { Environmental-Space } \\
\text { Operation }\end{array}$} \\
\hline Temperature $\left({ }^{\circ} \mathrm{F}\right)$ & 50 to 875 \\
\hline Pressure & $10^{-8}$ torr or less \\
\hline Acceleration $(\mathrm{g})$ & 0.10 maximum in any direction \\
\hline Irradiation & Same as for ground test \\
\hline
\end{tabular}

AI- AEC- 13075 


\section{b. Reflector Control Drive Selection}

Trade studies were also conducted to determine the method of reflector support, the type of drive mechanism, the gearing and bearing requirements, and the reflector anti-rotation devices. Studies were conducted to determine the preferred location of drive motors and other components on the basis of minimum envelope and weight constraints. A key restraint was the requirement that backup EOL shutdown for ground test be accomplished by swinging the reflector halves away from the core. A ball screw with a translating nut was selected as the final reflector drive design because it is efficient and simple. The major advantages are low drive torque, minimum self-welding potential, simple and reliable design, and availability of supporting test data at operational conditions.

The actuator was located near the shield instead of at the opposite (top) end of the reactor because of greater design flexibility, and because more space is available in which to locate the drive components. In addition, this layout shortens the screw drive and locates it near the center of gravity of the segment, locates the actuator adjacent to the load carrying structure, and shortens the electrical cables.

\section{Design Description}

The final conceptual design of the reactor control reflector system is shown in Figure 17. Two half reflector assemblies are individually hinged to the core vessel structure near the coolant outlet, and held together at the opposite end by a retaining device. The device incorporates a spring to take up the deflection between the two reflector halves caused by the thermal expansion of the core vessel.

The reactor control reflector is essentially a 16-in. -high, thick-walled beryllium cylinder, with an ID of $10.7 \mathrm{in.}$ and a minimum wall of $\sim 1.2 \mathrm{in}$. at one end, increasing uniformly at a half cone angle of $8.5^{\circ}$. Each fixed half reflector has a 10-in. -high window which subtends an angle of $117.5^{\circ}$, located at the thick end, to accommodate the movable control sector. The fixed reflector and the lower support bracket form the basic structure of each half reflector assembly. The reflector hinges, locating and retention devices, the movable control sector and its guide, and drive mechanisms are attached to this main 


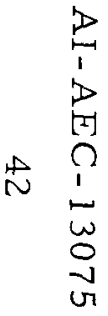

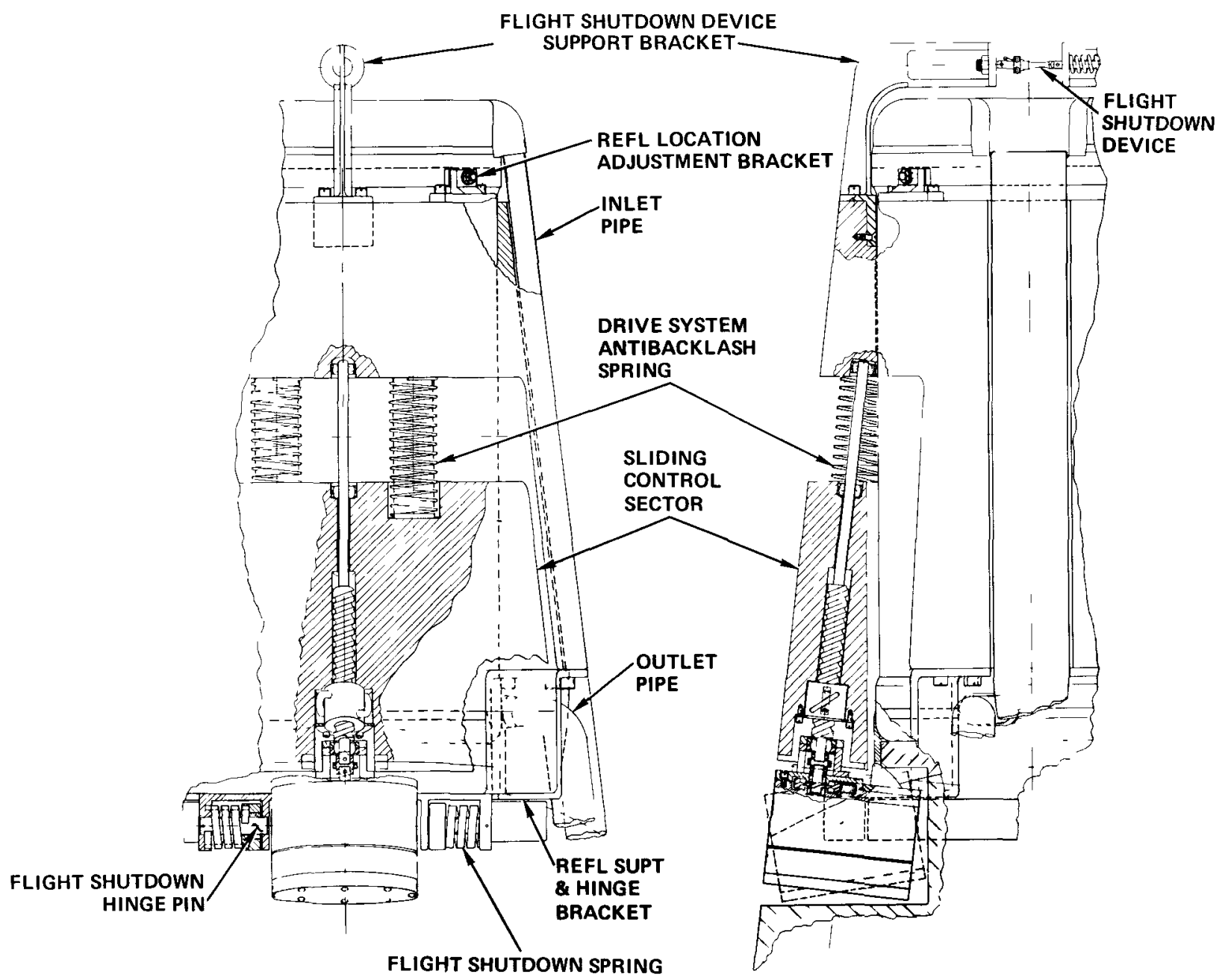

$72-J U 7-2-76$

Figure 17. Sliding Reflector Control Drive 
structure. The fixed reflector and the control sectors are of nuclear grade beryllium. The surfaces facing outward are black anodized, and surfaces facing the reactor core vessel are uncoated to minimize the beryllium temperatures.

a. Control Sector Guide and Drive Mechanism

The reactor operation, from the initial shutdown through startup and longterm power operation, is controlled by the axial positioning of the two control sectors which adjusts width of the neutron escape windows in the reflector system. A simple translating ball screw mechanism both guides and drives the control sector. The drive screw, in turn, is supported by bearings in the fixed reflector and the lower support bracket. All three of the guide bearings are of the self-aligning monoball design and are identical. The configuration and material combination of carbon graphite ball within the alumina coated spherical socket, and rotating on an alumina coated shaft, are the same as the S8DR control drum bearings. The bearing motion and loading (radial only or radial and thrust) on the drive screw shaft bearings are also similar to the S8DR. The control sector guide bearing undergoes simultaneous rotation and translation under very light radial loads. While this type of bearing action was not present on the S8DR, pure translational carbon graphite bearings were successfully operated on the S8DR scram snubbers. In addition, $\mathrm{MoS}_{2}$ dry-film lubricant on the bearing surfaces will lower friction and enhance bearing operation.

The critical ball screw parameters (ball diameter, pitch diameter, and materials) of the conceptual design were selected to provide large design margin under the expected operational conditions. The calculated life is $10^{6}$ in. of travel under 350-1b load, compared to the maximum operational requirement of $1.8 \mathrm{x}$ $10^{3}$ in. of travel under $26 \mathrm{lb}$. The double ball circuit feature was selected to resist the overturning moment induced by the center of gravity of the control sector being located off the drive screw center line.

A variable reluctance d-c stepping actuator generates the motive torque for the reflector drive. This actuator is a configurational and dimensional modification of the successfully tested S8DR actuator design. The materials, electromagnetic design, and the coil fabrication techniques are identical to the S8DR. As with the S8DR, the actuator produces discrete steps of $1.8^{\circ}$ of rotation when the successive phases are energized. The 2.78:1 ratio of the integral gear box coupled with the 0.75 -in. lead of the ball screw results in 0.0054 in. of control sector AI-AEC- 13075 
motion $\left(0.5 \notin\right.$ of reactivity change) for each $7.2^{\circ}$ rotation of the actuator. The $7.2^{\circ}$ actuator rotation per control step, which represents a complete electrical revolution of the electromagnetic phases, was selected to simplify the controller requirements.

A builtin mechanical brake locks the actuator rotor in place except when stepping motion is required. Face gears on the mating brake discs provide positive braking with minimal braking force. Rotational backlash of th brake is eliminated by utilizing a torsionally rigid bellows to give the fixed brake disc axial flexibility for the engagement and disengagement. The brake is mechanically designed to hold the control sector in place during the spacecraft launch.

Both the actuator stator and the brake are designed to accommodate sheathed cabling. The sheath of each single conductor cable is clamped at the terminal box and the conductor is welded to a cable junction which, in turn, is clamped at an insulated terminal strip. The termination design permits attachment of "jumper cables" to operate the actuator until the final installation and welding of the system cables.

The actuator assembly is attached to the lower reflector bracket and the output shaft of the gear box is attached to the shaft of the ball screw drive through a bellows-type flexible coupling. The axial and angular flexibility of the coupling separates the bearings and shaft of the actuator gear box and those of the ball screw drive to prevent any binding reaction between the two units.

Two tapered lock pins on the lower reflector bracket engage mating holes in the control sector when the sector is in the full-out position. These pins not only act as mechanical full-out stops, but also prevent rotation of the control sector during the launch. An S8DR type limit switch signals that the control sector is in the full-out position.

The hinge mounting feature of each reflector half assembly is utilized to achieve the end of life shutdown. Torsional springs located at each hingepin are designed to overcome the bending resistance of the sheathed cable to rotate the reflector assembly away from the core vessel when the retaining device is separated. The reflector retaining device will be an electrically actuated fusible link similar to that of the SNAP IOA system. Upon receipt of the final shutdown

AI- AEC- 13075 
signal, electrical energy is applied to a small heater located within the device, heating the housing until its strength falls below the applied load, causing rupture and separation.

The normal shutdown requirement is achieved by the rapid withdrawal of both control sectors by the continuous operation of both actuators. In this operational mode, the actuator brake is disengaged by continuously energizing the brake solenoid, while the actuator is being stepped at 6-rpm rate until the full-out limit switch is actuated. At the end of the shutdown, the brake solenoid is de-energized and the mechanical brake engaged to lock the control sector prior to de-activating the actuator phases.

b. Ground Test Shutdown Mechanism

The end-of-life shutdown capability of the reflector system is also used to provide a backup shutdown feature for ground testing. As shown in Figure 18, the reflector system is modified slightly and reflector latching and reset mechanisms are added. The reflector retaining device and its thermal expansion spring are removed from the reflector, and a restart arm is attached to each reflector half assembly. This arm contains the armature of the scram magnet and the thermal expansion spring. A dual coil magnet acting on the armature, which, in turn, is spring mounted to the arm, holds each reflector half assembly against the core vessel during normal operation. When the backup shutdown signal is initiated, the power to both coils of the magnet is shut off, de-energizing the magnet, allowing the end-of-life shutdown torsion springs at the hinges to rotate each reflector half assembly away from the core. In the expected coolant-inlet-down orientation of the ground test, the center of gravity effect of each reflector half assists in the rotation away from the core. A snubber spring within the pneumatic reset cylinder cushions the reflector assembly at the end of the rotation. The thermal expansion spring, which mounts the magnet armature, acts as a secondary snubber.

To reset the reflector assembly for the reactor restart, each pneumatic reset cylinder is pressurized with inert gas to rotate the reflector half against the core vessel. A slight additional force compresses the expansion spring to permit contact between the magnet armature and the magnet face, establishing the magnetic latching. A limit switch is actuated when the reflector half is in 


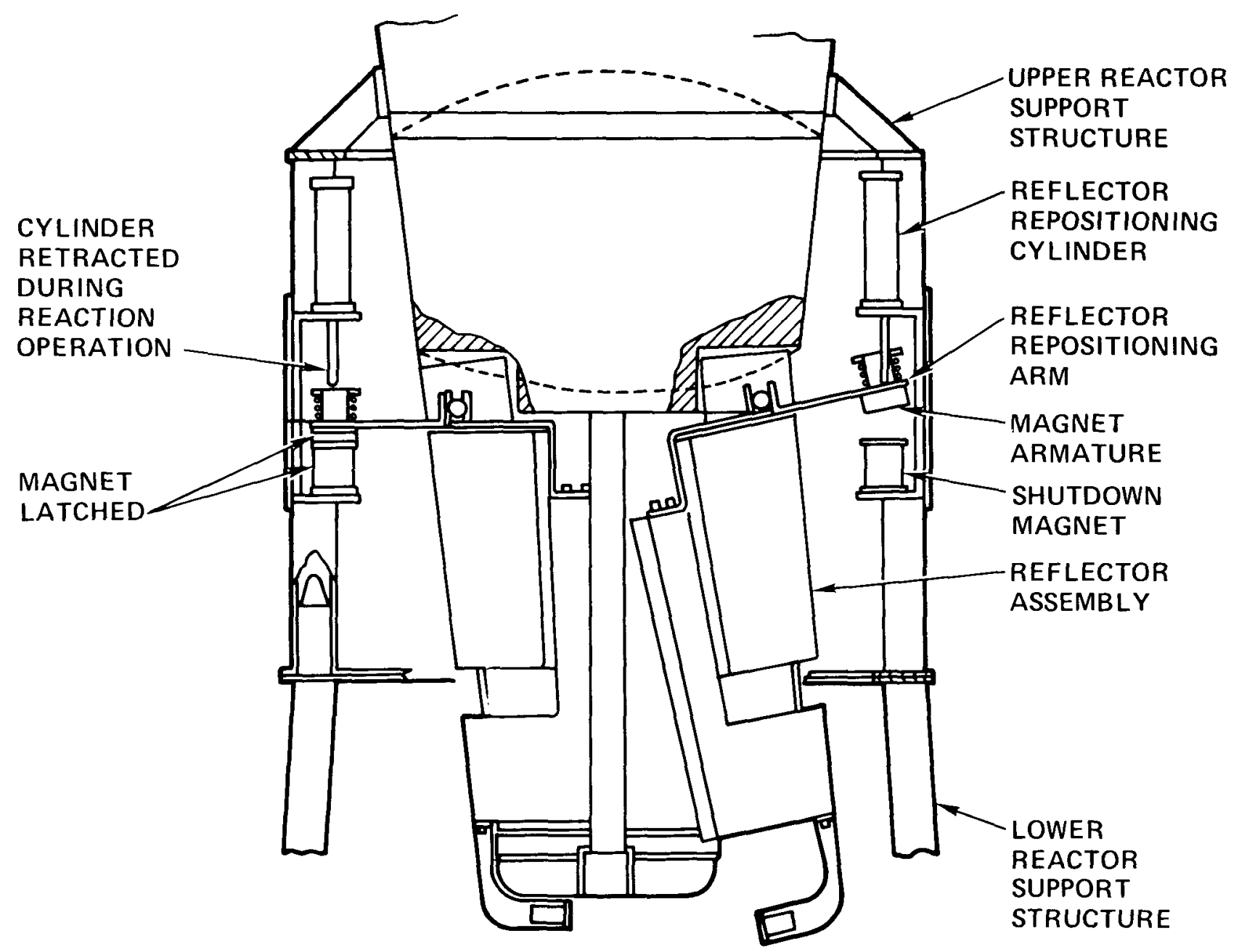

$72-\mathrm{JU} 14-2-97$

Figure 18. Backup Shutdown-Restart Mechanism 
the reset position. Upon depressurization of the pneumatic cylinder, the return spring within the cylinder repositions the piston to the ready-to-snub location. An indicator switch on the cylinder indicates when this piston position is reestablished. This signal is necessary prior to reactor startup, to assure that each reflector assembly is capable of another backup shutdown operation.

In the coolant-inlet-down orientation of the reactor during the ground test, the gravitational effect on the movable control sector is toward the more reactive direction. Normally, the actuator brake holds the control sector at its position except during stepping. The torque generated at the actuator rotor during stepping is adequate to raise or lower the sector against the gravitational pull.

If, however, one or more actuator phase is inactive, and the stepping is initiated, the gravitational pull on the sector may cause it to move downward until the stepping is completed and the brake is again mechanically applied. Such a failure of the actuator phase could be caused by the following malfunctions: open circuit in both coils of a phase, failure in the electrical cables between the controller and the actuator terminals, or malfunction of the controller. To preclude this possible incident, the weight of the control sector is counterbalanced. The normal flight anti-backlash springs between the fixed reflector and the sector are replaced with heavier anti-gravity springs. The counterbalancing action of these springs is sufficient to prevent inadvertent uncontrolled downward (inward) motion of the control sector in the event of actuator malfunction.

\section{Expected Performance}

The conceptual reflector system is designed to structurally withstand the launch environment and, subsequently operate for five years in space environment. Additionally, the system is capable of operation in the ground test environment of $10^{-5}$ Torr or less pressure and $1-\mathrm{g}$ gravity.

During reactor startup the actuators are stepped to move alternate sectors at selected rate(s) not exceeding one $7.2^{\circ}$ step/sec or $\sim 0.5 \not /$ sec. Once the power operation is established, an actuator is stepped periodically only to maintain the power level or to change power level. This periodic actuator 


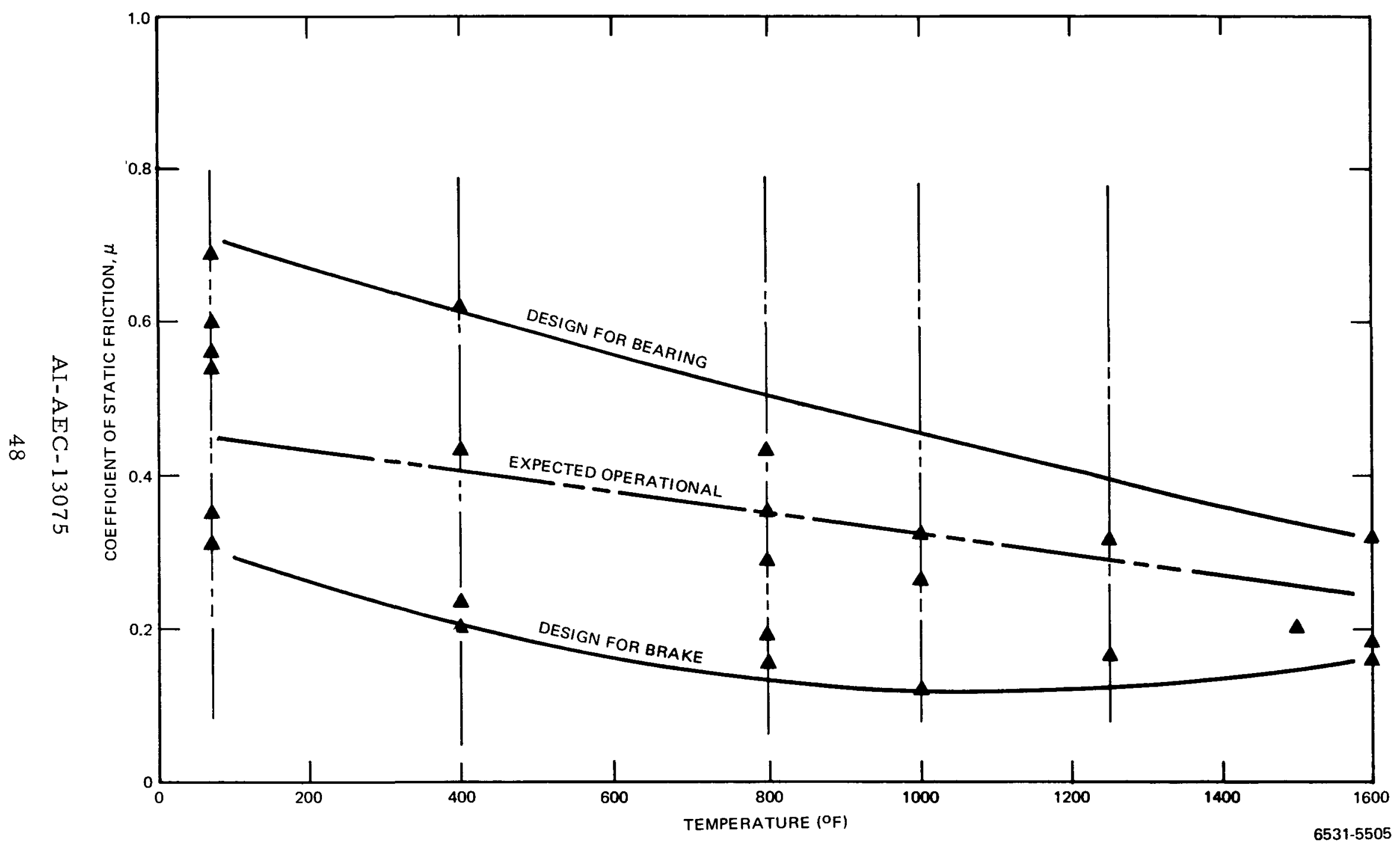

Figure 19. Alumina vs Carbon-Graphite Friction 
motion will continue until both sectors are moved to the full-in position or the shutdown signal is given.

In addition to the startup and periodic stepping, reactor $\operatorname{scram}(5 \not / \mathrm{sec})$ by the rapid rotation of the actuator may be required during the ground test. The system design is capable of 50 such scrams and subsequent restart during the 5 -year lifetime. The number of shutdowns employing the backup shutdown system is expected to be very limited.

The torque required at the actuator rotor to position the control sector under the normal control mode is dependent on the net effective weight of the sector, bearing loads, the friction coefficient of the bearings, and the efficiencies of the ball screw and gear drives. Figure 19 shows a summary of friction data used for design of the reflector drive torque requirements.

An expected coefficient of static friction of 0.35 was selected for performance predictions with 0.10 and 0.60 as the possible lower and upper limits. The expected torque requirements under the ground test and flight conditions are shown in Figures 20 and 21 . The torque values for friction coefficients of 0.35 and 0.60 were based on the lowest expected ball screw efficiency of 0.70 , while the highest expected efficiency of 0.90 was used with the friction coefficient of 0.10 . The gear efficiency was maintained at $90 \%$ for all cases.

Control sector scram, during ground test only, will require movement toward the full-out position. The maximum torque required to move the sector in this direction is approximately $66 \%$ of the maximum torque required to move the sector to full-in. The expected torque output of the S8DR-type actuator at the scram speed of $6 \mathrm{rpm}$ is approximately $70 \%$ of slow speed stepping torque output. Thus, an actuator designed to meet the torque requirement to step the sector to full-in has adequate torque capability for the scram requirement. The actuator torque requirements of $100 \mathrm{oz}$-in. during stepping and $70 \mathrm{oz}$-in. during scram were selected to allow approximately $33 \%$ margin over the maximum expected drive requirements.

AI-AEC- 13075 


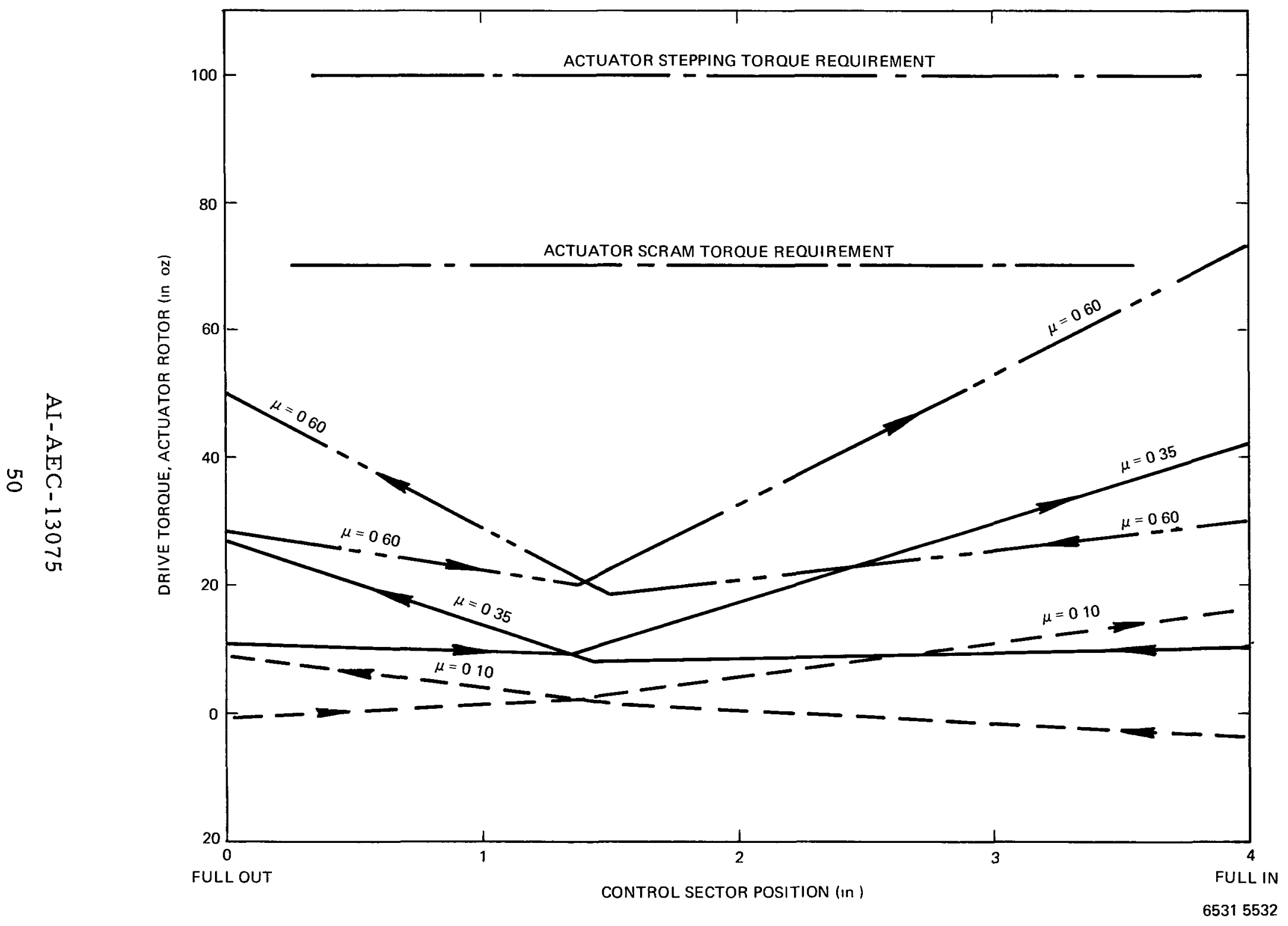

Figure 20. Ground Test Torque Requirements 


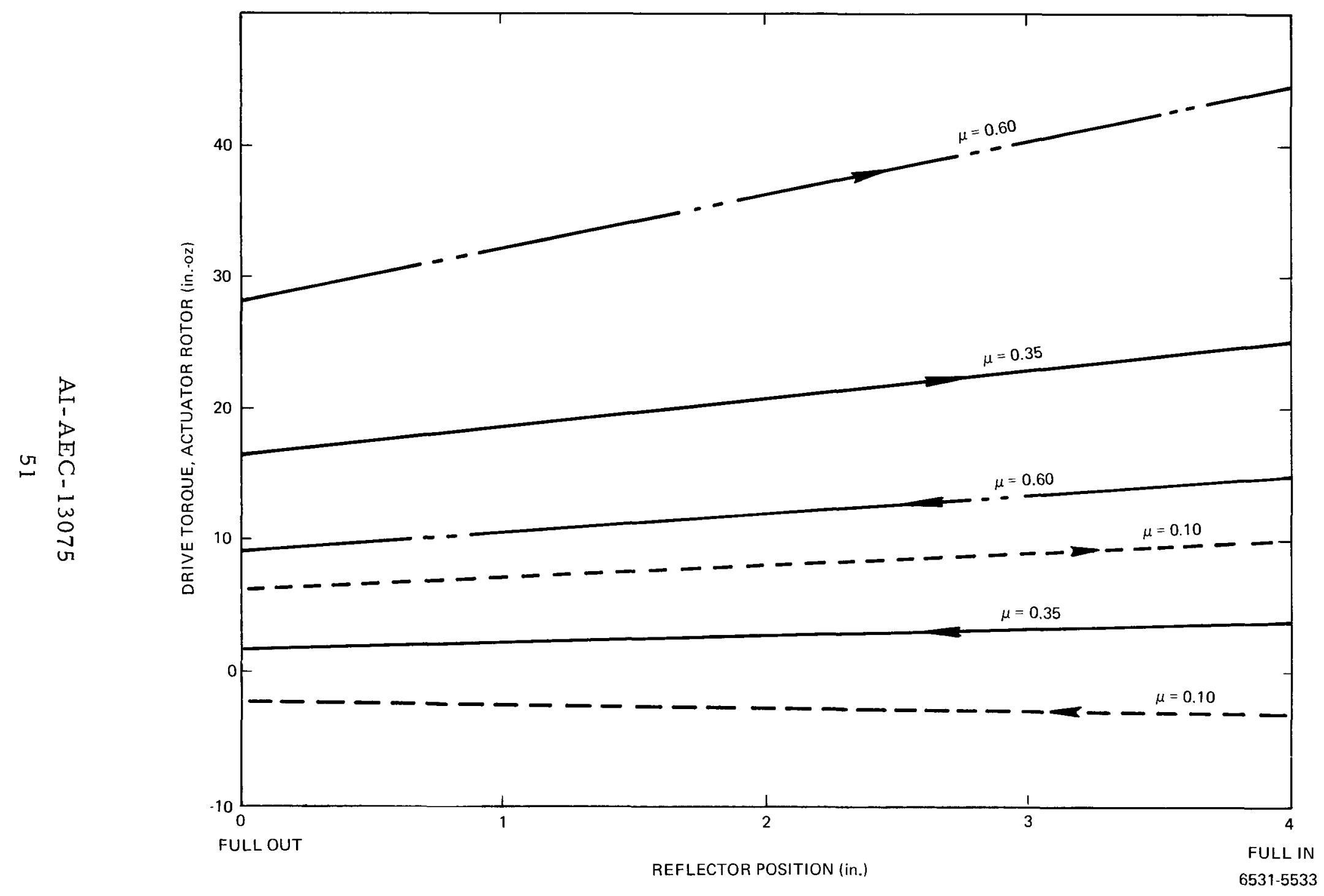

Figure 21. Flight Test Torque Requirements 


\section{BLANK}




\section{THERMAL AND HYDRAULIC DESIGN AND PERFORMANCE}

\section{A. INTRODUCTION}

The reactor core and fuel elements were designed to achieve improved thermal and hydraulic characteristics over the previous generation reactor, S8DR. The S8DR (SNAP 8 Developmental Reactor) operated at a power of $600 \mathrm{kw}$ and a coolant outlet temperature of $1300^{\circ} \mathrm{F}$. Fuel temperatures were well in excess of $1400^{\circ} \mathrm{F}$ (the design value) during power operation.

Several S8DR fuel elements were found with cracked cladding when the reactor was disassembled. The cladding ruptures were attributed to excessive cladding strain caused by fuel swelling, which had exceeded design limits because of overtemperature fuel conditions. (6)

The principal contributor to the high temperatures was the fuel element bow and cluster patterns, which formed clusters of hot coolant channels in the core. Very little coolant mixing between channels existed to moderate these hot channels. Other contributors to high fuel temperature included the greater than anticipated bypass coolant flow at the core periphery and the detrimental effects of entrained gas from the surge tank on the fuel to coolant heat transfer process. Post-operation hydraulic tests of the flow-through surge tank showed that gas was entrained into the coolant in the tank. The flow distribution in the coolant inlet plenum also contained two vortexes which would tend to concentrate the entrained gas at the vortex locations. Changes were made to alleviate all of the above problem areas for the current reactor design.

\section{B. PLENUM AND CORE HYDRAULICS}

The following changes were made to improve the hydraulic characteristics of the reactor system.

1) Fins were added to the fuel elements to prevent clustering and to promote interchannel mixing.

2) The core bypass flow was essentially eliminated by using a core liner. 


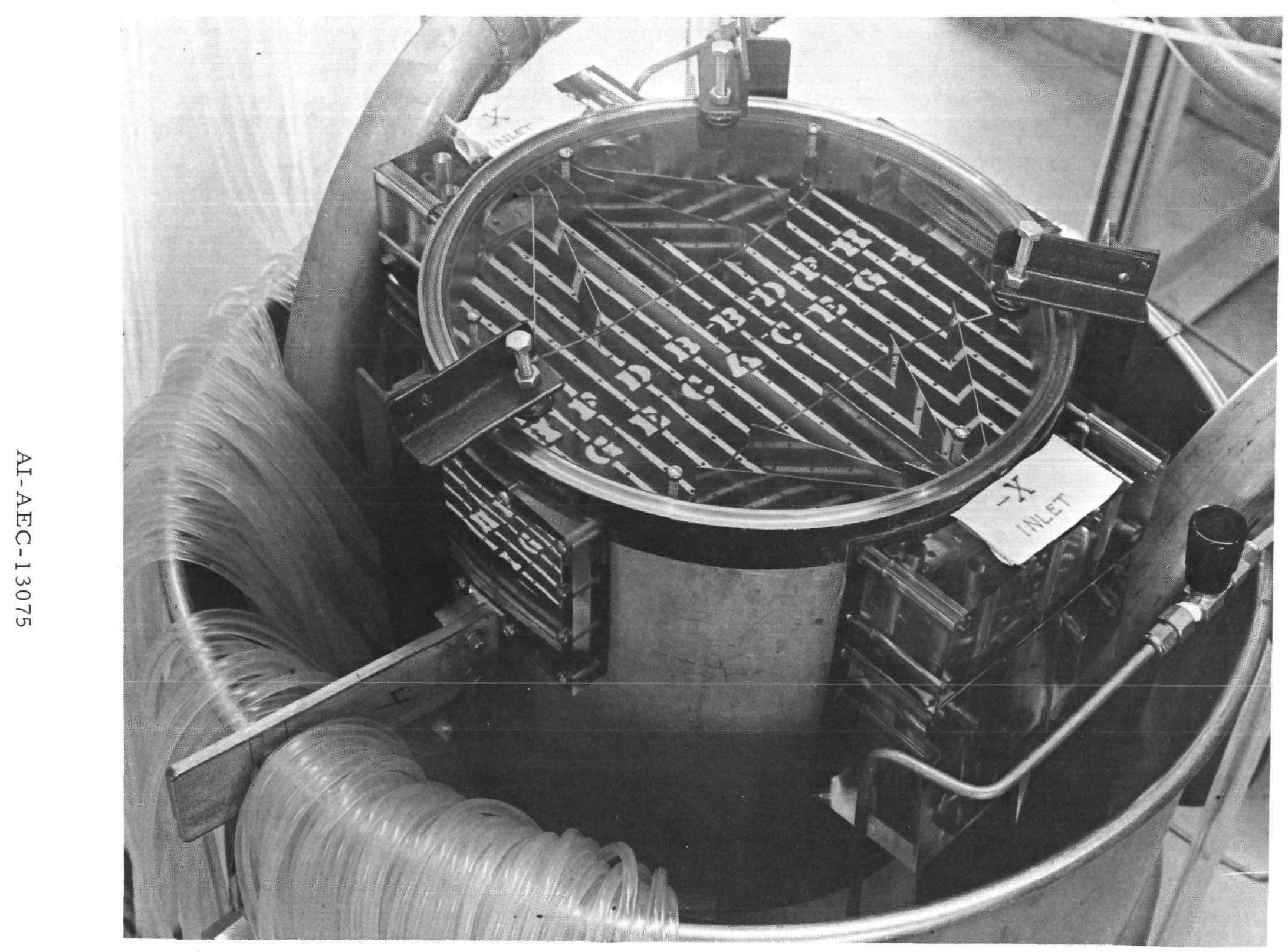

$6531-4047$

Figure 22. Plenum Model 
3) The flow-through surge tank was replaced by standoff volume accumulator units utilizing bellows to accommodate $\mathrm{NaK}$ volume expansion without a NaK-gas interface.

4) Spreading vanes and baffles at the core coolant inlet lines provide a uniform flow at the inlet grid plate.

Hydraulic tests were run with water to aid in the design of the fuel element fins and the coolant inlet plenum. Details of the test setups are given in the Hydraulic Test Summary Report. (7)

\section{Inlet Plenum Hydraulic Tests}

In keeping with the requirement of a lighweight reactor system, the inlet coolant plenum has been designed to be only about $2 \mathrm{in.} \mathrm{high.} \mathrm{The} \mathrm{initial}$ design had a convex, dished in, plenum head. The coolant enters the plenum through two opposing inlet nozzles. The inlet lines to the nozzles have a flattened cross section with cylindrical ends. The design dimensions at the time of the hydraulic tests were $2.62 \mathrm{in.} \mathrm{by} 0.75 \mathrm{in}$. outside by $0.070 \mathrm{in}$. wall. Currently the wall thickness has been increased to $0.083 \mathrm{in}$, but the inlet nozzles are essentially unchanged.

It is desired to spread the coolant in the plenum to provide a uniform flow to the inlet grid plate. Vortexes like those found in the S8DR plenum are to be eliminated. The purpose of the hydraulic tests was to find an acceptable baffle design to achieve the desired flow distribution. The reactor coolant flow is approximately $17,000 \mathrm{lb} / \mathrm{hr}$ of $\mathrm{NaK}$, which at $1100^{\circ} \mathrm{F}$ is equivalent to $0.103 \mathrm{ft}^{3} / \mathrm{sec}$. This gives a Reynolds number of $1.85 \times 10^{5}$ in the plenum inlet lines. The acceptable pressure variation in the coolant at the grid plate is $\pm 0.008 \mathrm{psi}$, or $\pm 5 \%$ of the reactor $\triangle \mathrm{P}$.

Hardware from a previous test was modified to provide a scale model of the plenum (see Figure 22). The model was tested at various flows in a water loop. Horizontal baffles and various shapes of vanes were tested along with different shaped plenum heads in the effort to achieve the desired uniform flow.

In preparation for the test, calculations were performed with a potential flow model to determine the ideal flow streamlines for two inlet plenum configurations. The calculations were performed for a total reactor coolant flow 


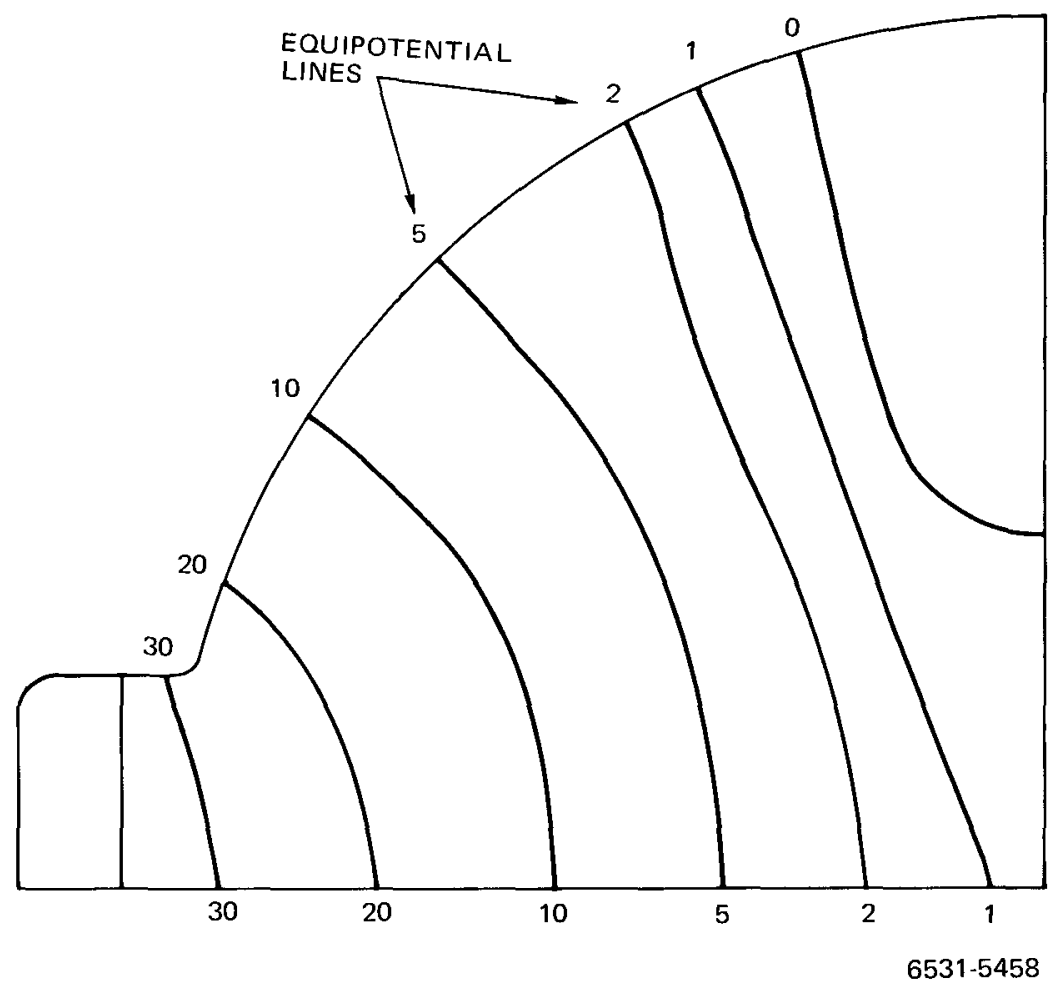

Figure 23. Potential Flow Lines at Top of Inlet Plenum - 1-1/2-in. Inlet Line Height

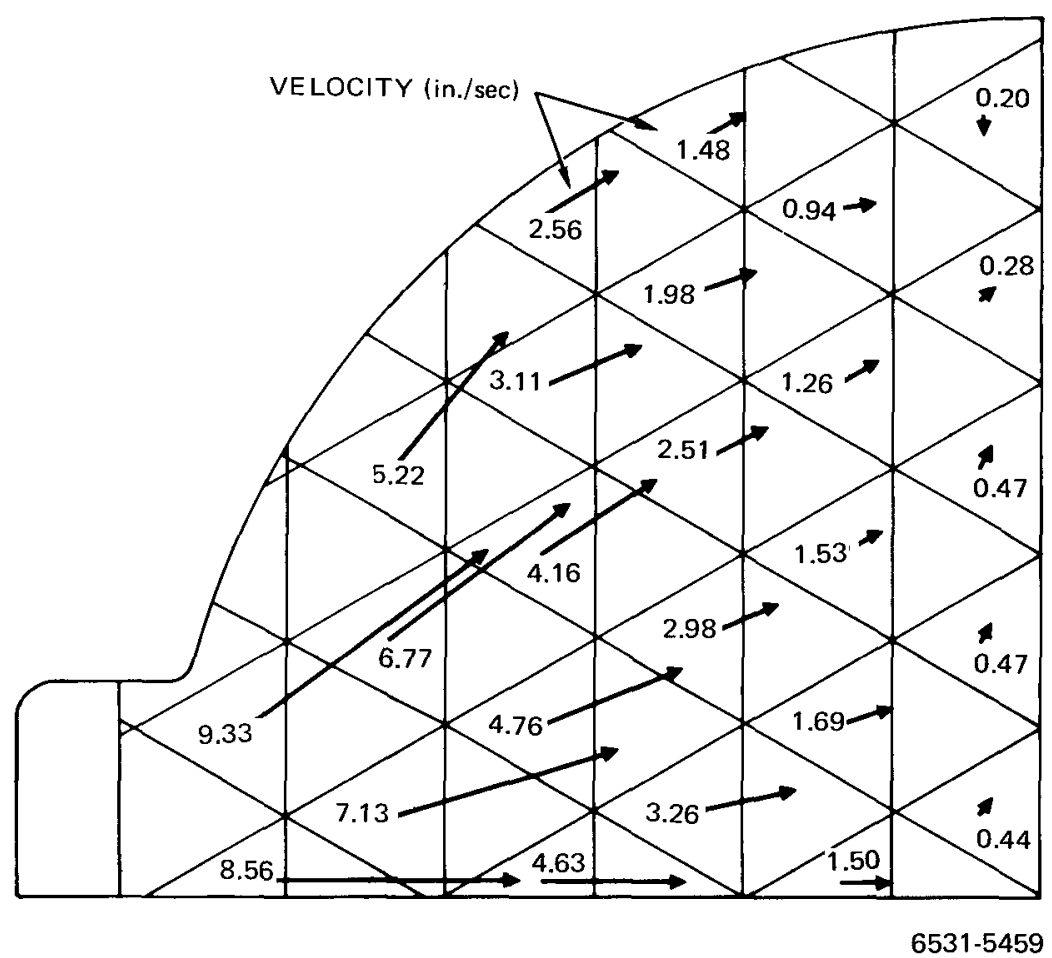

Figure 24. Horizontal Velocity Vectors at Top of Inlet Plenum - 1-1/2-in. Inlet Line Height

$$
\text { AI-AEC- } 13075
$$


of $16,300 \mathrm{lb} / \mathrm{hr}$. For other flows, the resulting potential function and velocity vector magnitudes vary proportionally. The calculational results for the basic plenum with no vanes or baffles present are shown in Figures 23 and 24. Equipotential lines and velocity vectors are shown for a horizontal cross section just below (3/16 in.) the inlet grid plate. The flow velocity is determined by taking the negative derivative of the flow potential function.

Figures 25 and 26 show the results of similar calculations for the plenum, but with two horizontal baffles present. The baffles force the flow to spread laterally before passing through the slot midway between the two inlets. The baffles were assumed to block off about one-third of the inlet line openings because of their particular location in the plenum. The potential flow calculations give results for ideal, frictionless flow. The actual flow in the plenum is not frictionless, however, and it is necessary to force the flow to follow the ideal flow streamlines by using spreading vanes at the plenum inlets. The vane configuration was designed by a method similar to the method of Feil, (8) with the flow being forced to spread slightly faster than ideal flow streamlines. Feil's paper gives the optimum amount to force the flow for a given diffuser configuration. Diffuser nomenclature is shown in Figure 27. The area ratio from the coolant inlet nozzle to the edge of the horizontal baffle which was considered is 3.36 (Figure 27). However, the nozzle and plenum do not form a simple straight diffuser. The area can be approximately separated into two sections, one coming out of the nozzle and the second on into the plenum. The vane design followed this approximation. The vanes were straight except for a single bend instead of having a slight curvature as the actual ideal streamlines would.

Figure 28 shows two charts from the work of Kline ${ }^{(9)}$ and his associates which indicate the type of flow which can be expected for various diffuser angles. From Figure $28 \mathrm{~b}$, for an area ratio of 3.36 , it is essentially impossible to be in the region of "no appreciable stall" even with many closely spaced vanes. However, vanes can be used to minimize the extent of the stall and to direct the flow into the desired areas. Five vanes per inlet were chosen as a reasonable number. The initial divergence angle (2 $\theta$ ) between the vanes

AI- AEC- 13075 


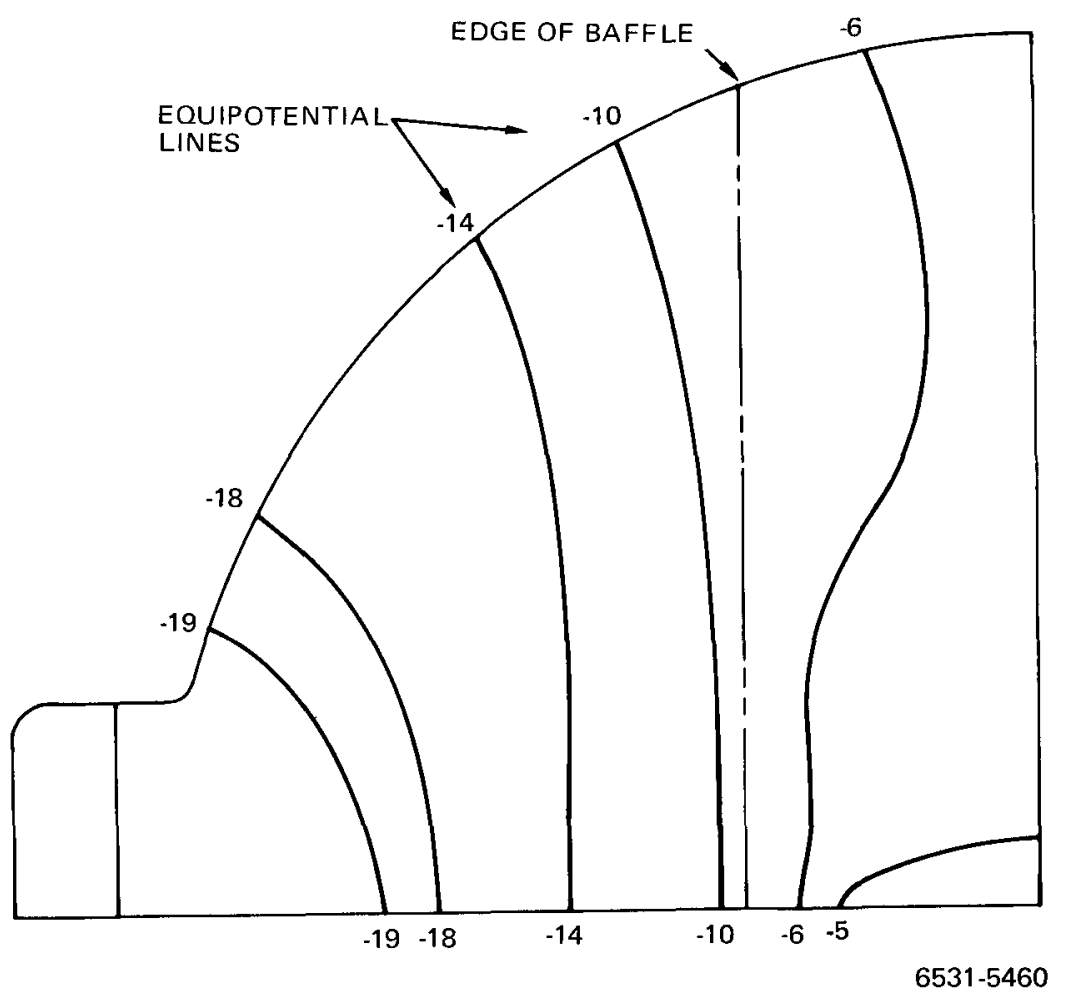

Figure 25. Potential Flow Lines at Top of Inlet Plenum - Horizontal Baffle in Plenum

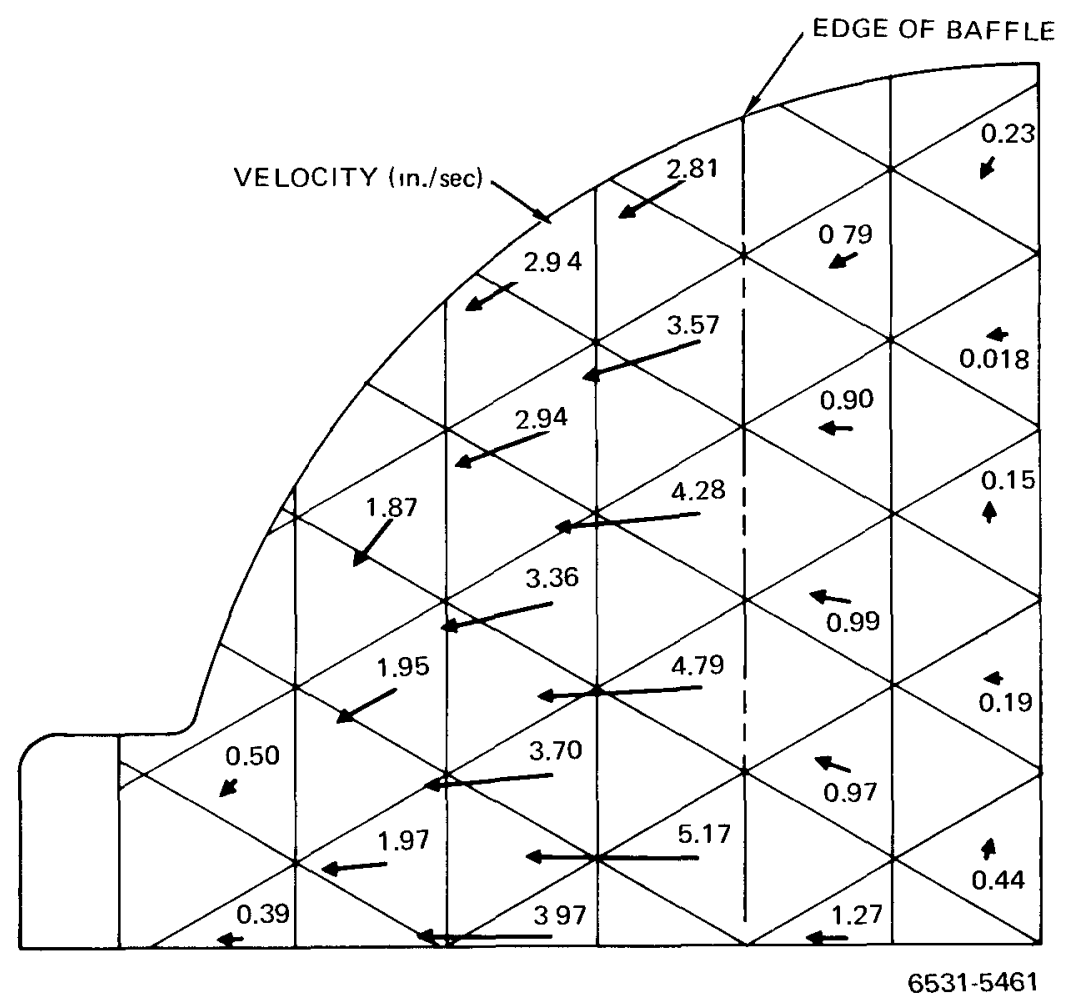

Figure 26. Horizontal Velocity Vectors at Top of Inlet Plenum - Horizontal Baffle in Plenum

$$
\text { AI-AEC- } 13075
$$



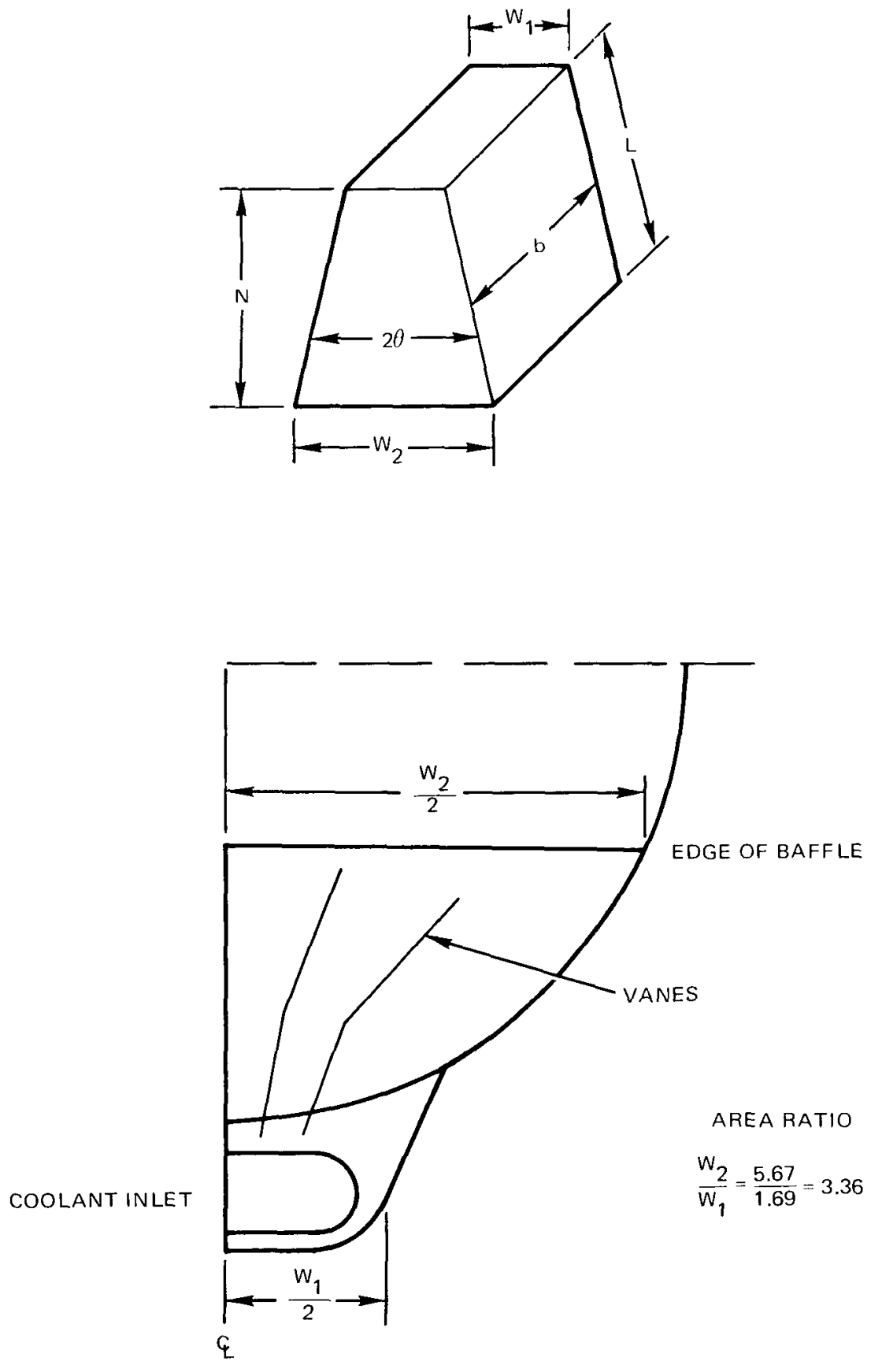

Figure 27. Diffuser Nomenclature

AI- AEC- 13075 

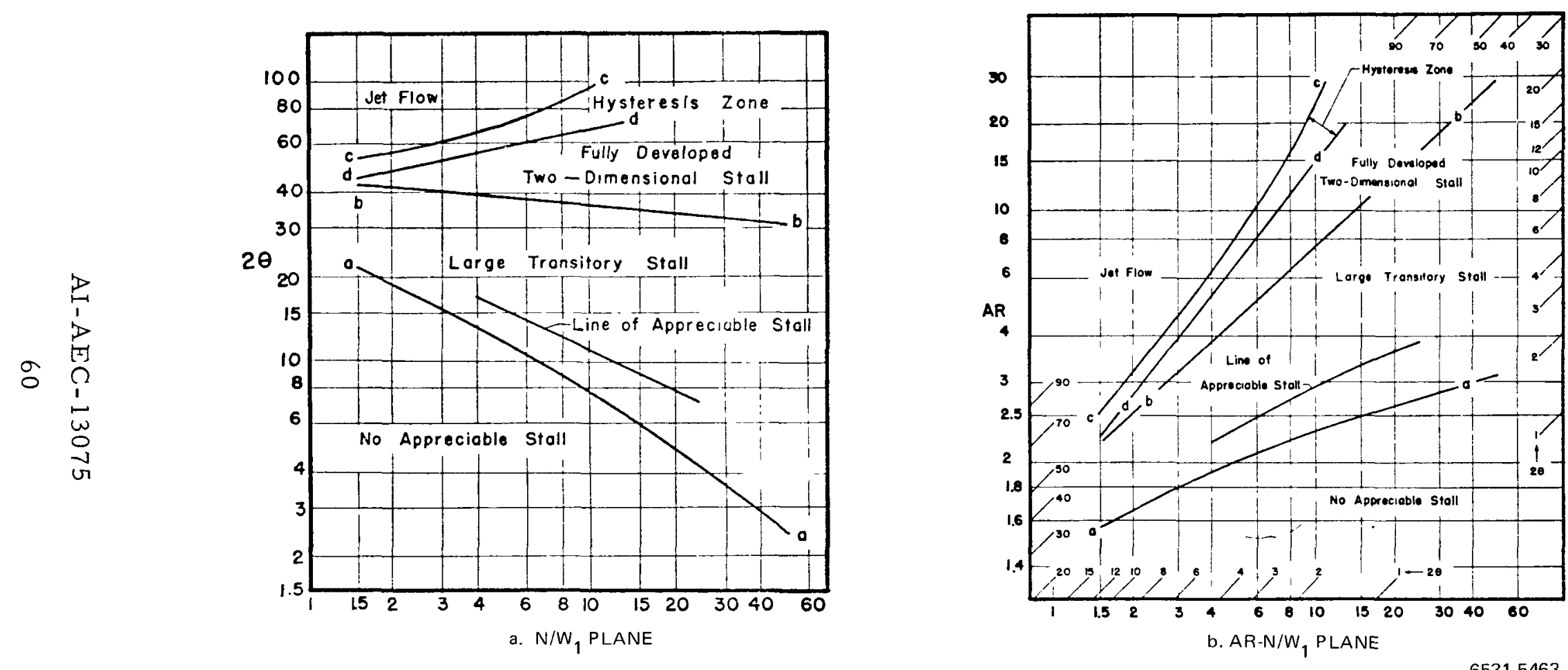

Figure 28. Flow Regimes in Straight-Wall, Two-Dimensional Diffusers 
was $11^{\circ}$, which is within the region of "no appreciable stall" (Figure 28a). The final divergence angle after the bend in the vanes was $21^{\circ}$ and some stall might be expected.

The various plenum configurations were compared according to the following criteria:

1) Pressure variation at the grid plate surface

2) Visual observation of flow behavior in the plenum

3) Inlet line static pressure (related to $\Delta P$ through the plenum).

The pressure variation at the inlet gridplate was measured by 199 water manometers attached to the gridplate. These manometers provided quantitative data from which to make the final selection of the plenum configuration.

Flow in the basic plenum was dominated by the streams from the two inlet nozzles impacting in the center of the plenum to create a relatively high pressure in the central region with lower pressures at the periphery of the plenum. Two regions of relatively stagnant flow existed, one at each edge of the plenum midway between the two inlets. These regions were each characterized by two swirls or vortexes which irregularly formed and disappeared. The vane and baffle configurations tested were designed to spread the flow before the two inlet streams collided and, also, to minimize the swirls in the peripheral stagnant areas. A number of configurations were tested. (7)

The water flow in the test loop was sufficient to give a velocity almost twice the NaK coolant velocity. However, this provided a Reynolds number of only about $60 \%$ of the NaK Reynolds number. Pressure data taken at different flows were converted to equivalent $\mathrm{NaK}$ pressures and plotted as a function of inlet line Reynolds number. The data were then extrapolated to the design Reynolds number $\left(1.85 \times 10^{5}\right)$. The development of the equations for pressure conversion from water to $\mathrm{NaK}$ is shown as follows:

$$
\Delta P=\frac{f \rho V^{2} L}{2 g_{c} D}
$$




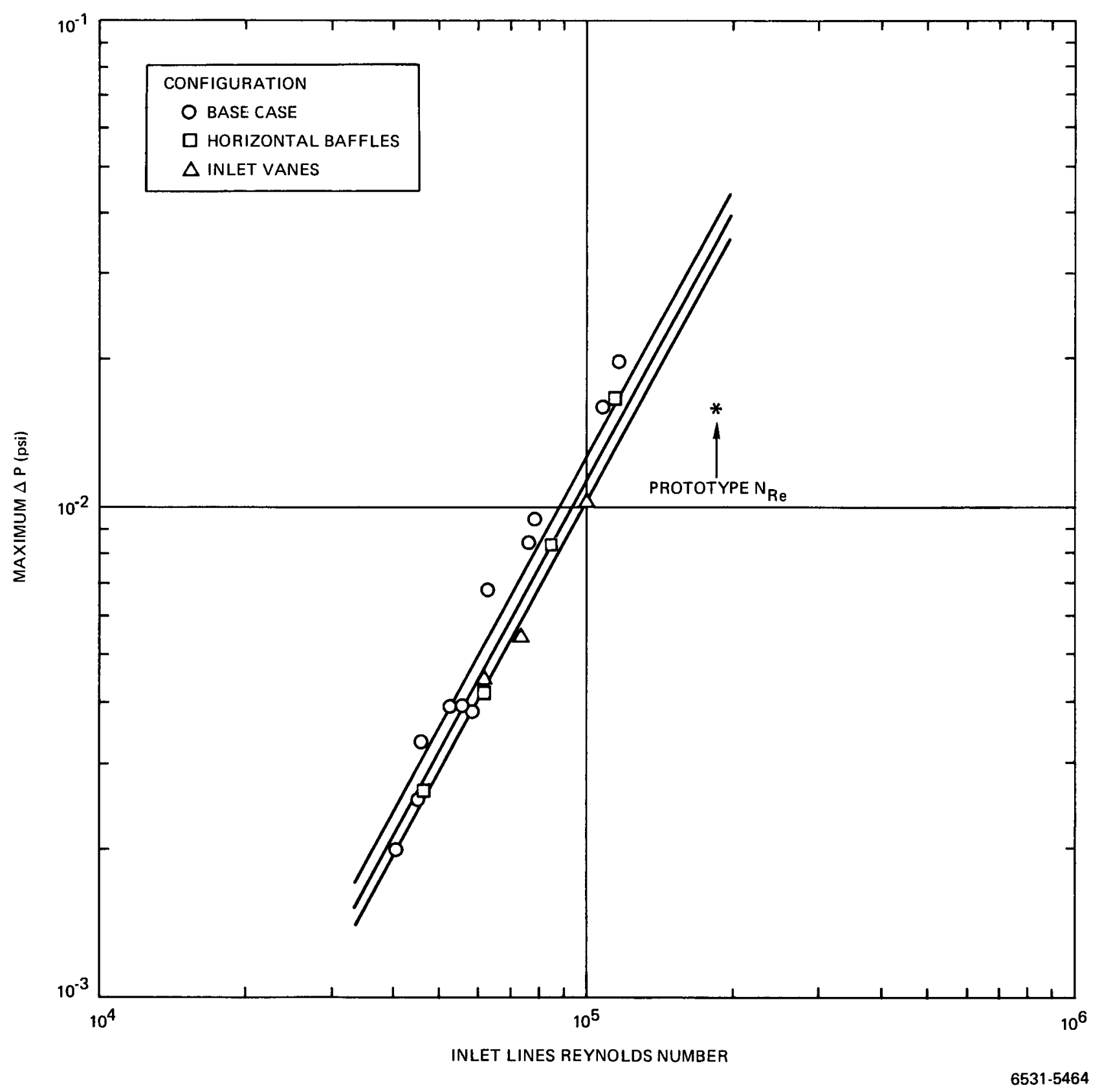

Figure 29. Hydraulic Test Data, Initial Tests

AI-AEC-1 3075 


$$
\begin{aligned}
\mathrm{N}_{\mathrm{Re}} & =\frac{\mathrm{DV} \rho}{\mu} \\
\mathrm{V} & =\frac{\mathrm{N}_{\mathrm{Re}} \mu}{\mathrm{D} \rho} .
\end{aligned}
$$

Also

$$
f \propto N_{R e}-\mathbf{x}
$$

Now

$$
\frac{\Delta \mathrm{P}_{\mathrm{NaK}}}{\Delta \mathrm{P}_{\mathrm{H}_{2} \mathrm{O}}}=\left(\frac{\mathrm{N}^{2-\mathrm{x} \mathrm{\mu}^{2} \mathrm{~L}}}{\mathrm{D}^{3} \rho}\right)_{\mathrm{NaK}}\left(\frac{\mathrm{D}^{3} \rho}{\mathrm{N}_{\mathrm{Re}}^{2-\mathrm{X}_{\mu}^{2} \mathrm{~L}}}\right)_{\mathrm{H}_{2} \mathrm{O}}
$$

Since

$$
\mathrm{D} \propto \mathrm{L}
$$

$$
\frac{\Delta \mathrm{P}_{\mathrm{NaK}}}{\Delta \mathrm{P}_{\mathrm{H}_{2} \mathrm{O}}}=\left(\frac{\mathrm{N}_{\mathrm{Re} \mathrm{NaK}}}{\mathrm{N}_{\mathrm{Re} \mathrm{H}_{2} \mathrm{O}}}\right)^{2-\mathrm{x}}\left(\frac{\mu_{\mathrm{NaK}}}{\mu_{\mathrm{H}_{2} \mathrm{O}}}\right)^{2}\left(\frac{\mathrm{D}_{\mathrm{H}_{2}} \mathrm{O}}{\mathrm{D}_{\mathrm{NaK}}}\right)^{2}\left(\frac{\rho_{\mathrm{H}_{2} \mathrm{O}}}{\rho_{\mathrm{NaK}}}\right)
$$

at equivalent Reynolds Numbers;

$$
\frac{\Delta \mathrm{P}_{\mathrm{NaK}}}{\Delta \mathrm{P}_{\mathrm{H}_{2} \mathrm{O}}}=\left(\frac{\mu_{\mathrm{NaK}}}{\mu_{\mathrm{H}_{2} \mathrm{O}}}\right)^{2}\left(\frac{\mathrm{D}_{\mathrm{H}_{2} \mathrm{O}}}{\mathrm{D}_{\mathrm{NaK}}}\right)^{2}\left(\frac{\rho_{\mathrm{H}_{2} \mathrm{O}}}{\rho_{\mathrm{NaK}}}\right)
$$

The converted pressure data for the basic plenum case is shown in Figure 29. The $\triangle P$ plotted for each run is the maximum to minimum variation at the grid plate as measured by water manometers (and converted to equivalent NaK pressure). The maximum allowable pressure goal is shown by an asterisk (*) in Figure 29. Also shown in the same figure are the case with the horizontal baffles and a case with spreading vanes at the inlet nozzles. Each case gave a slight improvement over the empty plenum, but not nearly as much as required to reach the goal. The lines shown through the experimental data points all have the same slope, which is the statistically averaged slope from the test data. 


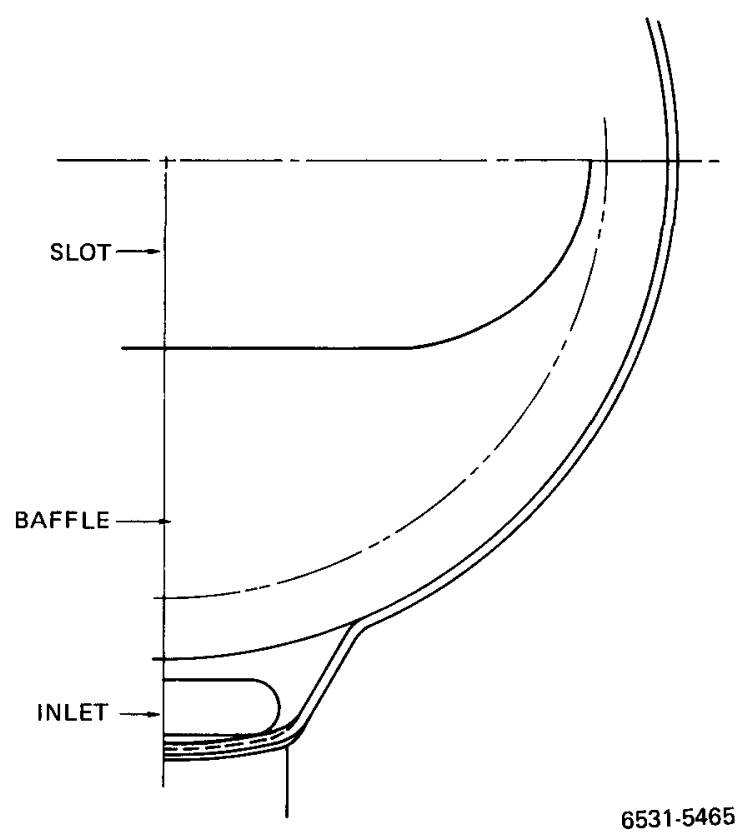

Figure 30. Quarter Section of Configuration I Baffle

An additional improvement was obtained by combining the modified vanes with a flat plenum head, in place of the convex head. A combination of the horizontal baffles, spreading vanes, and flat head resulted in the first configuration which gave an acceptable flow profile and was within the allowable pressure variation. A flat plenum head is structurally unacceptable. Therefore, the vane-baffle combination was tested with a concave (dished out) plenum head. These results showed a maximum pressure variation only half the allowable.

To improve the structural stability of the horizontal baffles, they were combined into a single baffle plate with a center slot (Figure 30). Also, the spreading vanes were re-designed to fit snugly between the horizontal baffle and the concave head. The previous vanes had to be cut down to clear the original convex plenum head. Pressure data from this configuration were greater than allowable. The baffle was further slotted (Figures 10 and 31 ) to decrease the $\triangle P$. The spreading vanes, except for the center ones, were cut down so they no longer fitted snugly to the plenum head. The outside vanes were cut to a height of $1 \mathrm{in.}$ and the adjacent ones to $1.2 \mathrm{in.}$ These modifications brought the pressure variation at the grid plate back within the acceptable range.

AI- AEC- 13075 


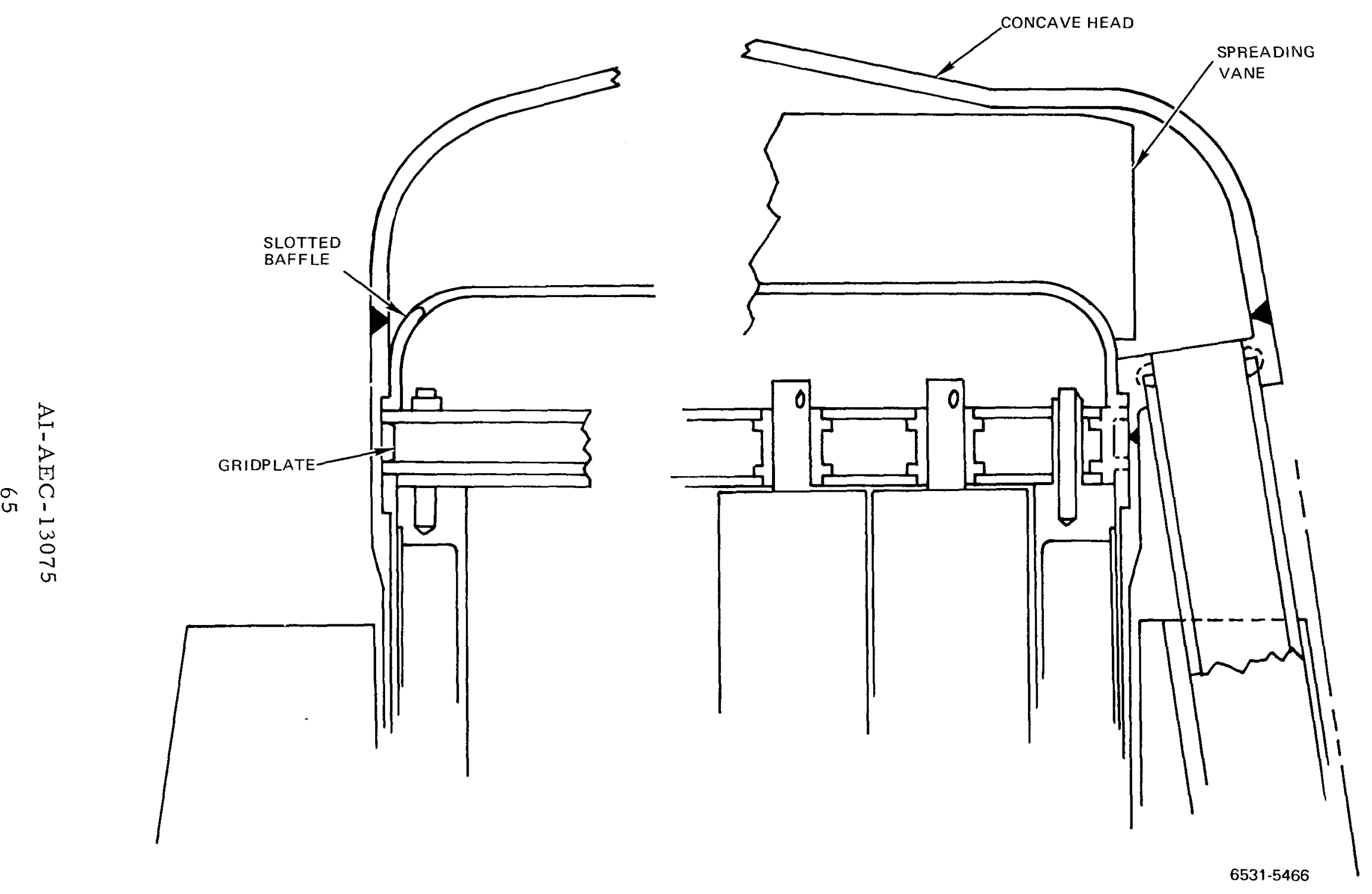

Figure 31. Inlet Plenum Design 


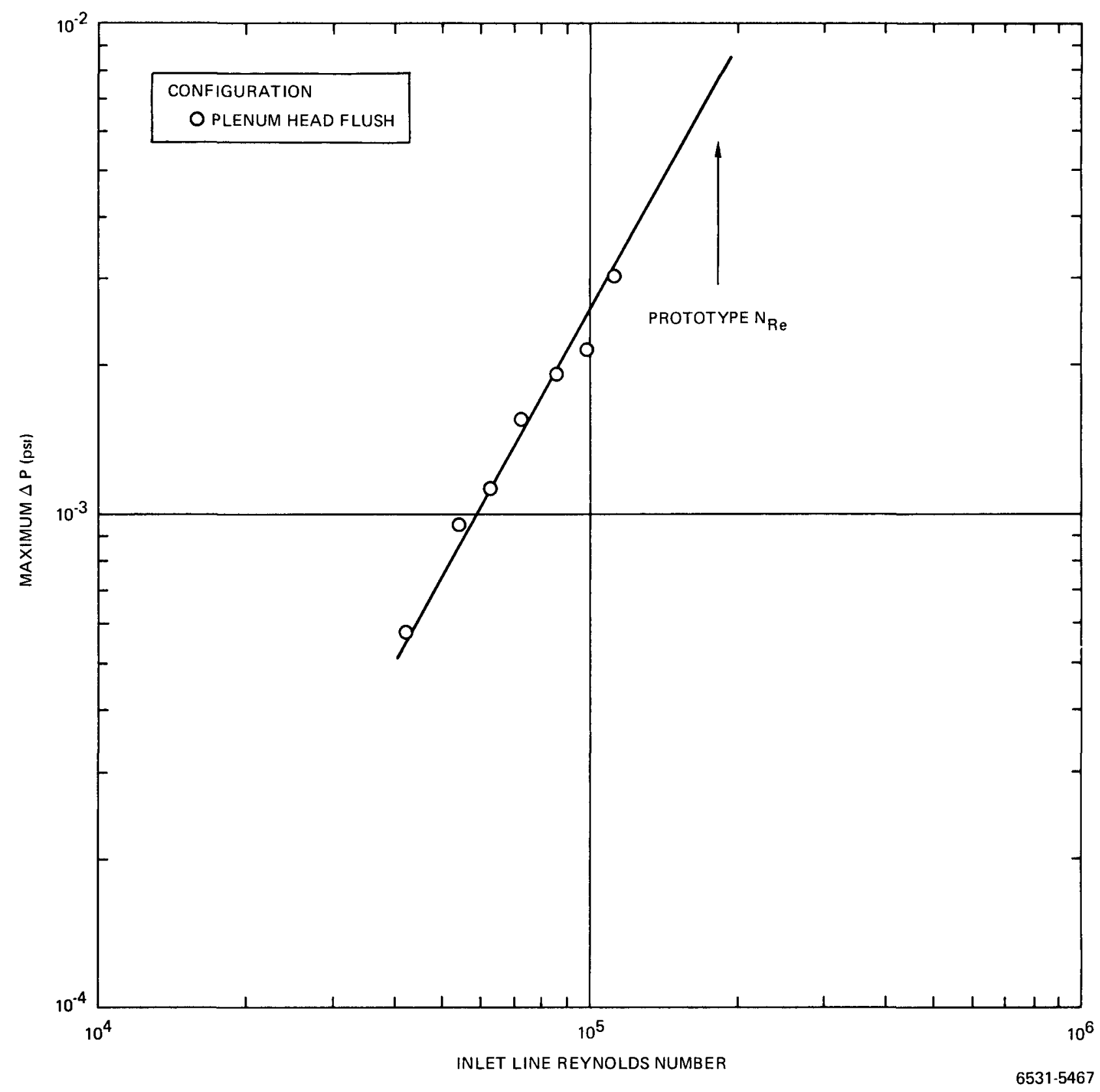

Figure 32. Hydraulic Test Data, Final Configuration 
To further improve the flow profile, the plenum height was increased $0.15 \mathrm{in.}$ to allow a full inch between the baffle plate and grid plate. This resulted in a noticeable improvement. Figure 32 shows the results of this configuration, which is the one incorporated in the reactor design. ${ }^{*}$ A static pressure plot comparison of the accepted configuration with the base case is shown in Figure 33.

\section{Mixing Tests}

The finned elements provide much more coolant mixing between channels than non-finned elements. The amount of mixing caused by the fins is, however, difficult to predict theoretically. Empirical correlations found in the literature for mixing by finned elements are for fins with a much longer pitch and extrapolation is not recommended. A series of mixing tests ${ }^{(7)}$ were run with water to measure the interchannel mixing for finned elements similar to those to be used in the reactor.

A diagram (top view) of the mixing test bundle is shown in Figure 34 . The RLN (right-left-neutral) fin configuration allows the fins to aid one another in moving fluid from one coolant channel to another. The mixing tes $t$ bundle has 19 full elements with a neutral (no fins) element starting the RLN configuration at the bundle center. The mixing test was performed by injecting a salt solution $\left(\mathrm{NaNO}_{3}\right.$ ) into one or more coolant channels at the inlet grid plate. Mixing was then determined by measuring the salt concentration at different points in the test bundle and comparing the results to calculations with assumed mixing rates. Figure 34 shows three symmetrical injection points, which allow more simple calculations than for a single injection channel.

For the triple injection scheme, a $1 / 6$ section $\left(60^{\circ}\right)$ of the test bundle is the mirror image of its adjacent neighbor sections, and therefore, the calculations can be based on a $60^{\circ}$ section. A symmetrical section is outlined in Figure 34. It was found that, within the axial length of the test section, no appreciable salt returned to the injection channel.

The detailed calculations divided each coolant half channel into 30 subchannels. Fifteen of these subchannels (those near the neutral element) were

*Layout Drawing RN652200001, see Appendix. 


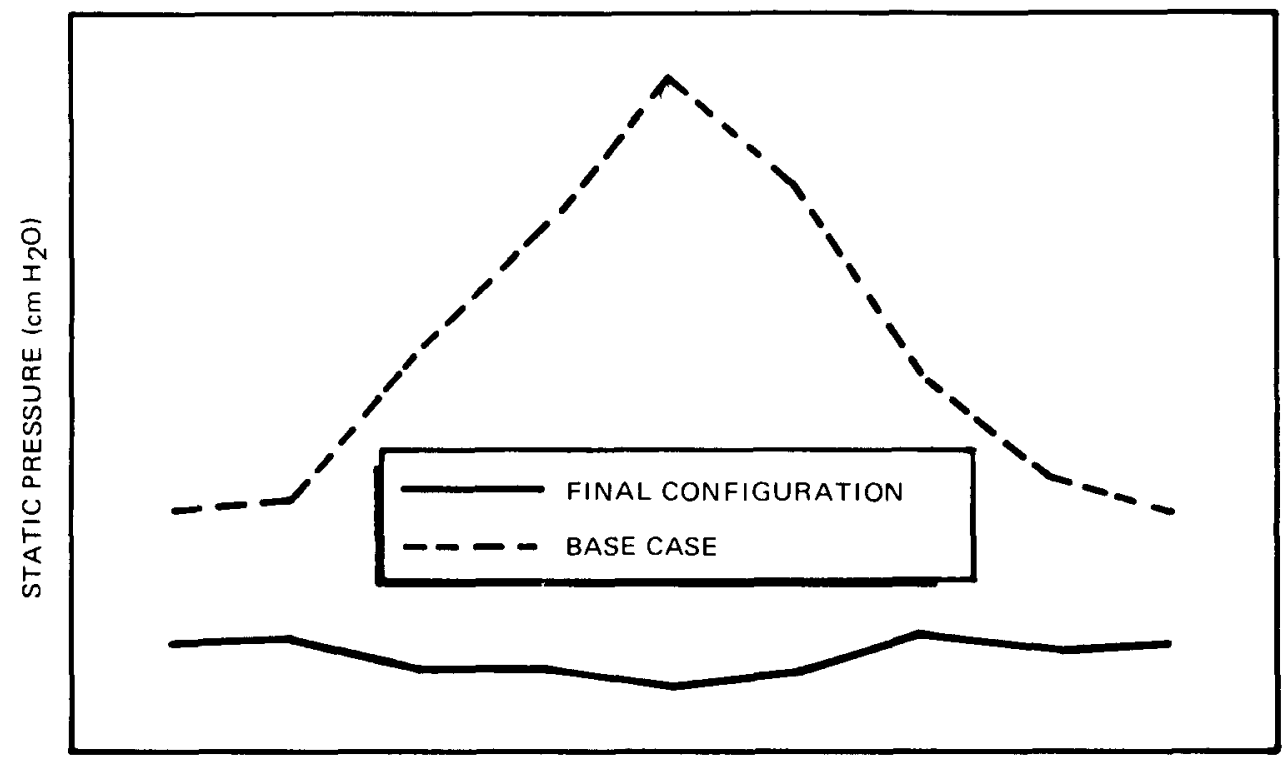

Y AXIS (NORMAL TO INLETS)

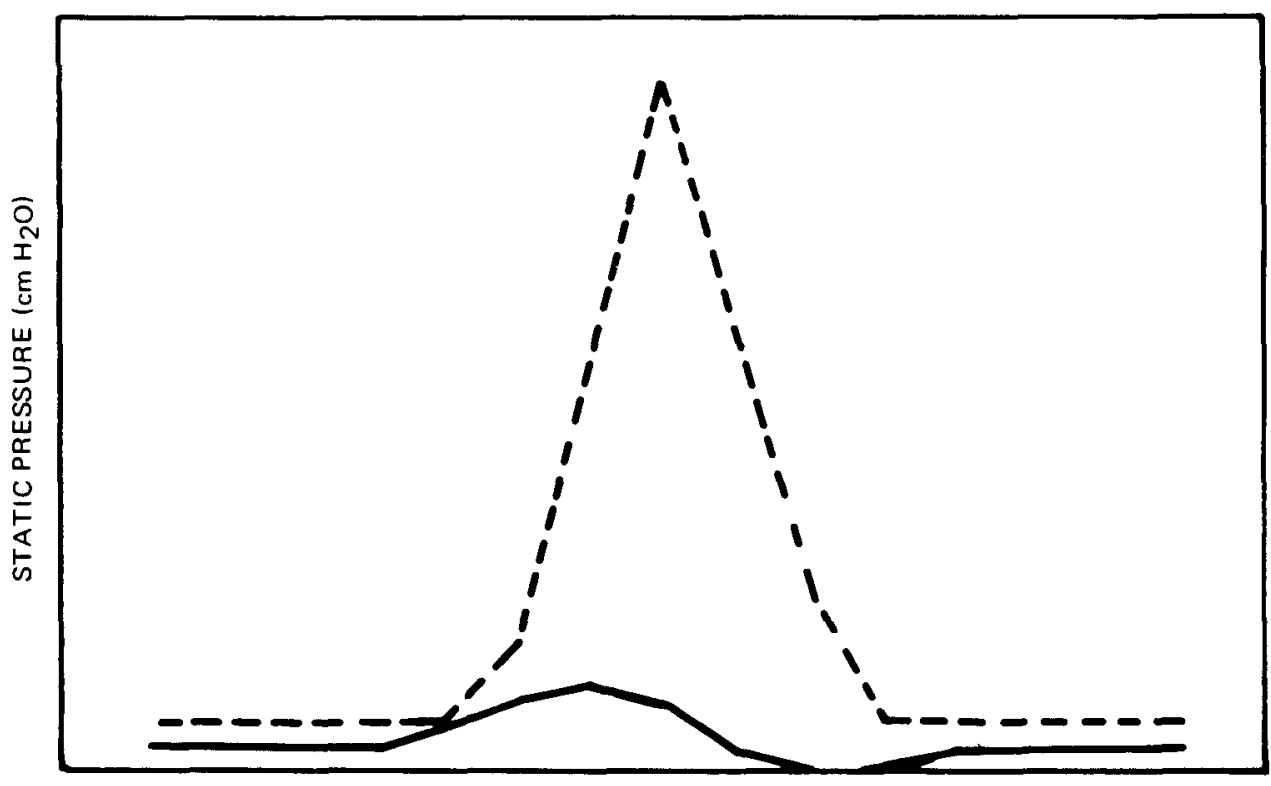

X AXIS (ALONG INLET LINE)

$6531-5468$

Figure 33. Hydraulic Test Grid Pressure Variation, Base Case and Final Configuration 


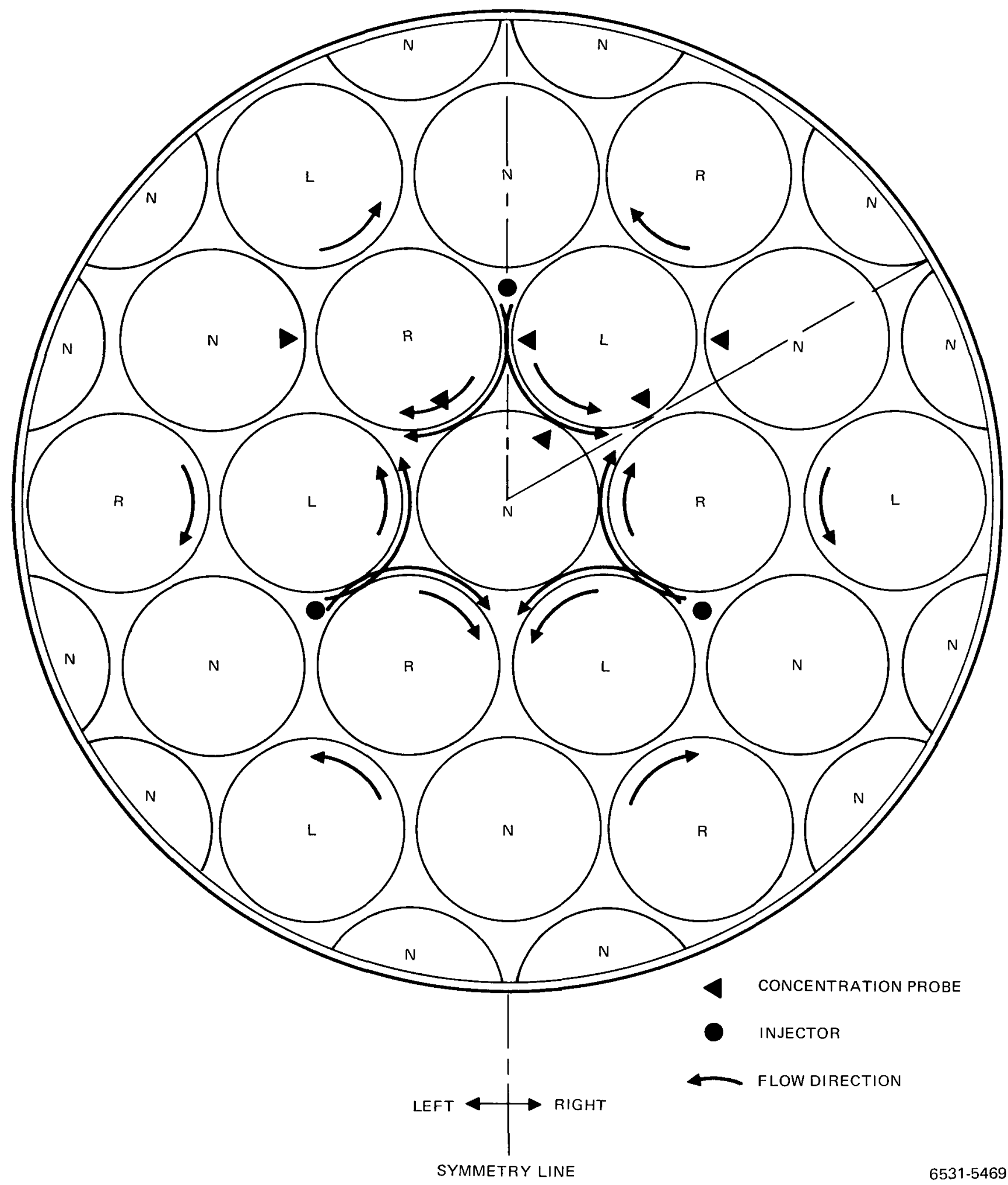

Figure 34. 19-Element Mixing Test Bundle, RLN Fins, Triple Injection

\section{AI-AEC- 13075}


TABLE 10

NOMENCLATURE FOR MIXING EQUATIONS

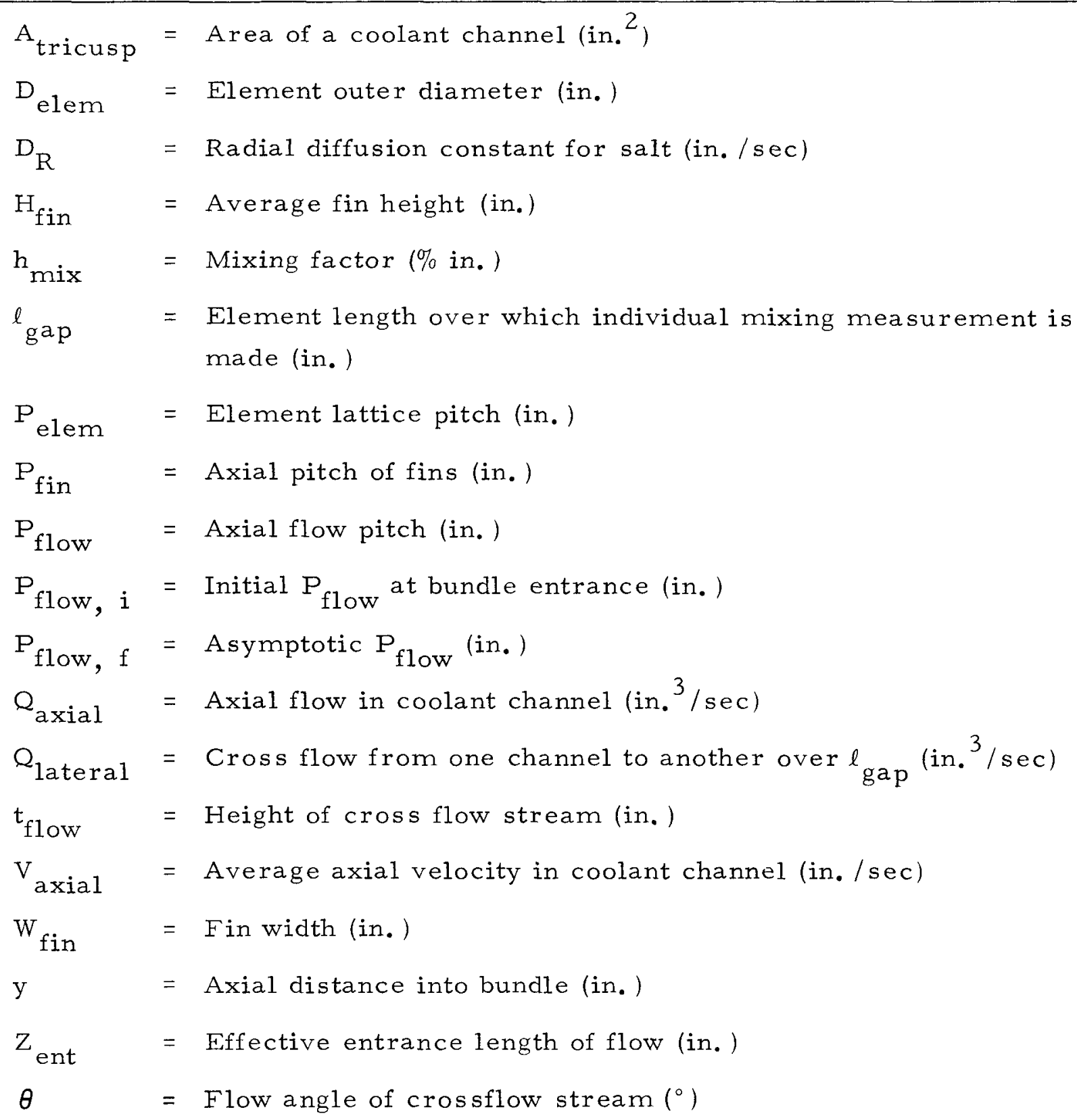


divided into rotational subchannels and diffusional subchannels. The remaining 15 subchannels are rotational only. It was assumed that the salt proceeded from one rotational subchannel to the next by mass convection. Salt movement between rotational and diffusional channels was assumed to occur by diffusion. It was found that correspondence between diffusional subchannels could be as sumed zero.

The mixing factor is usually given in units of $\% /$ in., where the $\%$ is the ratio of lateral (mixing) flow to the axial channel flow and the length is the axial distance up the flow channel. Nomenclature for the mixing factor correlation is given in Table 10 and Figure 35. The lateral flow between two channels is given by the equation:

$$
Q_{\text {lateral }}=2 \times t_{\text {flow }} \times \ell_{\text {gap }} \times V_{\text {axial }} \times \tan \theta
$$

where

$$
\tan \theta=\frac{(1 / 6) \pi \mathrm{P}_{\text {elem }}}{(1 / 6) \mathrm{P}_{\text {flow }}}
$$

The axial flow is

$$
Q_{\text {Axial }}=A_{\text {tricusp }} \times V_{\text {Axial }}
$$

The mixing ratio, $\frac{Q_{\text {Lateral }}}{Q_{\text {Axial }}} / \ell_{\text {gap }}$, then becomes

$$
h_{\text {mix }}=\frac{2 \pi t_{\text {flow }}{ }^{P} \text { elem }}{A_{\text {tricusp }} P_{\text {flow }}} \times 100 \% / \text { in. }
$$

The flow pitch, $\mathrm{P}_{\text {flow }}$, has an initial entrance value and a final asymptotic value, both of which are given in Figure 35. The value of $P_{\text {flow }}$ varies according to the equation:

$$
P_{\text {flow }}=P_{\text {flow, } f}+\left(P_{\text {flow, } i}-P_{\text {flow, } f}\right) e^{-3 y / Z} \text { ent }
$$

where

$$
Z_{\text {ent }}=0.0663 / \mathrm{H}_{\text {fin }}
$$



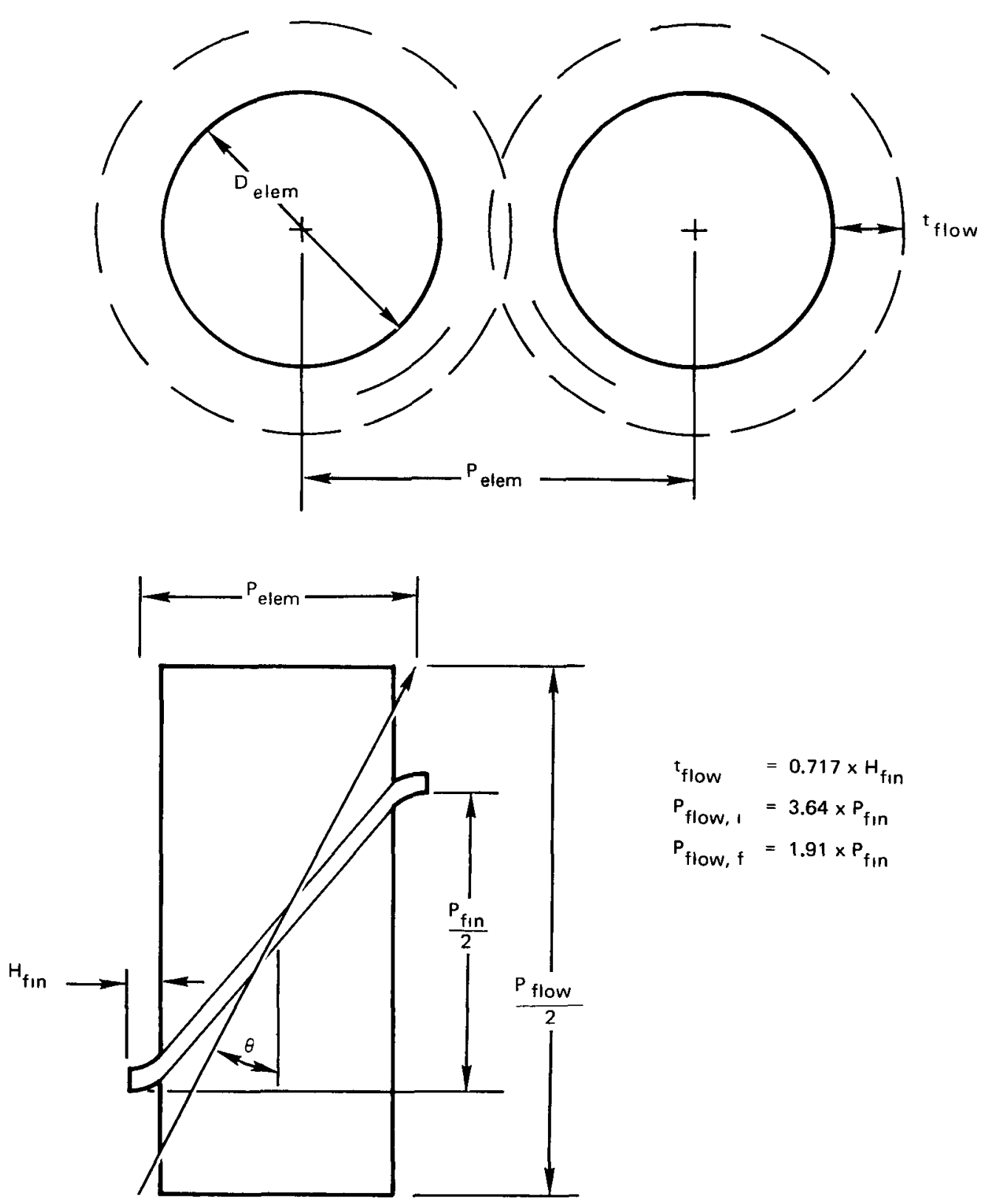

$$
\begin{aligned}
& t_{\text {flow }}=0.717 \times \mathrm{H}_{\text {fin }} \\
& P_{\text {flow, } 1}=3.64 \times P_{\text {fin }} \\
& P_{\text {flow, } f}=1.91 \times P_{\text {fin }}
\end{aligned}
$$

Figure 35. Mixing Equation Nomenclature 
The equation for coolant channel flow area is:

$$
A_{\text {tricusp }}=\frac{\sqrt{3}}{4} P_{\text {elem }}^{2}-\frac{\pi}{8} D_{\text {elem }}^{2}-W_{\text {fin }} H_{\text {fin }}
$$

We combine the above equations to get:

$$
h_{\operatorname{mix}}=\frac{236 P_{\text {elem }} H_{f i n}}{P_{f i n}\left(0.433 P_{e l e m}^{2}-0.393 D_{e l e m}^{2}-W_{f i n} H_{f i n}\right) 1+0.91 e^{\left(-45.2 H_{f i n} y\right)}}
$$

where

$\mathrm{h}_{\operatorname{mix}}$ is in units of $\%$ per unit length.

The above correlation was derived from experimental data for the three geometries listed in Table 11 . The 20-mil-high fins were made from plastic tape, which was attached to the elements. The 15-mil and 30-mil fins were hobbed into the test element metal. The mixing data for each configuration was found to be independent of Reynolds number. A fit of the theoretical calculations to the experimental data for the 30-mil fin case is shown in Figure 36.

The results and correlations from the mixing tests have been incorporated in the design calculations of the reactor hydraulics.

TABLE 11

SPECIFIC TEST GEOMETRY CHARACTERISTICS

\begin{tabular}{l|l|l|l}
\hline \multicolumn{1}{c|}{ Characteristic } & 30-mil Fins & 15 -mil Fins & 20-mil Fins \\
\hline Fin Type & Hobbed & Hobbed & Plastic Tape \\
Number of Fins per Element & Three & Three & Three \\
Element Outer Diameter (in.) & 0.642 & 0.657 & 0.560 \\
Elem-Elem Separation (in.) & 0.670 & 0.670 & 0.584 \\
Actual Fin Height (in.) & 0.0265 & 0.0115 & 0.0180 \\
Fin Width (in.) & 0.070 & 0.070 & 0.050 \\
Axial Fin Pitch (in.) & 5.50 & 5.50 & 4.00 \\
Finned Length (in.) & 16.0 & 16.0 & 16.0 \\
\hline
\end{tabular}

AI- AEC- 13075 


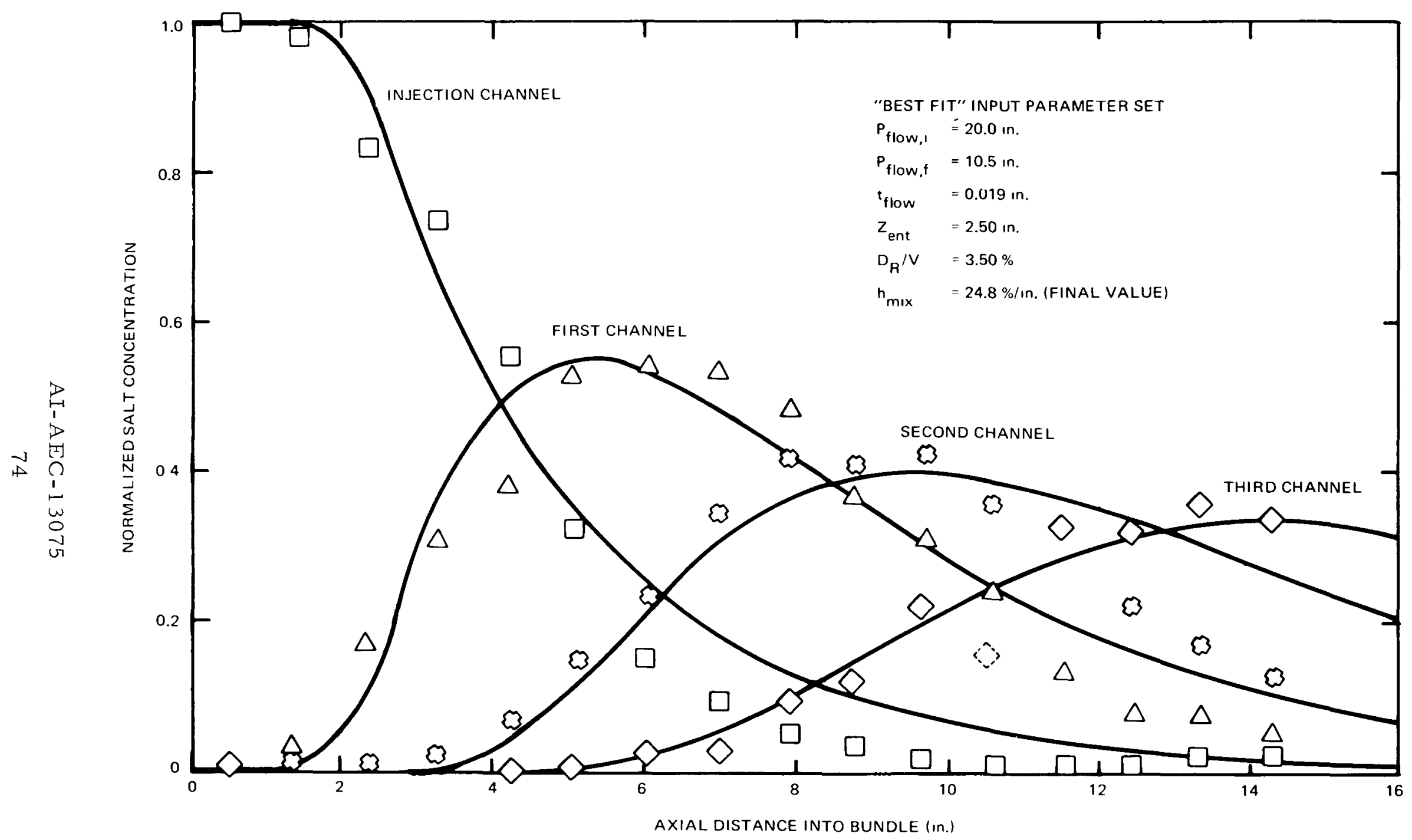

$6531-5471$

Figure 36. Theoretical-Experimental Comparison, 30-mil Fin Data 


\section{Hydraulic Performance}

The reactor coolant flow, supplied by the primary thermoelectric pump, is $17,500 \mathrm{lb} / \mathrm{hr}$ initially and $17,400 \mathrm{lb} / \mathrm{hr}$ after 5 years. The "design to" flow is $17,900 \mathrm{lb} / \mathrm{hr}$, which corresponds to a $100^{\circ} \mathrm{F}$ core $\Delta \mathrm{T}$ at the "design to" reactor power of $110 \mathrm{kw}$.

The 85 element core has 204 coolant channels. At the design flow the average coolant channel velocity is $1.71 \mathrm{ft} / \mathrm{sec}$ and the core bundle pressure drop (plenum to plenum) is 0.19 psi. The fuel element spacing in the core is $0.020 \mathrm{in}$. The finned elements have three fins each, which extend $0.050 \mathrm{in}$. into the coolant channel, but are cut down to $0.010 \mathrm{in}$. between fuel elements. An average fin height of $0.030 \mathrm{in}$. has been used for interchannel mixing calculations. The interchannel mixing factor for a typical coolant channel is $27 \% /$ in.

In addition to the regular coolant channels in the core, there are four types of different sized channels at the core periphery (Figure 37). Each regular (Type 1) coolant channel is bounded by two finned and one neutral fuel element. Each of the three fins on a finned element must be in one of the six channels surrounding that element at any given time, so that a finned element contributes $3 / 6$ or $1 / 2$ fin to each channel. Thus, a Type 1 coolant channel has an average of one fin in it throughout its length. Similarly, Type 2 edge channels (Figure 37) contain an average of one fin. Edge channel Types 3 and 4 average $1 / 2 \mathrm{fin}$. Channel Type 5 is between a neutral element and the core edge. It contains no fins. Hydraulic information for the various channel types is shown in Table 12. The edge channels purposely have less area than a normal channel since the edge channels service only one or two fuel elements instead of three as the inner channels do. Any variation in inlet plenum pressure at the grid plate is small enough in comparison with the fuel bundle pressure drop that it need not be considered.

Core bypass flow around the grid plates has been eliminated by the sealed liner around the internal reflectors. Leakage along a ny gap between the liner and the internal reflectors will be less than $0.5 \%$ of the flow by keeping the gap at 0.010 in. or less. 


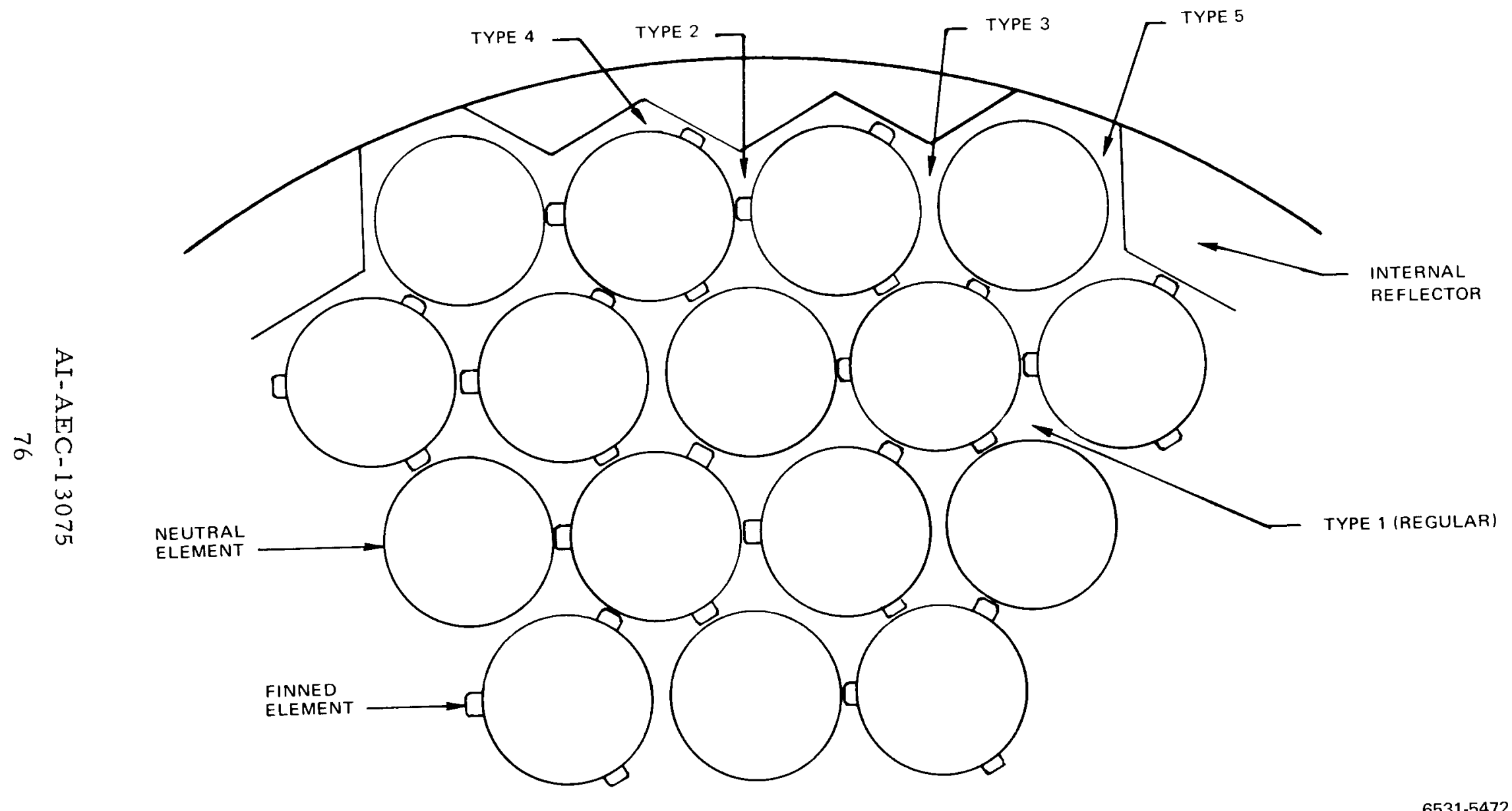

Figure 37. Flow Channels at Edge of Core 
TABLE 12

COOLANT CHANNEL DATA

\begin{tabular}{c|c|c|c|c|c|c}
\hline Channel Type & Number & $\begin{array}{c}\text { Area } \\
(\text { in. 2) }\end{array}$ & $\begin{array}{c}\text { Velocity } \\
(\mathrm{ft} / \mathrm{sec})\end{array}$ & $\mathrm{N}_{\mathrm{Re}}$ & $\begin{array}{c}\text { Fin Area } \\
(\text { in. 2) }\end{array}$ & $\begin{array}{c}\text { Flow } \\
(1 \mathrm{~b} / \mathrm{hr})\end{array}$ \\
\hline \multirow{2}{*}{1} & 138 & 0.0583 & 1.80 & 8300 & 0.0038 & 110.5 \\
2 & 6 & 0.0402 & 1.09 & 3225 & 0.0038 & 44.7 \\
3 & 24 & 0.0375 & 1.29 & 3790 & 0.0019 & 51.6 \\
4 & 12 & 0.0249 & 1.08 & 2995 & 0.0019 & 27.9 \\
5 & 24 & 0.0179 & 1.62 & 3580 & 0.0000 & 32.5 \\
Average & 204 total & 0.0486 & 1.71 & 6940 & 0.0030 & 87.6 \\
\hline
\end{tabular}

* Channel cross sectional area before subtracting the fin area.

\section{CORE THERMAL PERFORMANCE}

The core power requirements vary over the lifetime of the reactor because of the degradation of the thermoelectric components of the total system. In order to provide margins for uncertainties, the reactor is designed to operate at a level somewhat more severe than system requirements. The "design to" conditions are applied with the BOL (beginning-of-life) configuration when the fuel-cladding gas gap is largest, and thus, the thermal gradients are somewhat higher than the EOL (end-of-life) configuration. Because the exact manufactured configuration of each individual element is not known, other than that its dimensions are within a specified tolerance range, nominal operational conditions must be calculated for an "ideal" average element. The "ideal" is primarily the assumption that the element is perfectly straight and that the fuel segments are all centered in the cladding. The calculational methods used are described in Reference 2. Table 13 shows nominal operating conditions for "design to," BOL, and EOL conditions.

Hot channel factors have been calculated to take into account the expected range of uncertainties involved in the calculation of reactor power and temperatures. The uncertainties are divided into tolerance effects, property effects, and power flow effects. The parameter values assumed are the maximum 
NOMINAL OPERATING CONDITIONS

\begin{tabular}{l|l|l|l}
\hline \multicolumn{1}{c|}{ Parameter } & Design* & BOL & EOL \\
\hline Thermal Power (kwt) & 110 & 95 & 101 \\
Coolant Outlet Temperature $\left({ }^{\circ} \mathrm{F}\right)$ & 1200 & 1148 & 1200 \\
Coolant Temperature Rise $\left({ }^{\circ} \mathrm{F}\right)$ & 100 & 88 & 95 \\
Peak Fuel Centerline Temperature $\left(^{\circ} \mathrm{F}\right)$ & 1310 & 1247 & 1286 \\
Peak Fuel Average Temperature $\left(^{\circ} \mathrm{F}\right)$ & 1292 & 1232 & 1270 \\
Maximum Cross Element $\Delta \mathrm{T}\left({ }^{\circ} \mathrm{F}\right)$ & 21.4 & 18.8 & 17.2 \\
Core Flow Rate (lb/hr) & 17,900 & 17,500 & 17,400 \\
Average Channel Velocity (fps) & 1.71 & 1.67 & 1.66 \\
Average Reynolds Number & 6940 & 6760 & 6740 \\
Minimum Reynolds Number & 2990 & 2910 & 2900 \\
Core Pressure Drop (psi) & 0.19 & 0.18 & 0.18 \\
\hline
\end{tabular}

*BOL Power Distribution

expected variations, or tolerances, and are thus considered $3 \sigma$ limit values. The uncertainty factors are listed in Tables 14, 15, and 16 for "design to," BOL, and EOL conditions.

The tolerance effects have to do with the allowable range of parameters during the manufacture of the fuel element. The property effects are concerned with uncertainties in the material properties. The power and flow effects are concerned with the uncertainty in calculated powe $r$ profile and with the posible variations in flow and heat flux distributions from fuel element clustering and fuel slug asymmetry in the cladding tube.

For the design conditions, Table 14, the coolant outlet temperature uncertainty is $18.5^{\circ} \mathrm{F}$ and the maximum fuel temperature uncertainty is $20.8^{\circ} \mathrm{F}$. The maximum fuel temperature, after adding the $20.8^{\circ} \mathrm{F}$ uncertainty and a $5^{\circ} \mathrm{F}$ allowance for control band, is $1318^{\circ} \mathrm{F}$. 
TABLE 14

HOT CHANNEL FACTORS, CENTER ELEMENT, DESIGN CONDITIONS

\begin{tabular}{|c|c|c|c|}
\hline & Uncertainty & $\begin{array}{c}\Delta \mathrm{T}_{\text {coolant }} \\
\left({ }^{\circ} \mathrm{F}\right)\end{array}$ & $\begin{array}{c}\Delta \mathrm{T}_{\text {fuel }} \\
\left({ }^{\circ} \mathrm{F}\right)\end{array}$ \\
\hline $\begin{array}{l}\text { Tolerance Effects } \\
\text { Gas gap thickness (in.) } \\
\text { Hydrogen barrier thickness (in.) } \\
\text { Cladding thickness (in.) } \\
\text { Fuel uranium content (\%) } \\
\text { Fuel hydrogen content (atoms/cc) } \\
\text { Property Effects (\%) } \\
\text { NaK film heat transfer } \\
\text { Fuel thermal conductivity } \\
\text { Gas gap conductivity } \\
\text { Gas gap accommodation } \\
\text { Power and Flow Effects } \\
\text { Channel flow distribution ( } \%) \\
\text { Element/element power distribution }(\%) \\
\text { Fuel slug asymmetry } \\
\text { Thermocouple error } \\
\text { Statistical Sum }\end{array}$ & $\begin{array}{l} \pm 0.001 \\
\pm 0.0005 \\
\pm 0.0015 \\
\pm 0.3 \\
\pm 0.15 \times 10^{22} \\
\pm 30 \\
\pm 12 \\
\pm 14 \\
\pm 30 \\
\pm 6.4 \\
\pm 5 \\
\text { variable } \\
1 / 2 \% \text { per thermocouple } \\
(4 \text { are averaged) }\end{array}$ & $\begin{array}{r} \pm 8.9 \\
\pm 7.0 \\
\pm 14.0 \\
\pm 3.0 \\
\pm 18.5 \\
\text { Nominal } \\
1229 \\
1292\end{array}$ & $\begin{array}{l} \pm 9.9 \\
\pm 1.0 \\
\pm 0.2 \\
\pm 3.8 \\
\pm 2.8 \\
\\
\pm 2.9 \\
\pm 1.9 \\
\pm 8.8 \\
\pm 1.5 \\
\\
\pm 6.5 \\
\pm 9.7 \\
+6.0 \\
-24.0 \\
\pm 3.0 \\
+20.8 \\
-31.2 \\
\text { Hot Channel } \\
\\
1247.5 \\
1312.8 \\
1253.5 \\
1317.8\end{array}$ \\
\hline
\end{tabular}


TABLE 15

HOT CHANNEL FACTORS, CENTER ELEMENT, BOL

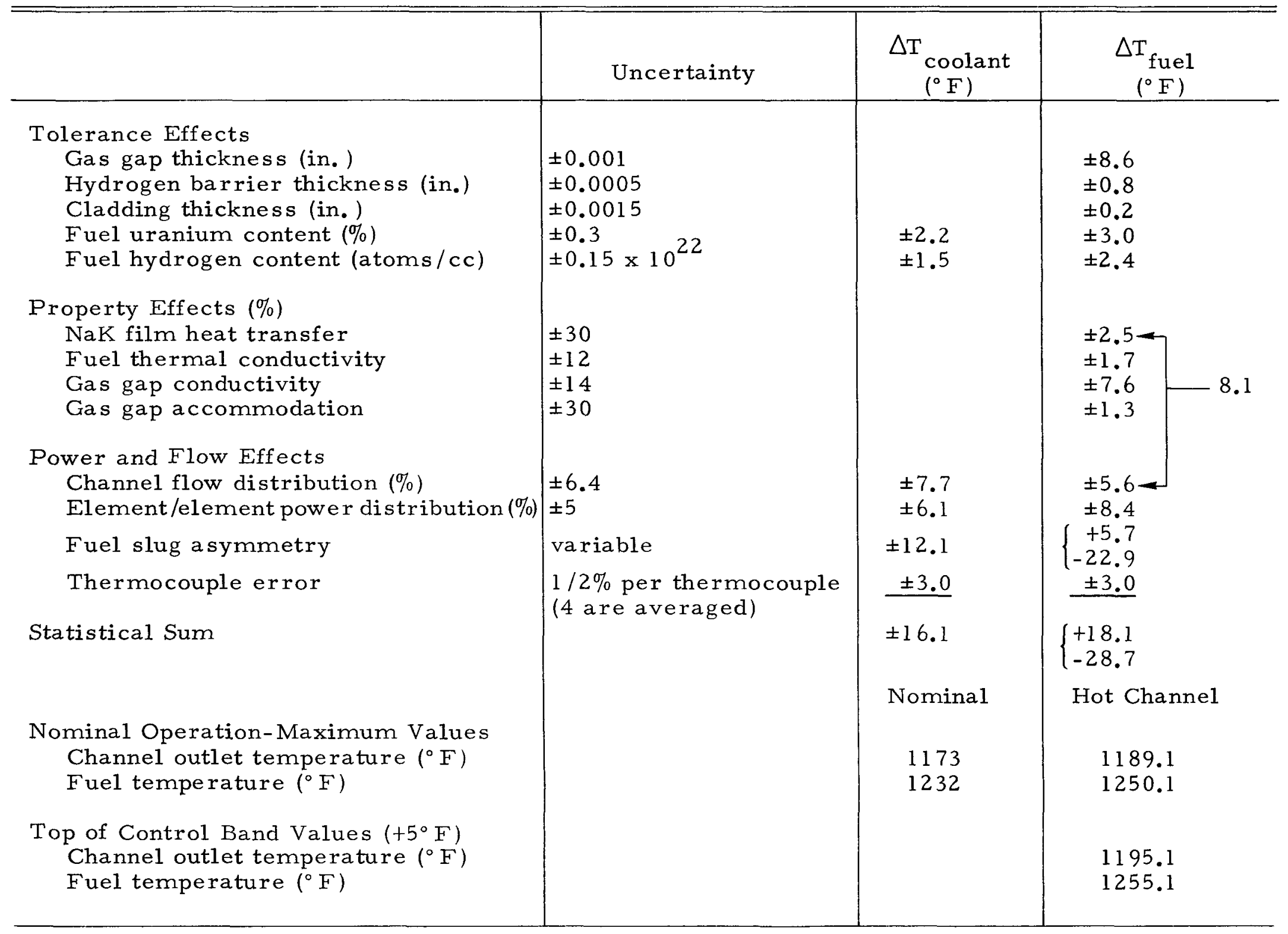


TABLE 16

HOT CHANNEL FACTORS, CENTER ELEMENT, EOL

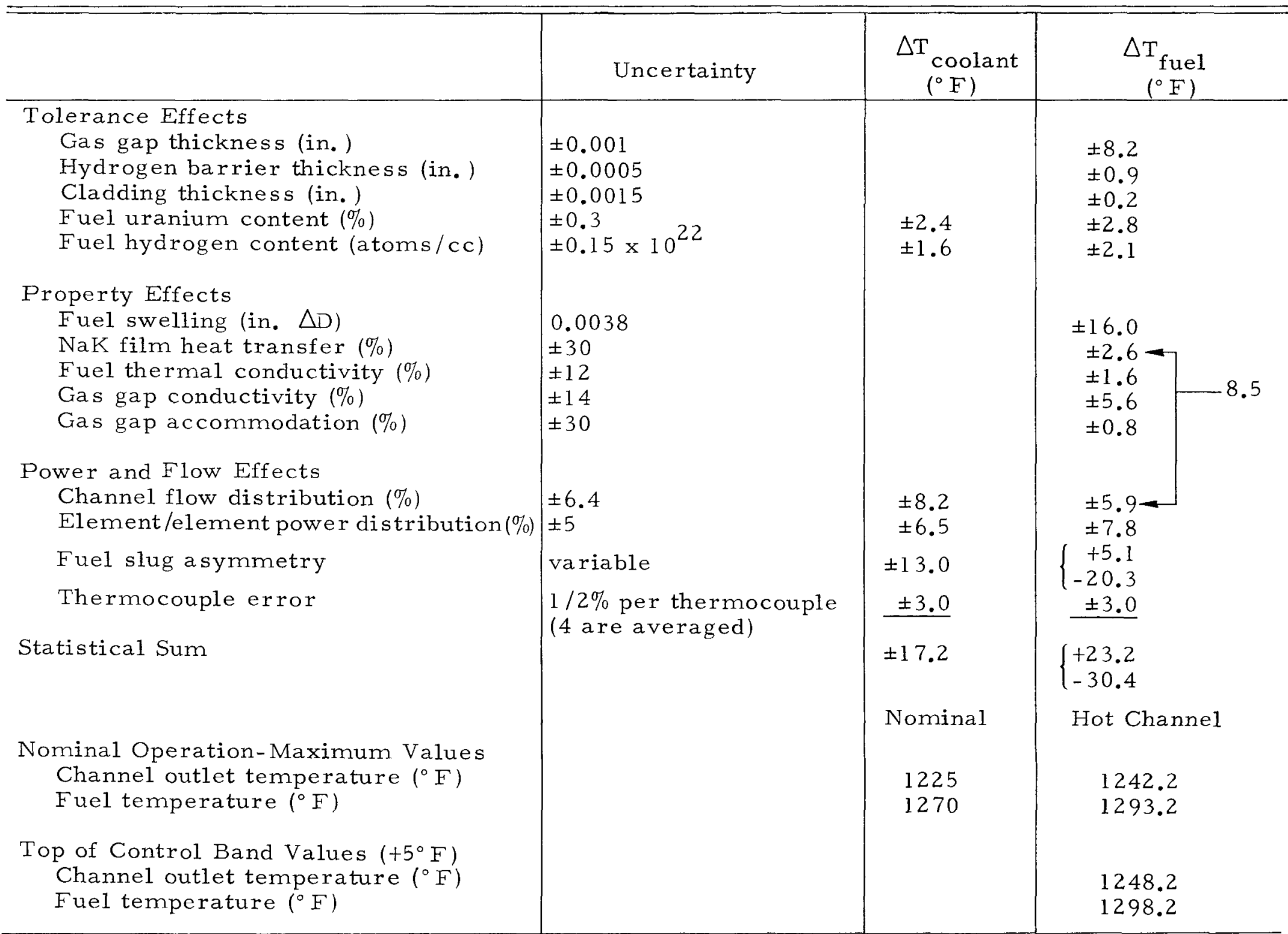



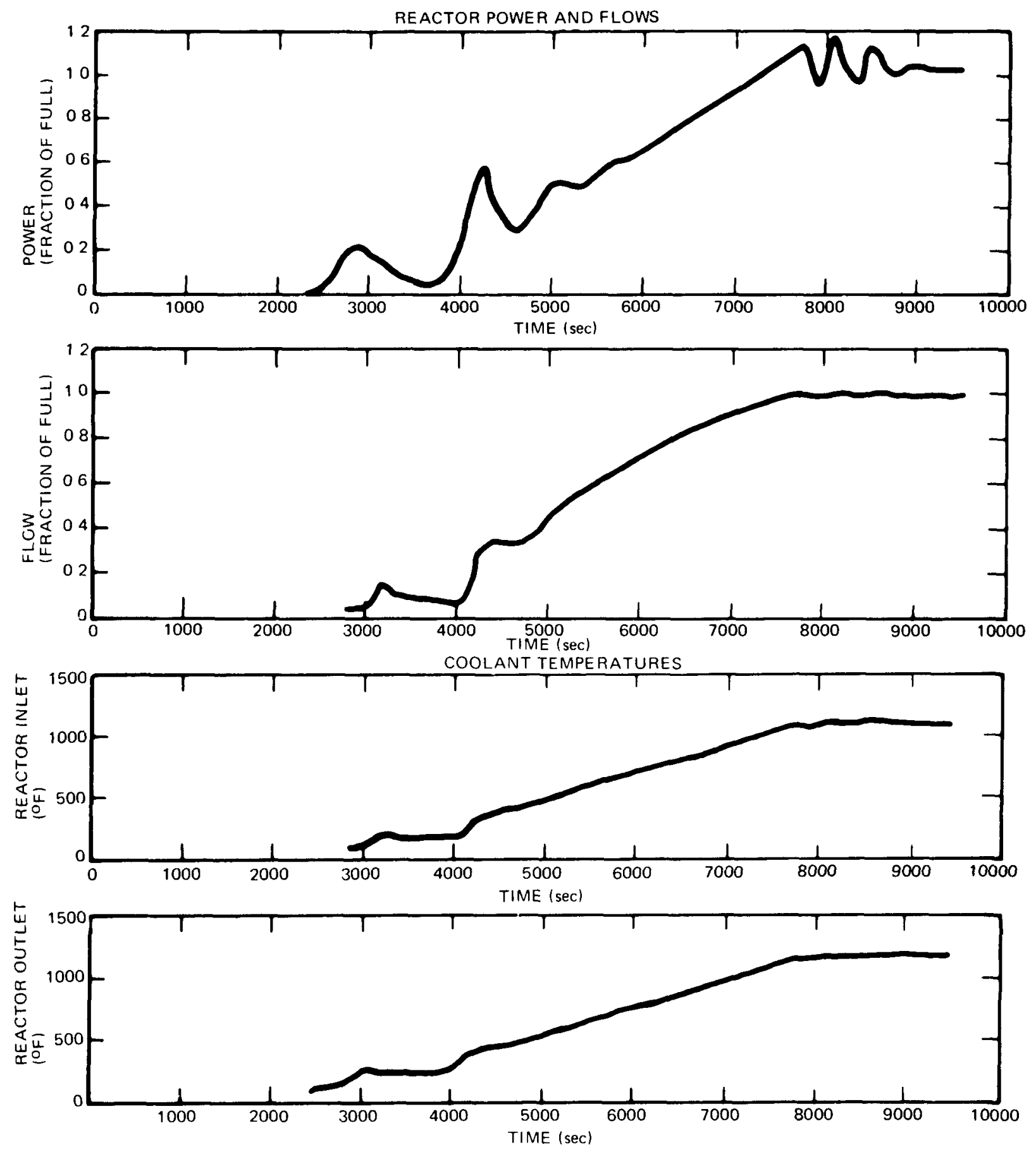

653151200

Figure 38. Reference Startup Transient

AI-AEC- 13075 


\section{THERMAL TRANSIENT BEHAVIOR}

\section{Reactor Startup}

The reference reactor startup transient is shown in Figure 38. The reactor first comes to sensible heat with the coolant flow still at 5\%. As the reactor power comes up the reactor $\Delta T$ increases, but the startup is specified such that the maximum core $\Delta \mathrm{T}$ does not exceed $150^{\circ} \mathrm{F}$. The most severe temperature transients and core $\Delta \mathrm{T}^{\prime} \mathrm{s}$ occur during the first two power peaks at $2800 \mathrm{sec}$ and at $4200 \mathrm{sec}$. During the first power rise the reactor core $\Delta \mathrm{T}$ reaches a peak of $148^{\circ} \mathrm{F}$ with the flow at $10 \%$ of full flow and the inlet temperature at $120^{\circ} \mathrm{F}$. During the second rise, the core $\triangle \mathrm{T}$ reaches $149^{\circ} \mathrm{F}$ with the flow at $25 \%$ and the inlet temperature at $240^{\circ} \mathrm{F}$. The peak coolant temperature rise rate occurs during the second power hump. The outlet temperature peak rate is $0.9^{\circ} \mathrm{F} / \mathrm{sec}$ and the inlet temperature peak rate is $1.5^{\circ} \mathrm{F} / \mathrm{sec}$.

\section{Internal Reflectors}

The thermal gradients imposed on the thicker of the two internal reflector pieces by the startup transient were determined. The results of an early startup study were used and the transient is more severe than for the reference startup. Thus we expect the results to be conservative. The reflector piece was studied for a vacuum in the annulus between the $\mathrm{BeO}$ and the cladding, and for 3 psi of helium in the annulus. The internal reflector piece will initially be evacuated, but helium will eventually build up from irradiation of the beryllium atoms.

The maximum $\Delta \mathrm{T}$ across the cladding during the transient was $52^{\circ} \mathrm{F}$ for the helium-filled case, and $69^{\circ} \mathrm{F}$ for the vacuum case.

\section{Reactor Inlet Nozzle}

The response of the reactor inlet nozzle to various inlet temperature transients during reactor startup and for some accident conditions were reviewed. The highest rate found was $2.0^{\circ} \mathrm{F} / \mathrm{sec}$, but only for a short time. A $1.3^{\circ} \mathrm{F} / \mathrm{sec}$ rate average for $4 \mathrm{~min}$ was found to be more realistic. Calculations were performed for both $-1.3^{\circ} \mathrm{F} / \mathrm{sec}$ and $-2.0^{\circ} \mathrm{F} / \mathrm{sec}$ ramp rates. As a limiting case, a collapse of the design $\Delta \mathrm{T}, 100^{\circ} \mathrm{F}$, was applied at the inlet as a $100^{\circ} \mathrm{F}$ step in $\mathrm{NaK}$ coolant temperature. For the most realistic transient, $-1.3^{\circ} \mathrm{F} / \mathrm{sec}$, the maximum temperature difference in the nozzle was $30^{\circ} \mathrm{F}$. For the $-2.0^{\circ} \mathrm{F} / \mathrm{sec}$ transient, the $\Delta \mathrm{T}$ was $45^{\circ} \mathrm{F}$. 


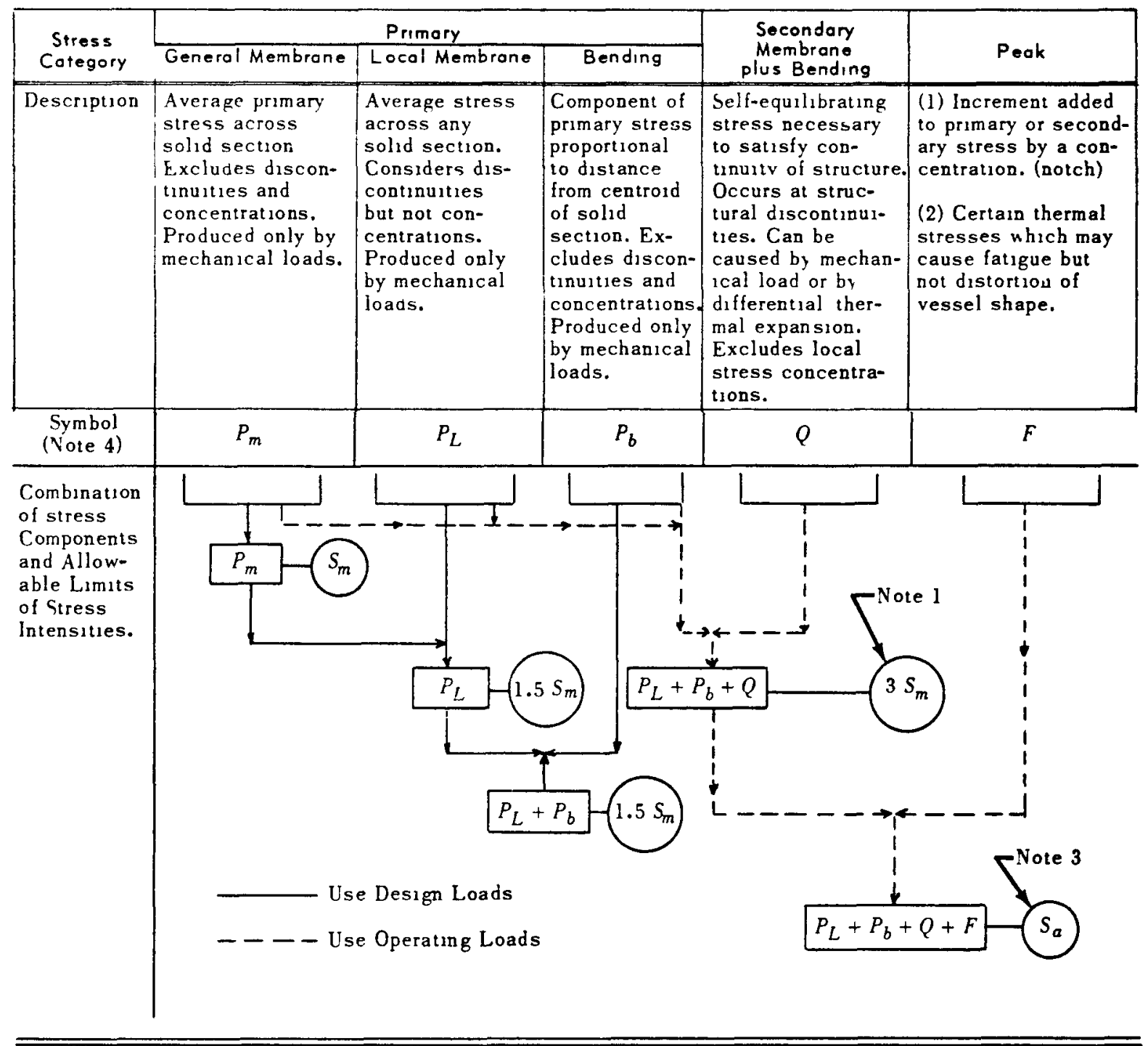

NOTE 1 - This limitation applies to the range of stress intensity. When the secondary stress is due to a temperature excursion at the point at which the stresses are beang analyzed, the value of $S_{m}$ shall be taken as the average of the $S_{m}$ values for the highest and the lowest temperature of the metal during the transient When part or all of the secondarv stress is due to mechanical load, the value of $S_{m}$ shall be taken as the $S_{m}$ value for the highest temperature of the metal during the transient.

NOTE 2 - The stresses in Category $Q$ are those parts of the total stress which are produced by thernal gradients, structural discontinuties, etc., and do not anclude primarv stresses which may also exist at the same point.

NOTE $3-S_{a}$ is obtained from the fatigue curves, The allowabie stress intensity for the full range of fluctuation is $2 S_{a}$

NOTE 4 - The symbols ${ }_{m}, P_{L}, P_{b}, Q$, and $F$ do not represent single quantitues, but rather sets of six quantitıes representing the $s i x$ stress components $\sigma_{l}, \sigma_{l}, \sigma_{r}, \tau_{l l}, \tau_{l r}$, and $\tau_{r l}$.

Figure 39. Stress Categories and Limits of Stress Intensity, $\mathrm{T}<800^{\circ} \mathrm{F}$

$$
\mathrm{AI}-\mathrm{AEC}-13075
$$




\section{STRUCTURAL DESIGN}

\section{A. REACTOR VESSEL STRUCTURAL DESIGN STATUS}

Preliminary analyses were performed to scope the structural aspects of the reactor vessel assembly. The basic structural requirements of the vessel include support of the core within the vessel, coolant pressure containment, support of the reflector-control assemblies externally, and support of the entire reactor assembly through its attachment to the neutron shield. Other structural considerations involve stresses induced in vessel components by temperature gradients that occur during reactor startup and shutdown, external piping reactions, etc.

\section{Design Criteria}

The design basis structural criteria were formulated using the requirements of Section III of the ASME Boiler and Pressure Vessel Code (for Class 2 nuclear components) as guidelines. The ASME BPVC was not intended for application to space power systems, and it was considered unrealistic to adopt the Code structural requirements in total. The nature of the operating conditions to which each type of system is subjected differ sufficiently to warrant modification to the design basis. In particular, the 5-kwe Reactor Thermoelectric System is not subjected to the many cycles of severe thermal transients which are so critical in the design of high temperature stationary nuclear systems. Further, Code requirements do not consider the penalties associated with weight in a space system. The requirements for Section III, Class 2, nuclear components were, therefore, adopted with modifications based on consideration of specific requirements.

The criteria are presented on Figure 39 for temperatures below $800^{\circ} \mathrm{F}$ and on Figure 40 for temperatures of $800^{\circ} \mathrm{F}$ and above. The criteria are based on the use of elastic structural analysis methods, but do not preclude rigorous inelastic analysis of individual component areas as required to satisfy good engineering practice and/or specific functional limits. The values of $\mathrm{S}_{\mathrm{m}}$ and $\mathrm{S}_{\mathrm{a}}$ applicable to Figure 39 are those listed in Section III of the ASME BPVC, and the values of $S_{0}, S_{m t}$, and $S_{a}$ applicable to Figure 40 are those presented in Cod $\epsilon$ Case 1331-6 of Section III of the Code. 


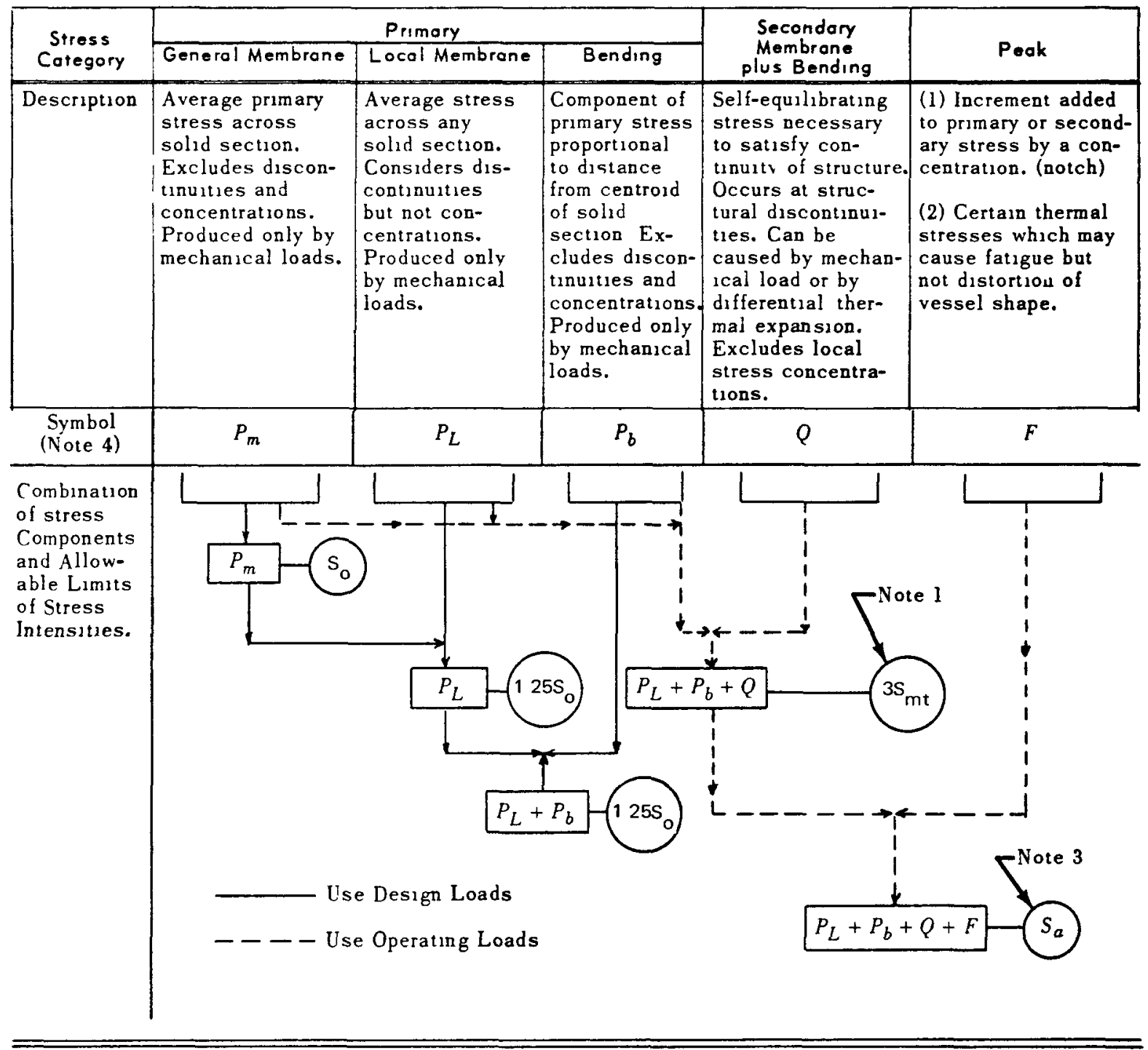

NOTE 1 - This limitation applies to the range of stress intensitv When the secondarv stress is due to a temperature excursion at the point at which the stresses are being analyzed, the value of $S_{m}$ shall be taken as the average of the $S_{m}$ values for the haghest and the lowest temperature of the metal during the transient Then part or all of the secondarv stress is due to mechanical load, the value of $S_{m}$ shall be taken as the $S_{m}$ value for the highest temperature of the metal during the transient

NOTE 2 - The stresses in Category $Q$ are those parts of the total stress which are produced by thermal gradients, structural discontinuitiea, ftc, and do not unclide primary stresses which may also exist at the same point.

NOTE $3-S_{a}$ is obtaned from the fatigue curves, fluctuation is $2 S_{a}$

NOTE 4 - The symbols $P_{m} P_{L} P_{o} Q$ and $F$ do not represent single quantities, but rather sets of six quantities representing the six stress components $\sigma_{t} C_{l} \sigma_{r} T_{t l}{ }^{\tau_{l}} l_{r}$, and $\tau_{r t}$.

Figure 40. Stress Categories and Limits of Stress Intensity, $\mathrm{T}>800^{\circ} \mathrm{F}$ 
Table 17 presents the reactor vessel structural design data applicable to defining the stress intensities and applying the design criteria.

TABLE 17

REACTOR VESSEL STRUCTURAL DESIGN DATA

\begin{tabular}{|c|c|}
\hline Reactor Weight (lb) & 497 \\
\hline Core & \\
\hline Vessel & \\
\hline Piping & \\
\hline Reflector & \\
\hline $\begin{array}{l}\text { Launch Loads, Equivalent Static } \\
(\mathrm{g})\end{array}$ & \\
\hline Limit Axial & 11 \\
\hline Limit Lateral & 8 \\
\hline Ultimate Axial & 16.5 \\
\hline Ultimate Lateral & 12 \\
\hline Coolant Pressure (psi) & 32 \\
\hline Design Temperature $\left({ }^{\circ} \mathrm{F}\right)$ & 1250 \\
\hline Design Lifetime $(\mathrm{hr})$ & 50,000 \\
\hline Material & Type 316 stainless steel \\
\hline Startup Cycles & 50 \\
\hline NaK 78 Coolant Flow (lb/hr) & 16,800 \\
\hline $\begin{array}{l}\text { Inlet Temperature, (BOL/EOL) } \\
\quad\left({ }^{\circ} \mathrm{F}\right)\end{array}$ & $1057 / 1110$ \\
\hline Radiation (nvt) & $\begin{array}{l}1.7 \times 10^{20}(\mathrm{E}>1 \mathrm{Mev}) \\
4.0 \times 10^{20}(\mathrm{E}>0.1 \mathrm{Mev}) \\
\text { (Maximum in vessel shell) }\end{array}$ \\
\hline
\end{tabular}

\section{Analyses Performed}

The structural analyses performed during the conceptual design were those required to define critical dimensions, such as where component-to-component interfaces were involved, and to verify the basic feasibility of the concept. In areas where adjustments in details of configuration and dimension could be made later without causing major changes in the design, the structural analyses were scheduled for subsequent phases of the design effort. 


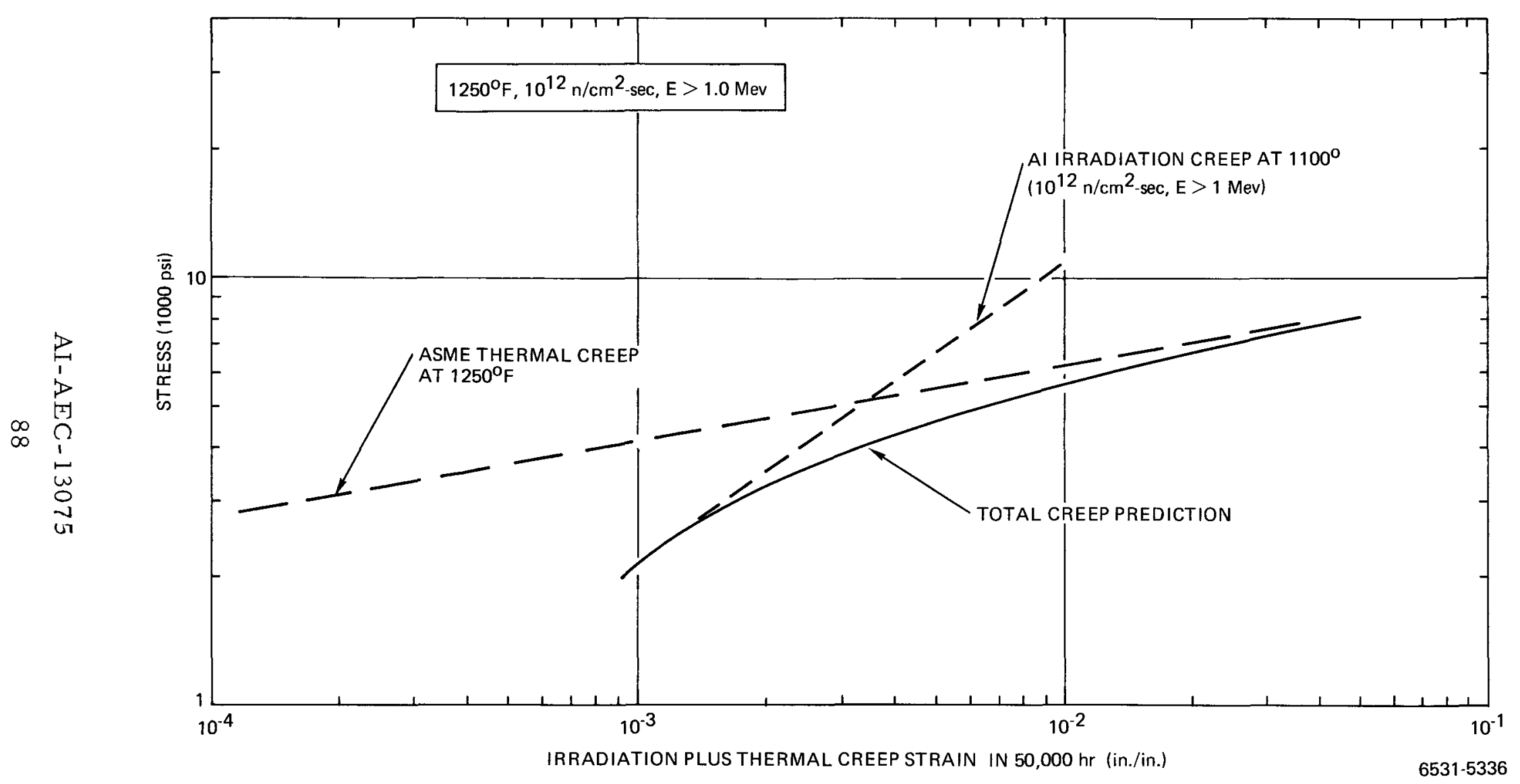

Figure 4l. Upper Limit Creep Prediction 
a. Vessel Shell Thickness

The inside diameter of the vessel was defined by the coredesign and internal clearance requirements. The thickness, and thereby the outside diameter, had to be established so that the design of the reflector assembly, which surrounds the vessel, could proceed on a firm basis.

The controlling criteria for the reactor vessel shell thickness are the $32-p s i$ internal pressure at a temperature of $1250^{\circ} \mathrm{F}$ for 50,000 hours. The ASME code allowable membrane stress $\left(\mathrm{S}_{\mathrm{mt}}\right)$ for these design conditions is $4900 \mathrm{psi}$ and thereby a minimum shell thickness of 0.035 in. would normally be specified.

The ASME code does not limit creep strain as such but does specify that the designer verify that creep distortions do not destroy functional aspects of the components and modify the design if necessary. The vessel shell is surrounded by the reflector control assembly with the initial clearance set at 0.060 in. If the radial deformation of the vessel was to equal the clearance, reflector ejection for end-of-life shutdown of a flight system or backup scram of the ground test system would be impaired. A large margin of safety against reflector contact is, therefore, necessary.

The ASME creep data do not include the effect of radiation on creep. Although the code requires that radiation effects be considered, it does not provide any design criteria or guidelines, leaving it to the designer to determine the required allowances.

In $\mathrm{AI}$ work related to fast breeder reactor core design, irradiation creep prediction equations have been developed. These indicate that for the 5 -kwe reactor conditions, the upper limit estimate of total creep be taken as the sum of ASME thermal creep data at $1250^{\circ} \mathrm{F}$ plus a radiation creep prediction using the $\mathrm{AI}$ equation at $1100^{\circ} \mathrm{F}$.

Based on the above, the creep prediction curves of Figure 41 were developed. Figure 41 includes three curves of creep strain in 50,000 hours (in. /in.) vs stress for (1) thermal creep at $1250^{\circ} \mathrm{F}$ based on data for Type 316 stainless steel from the ASME Code for Nuclear Vessels (Code Case 1331-6), (2) radiation induced creep based on the AI prediction equation applied at $1100^{\circ} \mathrm{F}$ at the dose rate of $10^{12} \mathrm{n} / \mathrm{cm}^{2}-\mathrm{sec}(\mathrm{E}>1 \mathrm{Mev})$, and (3) a total creep prediction which is the sum of thermal plus radiation creep.

AI- AEC- 13075 


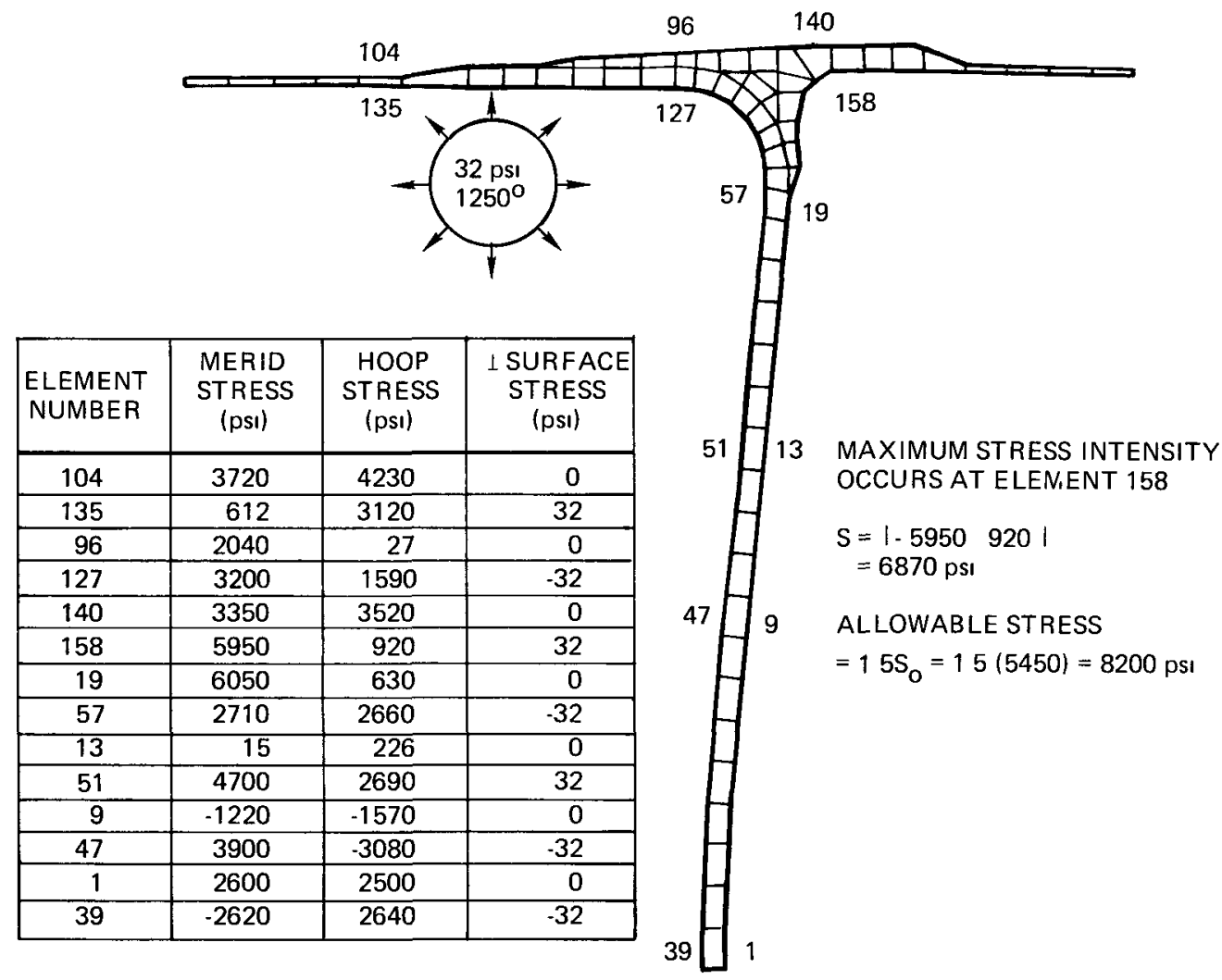

6531-5337

Figure 42. Outlet Plenum Head Finite Element Analysis 
From Figure 41, a limit of 3700 psi was selected for the primary general membrane stress in the vessel shell. The upper limit creep prediction (thermal plus radiation) is $0.0027 \mathrm{in.} / \mathrm{in}$. in 50,000 hours giving a radial displacement for the 5.25-in. vessel radius of $0.0142 \mathrm{in.}$ The elastic displacement is about 0.001 giving a total end of life displacement of $0.015 \mathrm{in.}$

\section{b. Vessel Heads}

The vessel plenum heads are spherically dished, both having a dish radius of $18 \mathrm{in.}$ The inlet head is dished outward and has a knuckle radius of $1.00 \mathrm{in.}$ The outlet head is dished inward and has a knuckle radius of $0.50 \mathrm{in}$.

The outlet head is completely axisymmetric and therefore amenable to analysis by a straightforward computerized finite element technique. The maximum calculated stress intensity is 6900 psi vs a design allowable of 8200 psi at $1250^{\circ} \mathrm{F}$. Figure 42 shows the network used for the analysis and includes a tabulation of the principle stresses at selected locations.

The inlet head is not axisymmetric due to the two projections which extend outward to cover the projections from the vessel where the inlet pipes connect (see Figure 1 and 10). An initial scoping analysis was performed, in which the head was assumed to be axisymmetric, and then a detailed analysis of the nonsymmetric areas of the head was performed.

The analysis of the nonsymmetric areas of the head, using the most advanced finite element techniques available, determined that the thickness in these areas should be increased to a minimum of $0.193 \mathrm{in.}$, and that the other areas of the head are acceptable with a 0.125 in. thickness.

\section{c. Reactor Support Skirt}

The reactor is supported through a cylindrical skirt, approximat ely 3 in. long, which is brazed to the outlet end plenum of the vessel and has the other end flanged for a bolting attachment of the reactor to the top of the neutron shield. Cut-outs are required at two places in the skirt for the control segment drive motors.

A plain cylinder analysis indicates that a skirt thickness of $0.040 \mathrm{in.}$ is required to accommodate the loading imposed by the axial and transverse accelerations of the reactor mass. The limiting condition is based on material

\section{AI- AEC - 13075}


stress allowable rather than the elastic stability limit of the cylinder, not considering the cut-out edges. Local reinforcement is required at the edges of the cut-outs.

The neutron shield has a very large heat capacity, approximately 100,000 Btu for a $500^{\circ} \mathrm{F}$ temperature change. In the startup sequence, the reactor outlet rises from approximately 100 to $1140^{\circ} \mathrm{F}$ (BOL) over a period of about 2 hours. Even with this relatively slow reactor startup, the heat capacity of the shield is so large that when the reactor has reached its operating temperature, the shield temperature will have changed very little. The result is a large temperature gradient across the reactor support skirt, approximately $1000^{\circ} \mathrm{F}$ when the reactor first reaches power, which decreases slowly as the shield temperature rises. When the shield temperatures reach equilibrium, many hours after startup, the top of the shield where the reactor support skirt is attached will be in the range of 800 to $900^{\circ} \mathrm{F}$, giving a temperature gradient of 300 to $400^{\circ} \mathrm{F}$ across the support skirt during operation.

The current design criteria require a capability of 50 startup-shutdown cycles. For a plain cylinder with fixed ends, having a linear axial temperature gradient, the maximum strain, $E_{m}$, is equal to $1.41 \frac{\alpha \Delta T}{L} \sqrt{R t}$.

With the $0.40 \mathrm{in}$. thickness the design fatigue limit, based on Section III of the ASME Code (Figure 11 of Code Case 1331-5) is 100 cycles of application of the $1000^{\circ} \mathrm{F}$ temperature gradient to the cylinder. If tolerances allow the thickness to increase to $0.050 \mathrm{in.}$, the design limit is reduced to 75 cycles.

Because the $50 \%$ margin on cycles was considered low, due to questions about the adequacy of the 50-cycle requirement, design modifications that would increase the cyclic capability of the support cylinder were studied. This included axial profiling of the thickness of the cylinder. A number of profiles were analyzed to find one which would locally decrease the temperature gradient at the vessel end of the cylinder. A beam-ended cylinder connection was used at the vessel end, thereby removing the circumferential restraint and reducing the stresses induced by axial flexure at this critical end.

A stepped thickness cylinder was selected as the reference concept for the conceptual design of the reactor support skirt. The thickness of the cylinder is increased over a $0.85 \mathrm{in.}$ length at the vessel end. An optimization study showed 
that with a 0.040 in. - thick cylinder, increasing the thickness of the vessel end of the cylinder to $0.150 \mathrm{in.}$ raised the design cyclic limit from 100 to 500 cycles. If tolerances allow the $0.040 \mathrm{in}$. to increase to $0.050 \mathrm{in}$, the limit is reduced to 300 cycles.

\section{d. Coolant Inlet Pipes}

The reactor inlet pipes traverse the reflector through grooves at the split plane. In order to reduce the depth of the grooves, and to keep the pipes within the shield shadow cone, the pipes are flattened. Three basic options were con-

sidered: (1) flattened tube (flat sides with radiused ends), (2) flattened tube with internal support web, and (3) elliptical tube.

Although the internally supported flat tube offered a potential $2-1 \mathrm{~b}$ weight advantage (neglecting meteoroid nonpuncture requirements), it was not considered worth the added difficulty and cost of installing the central support bar; i. e., obtaining and verifying a high integrity connection. The elliptical tube showed no advantage.

The basic flattened tube was selected for the reference conceptual design. Finite element analysis established that an 0.080-in. minimum thickness is required to keep the stresses, induced by the 32-psi internal pressure, within limits allowed by the ASME Code.

\section{B. FUEL ELEMENT OPERATIONAL STRESS}

Fuel elements, subject to a thermal gradient across the cladding, will assume a bowed shape dictated by the cross-element $\Delta \mathrm{T}$. If the thermal deflections are of sufficient magnitude and in the appropriate direction, elementto-element contact will occur resulting in forces being applied to the cladding. The RLN (right-left-neutral) fin system, used for positive spacing and interchannel mixing, results in a fin on cladding contact which causes localized stress concentrations in addition to the bending stress caused by the force. A further stress is developed by the circumferential temperature variation $(6 \theta$ ripple) which results from a close-packed triangular array rod bundle. Metal subjected to a continuous stress tends to change shape in the elastic range. This creep causes strain hardening of the material and results in lowered ductility.

AI- AEC - 13075 


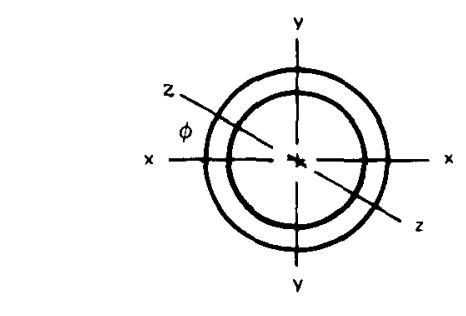

120 Elements f at Each Station I

Temperature Defined at Hot-Cold Line Every 30 degrees

$T=T_{1}+1 / 2\left[\frac{T_{1+2}+T_{1}}{2} \cdot T_{1+1}|| \cos \frac{20}{60} \cdot 1|+| T_{1+2}-T_{1} \mid \frac{\theta}{60}\right.$

$M_{x x}=\sum_{1}^{j=120} T_{1}, A_{s}$

$M_{v y}=\sum_{1}^{1=120} \tau_{1} x_{1} \Delta s$

$\phi=\operatorname{Tan}^{-1}\left(M_{\mathrm{yy}} / \mathrm{M}_{2 z}\right)$

$M_{R_{2 z}}=\sqrt{M_{x x}^{2}+M_{y y}^{2}}$
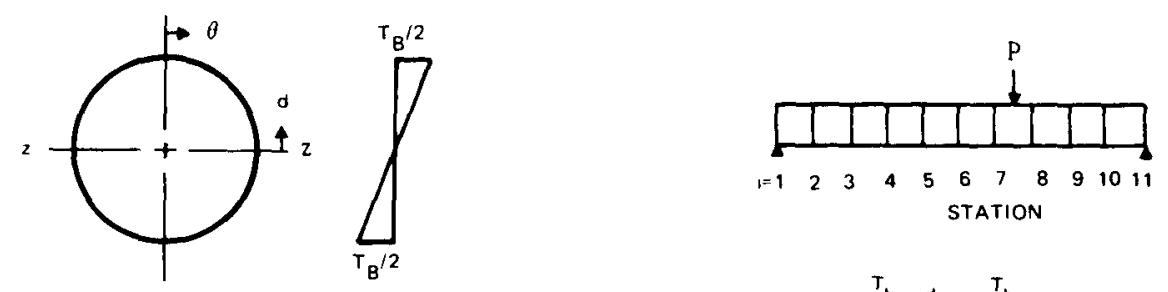

$$
\begin{aligned}
T_{\text {Bend } \beta} & =\frac{T_{b}}{2} \frac{d}{R}=\frac{T_{b}}{2} \cos \beta \\
M_{z 2} & =4 \int_{0}^{\pi / 2} \frac{T_{b}}{2} \cos \beta \cdot R \cos \beta d s \\
& =R^{2} \frac{T_{b}}{2} \int_{0}^{\pi / 2} \cos ^{2} \beta d \beta=\frac{R^{2} \pi}{2} T_{B e n d}
\end{aligned}
$$

$M_{22}-M_{R}$

$T_{\text {Bend }}=\frac{2}{R^{2}} M_{R}$

$T_{\text {'Bend }}=-\frac{T_{\text {Bend }}}{2} \cos (\beta)$

$$
\begin{aligned}
& T_{6 \theta_{1}} \quad T_{1} T_{\text {Average }} T_{\text {'Bend }} \\
& \sigma_{6 \theta_{1}}=E \sigma T_{6 \theta_{1}}
\end{aligned}
$$

Thermal Moment $=\int($ Force/Unit Length) (Distance $X)$ Rd $\theta$

$$
\begin{aligned}
& =4 \int_{0}^{\pi / 2} E a\left(T_{B} / 2\right) t R^{2} \cos ^{2} \theta d \theta \\
& =\frac{\pi}{2} E a t R^{2} \tau_{\text {Bend }}-\frac{E l a T_{B e n d}}{2 R}
\end{aligned}
$$

Deflection $=\int \frac{M \text { md } S}{E 1}$

$$
=\frac{P_{a}^{2} b^{2}}{3 E T Q} \quad \text { Ifor }
$$

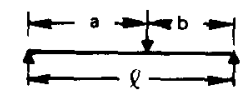

Solve for Load $(P)$ and Stresses Are Sum of Bending Due to $P$ and $6 \theta$

Figure 43. Bending and 68 Stress

$$
\text { AI-AEC- } 13075
$$


Calculation of the operational stresses was accomplished in the GEOM code simultaneously with the calculation of the temperature profiles in the reactor. The method has been fully described in Reference 10. The temperatures imposed in the fuel element were integrated at each of 11 axial stations to determine the amount of bowing due to a cross-element temperature gradient, and to find the $6 \theta$ stresses. The equations for determining the $6 \theta$ and bending stresses are shown in Figure 43. After the determination of the equivalent cross-element temperature gradient for each of 11 stations of all 85 elements, the contact forces were determined. Each element was balanced with respect to its neighbor, and an iteration technique was utilized to balance the whole core. The effects of manufacturing bow and outlet (lower) grid plate clearances were included in the analyses.

The creep analysis was a computerized extension of the bending and $6 \theta$ analysis. It calculated the stresses in the fuel element beam at each of 11 stations and determined the creep strain at 120 elements of each station for a given time increment. The resulting analysis was a step-by-step, strainhardening solution leading to the stress redistribution and load relaxation as a function of time, assuming a constant displacement. Figure 44 shows the basic equations of the computer analysis.

An experiment was conducted to determine the minimum stress in the cladding which would cause gross hydrogen leakage through the SCB coating applied to the cladding. The test rig consisted of a permeation test system modified to allow uniaxial loads to be applied to fuel elements. Loads were applied in 20-1b increments until a significant increase in hydrogen permeation from the element was noted. From this test the allowable cladding stress at $1200^{\circ} \mathrm{F}$ was determined to be $34,000 \mathrm{psi}$. In general, barrier failure occurred at or above the $0.2 \%$ offset yield strength of the cladding material.

The GEOM code was used to perturbate various parameters to determine their effects on fuel element stress. The margin of safety was defined as:

$$
\text { M. S. }=\frac{\sigma \text { allowable }}{\sigma}-1
$$

with a minimum goal of a positive margin and a desirable lower limit of 1. 
- USES SAME MODEL AS BENDING AND 60 STRESS PROGRAM

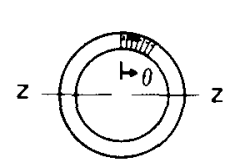

Element,

1,1 to 120

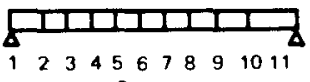

Station,

- given STATIC INITIAL STRESSES aND knOWN CREEP LaW

$$
\begin{aligned}
& \text { Creep Moment, }\left(M_{c_{1}}\right)=\int_{0}^{2 \pi} E_{\| l} J_{t E R^{2} \cos \theta d \theta} \\
& \text { Fictitious Deflection }=\int_{1=1}^{i=11} \frac{M_{c_{1}} \text { mas }}{E I} \\
& \text { Load Relaxation - Fictitious Deflection } \times \frac{3 E I}{a^{2} b^{2}}
\end{aligned}
$$

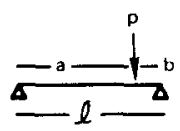

- TO MAINTAIN MOMENT CONTINUITY THE CREEP MOMENT $M_{C_{1}}$ IS REPLACED BY LINEAR MC/I MOMENT Moment Dıagrams

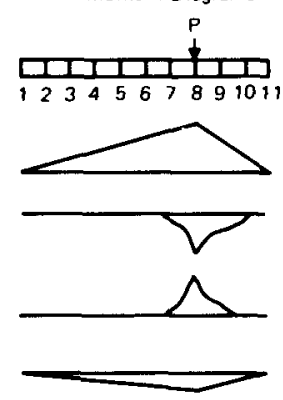

Moment Due to $P$

Moment Due to Creep Relaxation

Linear Moment to Replace Creep Momen

Moment Due to Load Relaxation

- axial loAd CONTINUITy MUSt BE MaINTAINED in the SaME MANNER

- total stresses

$$
\left.\sigma_{1}=\sigma_{160}+\sigma_{\text {'Bending }}+U_{1}(\text { Creep Relaxation })+U_{1} \text { (Moment Continuity }\right)+\sigma_{1} \text { (Load Relaxation }+U_{1}(\text { Axial Load Continuity) }
$$

- Residual stresses on REACTOR SHUTDOWN

- Creep Deflection Compared to Initial Bow to Determine if Contact Load Exists and Direction of Load

- Creep Moment Determined and Replaced with Equal and Opposite Limear Morment for Net Moment of Zero

$$
M_{c} \quad 2 \int_{0}^{\pi} \epsilon_{1 c} E_{r t} R^{2} \cos \theta d \theta
$$

- Do Same with Axial Load

- Add Moment Due to Contact with Adjacent Element

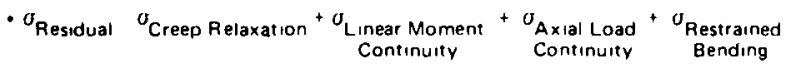

Figure 44. Beam Creep Analysis

AI-AEC- 13075 
It was recognized that by studied manipulation of the variables (fuel asymmetry, manufacturing bow magnitude and direction, cladding tolerances, etc.), very low or very high safety margins could be calculated. However, unrealistic configurations must be modeled to result in the extreme conditions. The study made considered primarily plausible configurations.

The first five cases consider all variables to be completely random within tolerances with the exception that the manufacturing bow is at least $50 \%$ of the maximum allowable. This was done since a perfectly straight element is virtually impossible to manufacture. These conditions resulted in only three elements in contact out of the 425 elements modeled in the five runs. The lowest safety margin was 17.8 corresponding to a stress of only 1809 psi.

The remaining 15 runs considered all fuel slugs in an element to be oriented the same axially. This condition is quite probable since heat treatment of the final closure weld is done with the element horizontal. Asymmetry was limited to $90 \%$ of the gap to take the small fuel slug thermal bow into account. Details for all 20 runs are given in Reference 2 .

\section{GRID PLATE LAUNCH STRESSES}

The weight of the 85 fuel elements (249 1b) is supported by the inlet grid plate. To account for the effects of acceleration, shock, and vibration imposed on the reactor during system launch, a 16.25-g equivalent static loading is specified for design.

For weight efficiency, the inlet grid plate is designed as a sandwich structure made up of 0.062 -in. thick facing sheets, an outer rim, and 85 spacer bushings located at the fuel element axis positions; furnace brazed into a composite structure. This design concept was used for the grid plates of the SNAP $10 \mathrm{~A}$ reactor and was extensively tested in developmental and qualification test programs.

Classical equations for calculation of stresses and deflections in circular plates loaded by pressure are readily available. These are for single thickness plates with no holes. The actual structure is a sandwich plate with many holes. A single plate thickness with a moment of inertia equivalent to that of the sandwich structure was calculated and used directly in the circular plate equations. The deflection equations were adjusted by the ratio of the total surface area

$$
\text { AI-AEC- } 13075
$$


minus the area of unreinforced flow holes. The stress equations were adjusted to account for the greater distance to the extreme fiber of the sandwich structure plus the effect of unreinforced holes on the basis of a representative stress section.

The above methods of calculations were tested by applying them to the SNAP $10 \mathrm{~A}$ grid plate design and comparing the results to experimental test data on those plates. The comparison showed the methods to be valid and they were then applied to the 5-kwe reactor grid plate design. Under the 16.25-g equivalent static design load, the calculated maximum stress is 18,200 psi, giving a margin of safety of 0.65 based on a minimum yield strength of 30,000 psi, and the peak deflection is 13 mils. 


\section{NUCLEAR DESIGN AND PERFORMANCE}

\section{A. INTRODUCTION}

This section describes the nuclear analyses leading to the selection of the conceptual design of a 5-kwe reactor. Both the parametric analyses made to select a minimum weight design and the detailed analyses of the selected design are discussed.

\section{B. PARAMETRIC STUDIES}

Reactor parametric studies were performed to select a conceptual design which meets the objectives of minimum reactor plus shield weight and minimum reactor envelope. The studies were made using the timeshare computer program, ZIP. (11) The parameters which were varied are listed in Table 18.

The results obtained from varying the number of fuel elements are shown in Table 19. The active fuel length was held constant at 16 in. and the external reflector midplane thickness was held constant at 2.19 in. for the se calculations. Reactivity was adjusted by varying the lattice pitch. In hexagonal geometry, there are certain total number of elements which pack into a circular core vessel better than others. This is illustrated by the results for a 73 -element core in which the vessel diameter is greater than that of the 85 -element core. For this reason, the 73 -element core is $28 \mathrm{lb}$ heavier than the 85 -element core. By maintaining a constant fuel length and reactor power, the average linear rod power (kwt/ft) varies inversely with the number of fuel elements. The increase in $\mathrm{kwt} / \mathrm{ft}$ with the decrease in number of elements results in higher fuel temperatures. The increased fuel temperature contributes to an increase in fuel growth and hydrogen loss. The 85 -element core was selected over the lighter 55 -element core because of the $40^{\circ} \mathrm{F}$ lower fuel temperature.

Variations in active fuel length were made over a range of 14 to 17 in. for an 85-element core. In these calculations, lattice pitch and external reflector thickness were varied to give the same end-of-life reactivity margin for all reactors. The results are shown in Table 20. As may be seen, the trade-off in reactor plus shield weight is small over the range. A 16-in. core was selected as a compromise between weight savings and reduced fuel temperature and fuel element stress.

AI - AEC - 13075 
TABLE 18

REACTOR PARAMETERS VARIED

\begin{tabular}{l|l}
\hline \multicolumn{1}{c|}{ Parameter } & \multicolumn{1}{c}{ Range } \\
\hline Number of Fuel Elements & 55 to 121 \\
Active Fuel Length (in.) & 14 to 17 \\
Cladding Thickness (mils) & 15 to 30 \\
Interelement Spacing (mils) & 15 to 25 \\
Cone Half-Angle (degrees) & 0.75 to 10 \\
Minimum Reflector Thickness (in.) & 70 to 100 \\
Reactor Thermal Power (kwt) & 60 to 90 \\
Core $\Delta$ T ( ${ }^{\circ}$ F) & 1100 to 1250 \\
Reactor Outlet Temperature $\left(^{\circ} \mathrm{F}\right)$ & 0 to 2.50 \\
EOL Reactivity Margin (\$) & 0 to 4.50 \\
Prepoison Loading (\$) & \\
\hline
\end{tabular}

TABLE 19

NUMBER OF FUEL ELEMENTS TRADE STUDY

\begin{tabular}{l|l|l|l|l}
\hline \hline Number of Elements & 55 & 73 & 85 & 121 \\
Lattice Pitch (in.) & 1.233 & 1.095 & 1.026 & 0.893 \\
Active Core Diameter (in.) & 9.61 & 9.82 & 9.93 & 10.31 \\
Internal Reflector Thickness (in.) & 0.275 & 0.442 & 0.261 & 0.274 \\
Core Vessel OD (in.) & 10.28 & 10.82 & 10.57 & 10.98 \\
Reactor Midplane Envelope (in.) & 14.66 & 15.20 & 14.95 & 15.36 \\
Relative Reactor Plus Shield & & & & \\
Weight (lb) & -31 & +28 & $*$ & +44 \\
BOL H/Zr ( - Fuel) & 1.64 & 1.65 & 1.66 & 1.67 \\
Cold BOL Radial Gap (mils) & 7.0 & 6.1 & 5.8 & 5.3 \\
EOL Nominal Peak-Average & 1326 & 1297 & 1286 & 1267 \\
Fuel Temperature ( F) & & & & \\
\hline
\end{tabular}

*Comparison Case

$\mathrm{AI}-\mathrm{AEC}-13075$ 
TABLE 20

FUEL LENGTH TRADE STUDY

\begin{tabular}{l|c|c|c|c}
\hline \hline Active Fuel Length (in.) & 14 & 15 & 16 & 17 \\
Lattice Pitch (in.) & 1.094 & 1.057 & 1.026 & 0.999 \\
Reflector Midplane Thickness (in.) & 2.05 & 2.12 & 2.19 & 2.26 \\
Core Vessel OD (in.) & 11.26 & 10.88 & 10.57 & 10.30 \\
Reactor Midplane Envelope (in.) & 15.36 & 15.12 & 14.95 & 14.82 \\
Relative Reactor Weight (1b) & -15 & -9 & $*$ & +11 \\
Relative Shield Weight (1b) & +14 & +6 & $*$ & -4 \\
Relative Reactor Plus Shield & & & & \\
Weight (lb) & -1 & -3 & $*$ & +7 \\
EOL Nominal Peak-Average & 1295 & 1290 & 1286 & 1283 \\
Fuel Temperature (ํ F) & & & & \\
\hline
\end{tabular}

*Comparison Case

The remainder of the parameters which were investigated proved to have a linear relationship in weight. For these parameters, weight coefficients were determined which are given in Table 21 . These coefficients were used in the overall reactor thermoelectric system optimization studies.

\section{NUCLEAR CHARACTERISTICS OF THE SELECTED DESIGN}

From the results of the reactor parametric studies and the reactorthermoelectric system optimization studies, the reactor design summarized in Table 22 was selected as the conceptual design. The reactor was designed for continuous operation for 5 years at $110 \mathrm{kwt}$. The thermoelectric system power requirements to produce $5 \mathrm{kwe}$ do not exceed $102 \mathrm{kwt}$. This has the effect of providing additional end-of-life reactivity margin.

\section{Reactivity and Reactivity Lifetime}

The reactivity requirements for the design power level and the operating power level are shown in Table 23. The reactor nuclear characteristics are shown in Table 24. As may be seen, a cold, unpoisoned reactivity of $\$ 7.74$ is needed to provide the reactivity requirements for 5 years of operation at $110 \mathrm{kwt}$ 
TABLE 21

SUMMARY OF PARAMETRIC STUDIES

WEIGHT SENSITIVE COEFFICIENTS

\begin{tabular}{|c|c|c|c|}
\hline \multirow[b]{2}{*}{ Parameter } & \multicolumn{3}{|c|}{ Weight Coefficients } \\
\hline & Reactor & Shield & $\begin{array}{l}\text { Reactor } \\
+ \text { Shield }\end{array}$ \\
\hline Cladding Thickness (1b/mil) & 1.95 & 1.05 & 3.00 \\
\hline Interelement Spacing ( $1 \mathrm{~b} / \mathrm{mil})$ & 0.55 & 0.45 & 1.00 \\
\hline Cone Half Angle (lb/degree) & 2.4 & 29.0 & 31.4 \\
\hline $\begin{array}{l}\text { Minimum Reflector Thickness } \\
\text { (1b/in.) }\end{array}$ & 7.0 & 21.8 & 28.8 \\
\hline Reactor Thermal Power (1b/kwt) & 0.41 & 1.38 & 1.79 \\
\hline Core $\Delta \mathrm{T}\left(\mathrm{lb} /{ }^{\circ} \mathrm{F}\right)$ & 0.22 & 0.14 & 0.36 \\
\hline $\begin{array}{l}\text { Reactor Outlet Temperature } \\
\left(1 \mathrm{~b} /{ }^{\circ} \mathrm{F}\right)\end{array}$ & 0.096 & 0.066 & 0.162 \\
\hline EOL Reactivity Margin $(1 \mathrm{~b} / \$)$ & 9.0 & 5.4 & 14.4 \\
\hline Prepoison Loading $(1 \mathrm{~b} / \$)$ & 2.4 & 1.4 & 3.8 \\
\hline
\end{tabular}

TABLE 22

REACTOR DESIGN SUMMARY

\begin{tabular}{l|c}
\hline \hline Thermal Power (kwt) & 110 \\
Number of Fuel Elements & 85 \\
Active Fuel Length (in.) & 16 \\
Lattice Pitch (in.) & 1.025 \\
Interelement Spacing (mils) & 20 \\
Cladding Thickness (mils) & 25 \\
Glass Thickness (mils) & 2.5 \\
Gap Thickness (mils) & 6.0 \\
Fuel Diameter (in.) & 0.938 \\
Active Core Diameter (in.) & 9.920 \\
Active Core Volume (liters) & 20.3 \\
Core Vessel OD (in.) & 10.600 \\
Vessel-Reflector Clearance (in.) & 0.060 \\
Reflector Midplane Thickness (in.) & 2.386 \\
Reactor Midplane Envelope (in.) & 15.492 \\
Taper Angle (degrees) & 8.5 \\
Segment Stroke (in.) & 4.0 \\
Movable Angle (degrees) & 235 \\
Fissile Mass (kg U235) & 9.0 \\
NH in Fuel (1022 at./cc) & 5.72 \\
\hline
\end{tabular}

$\mathrm{AI}-\mathrm{AEC}-13075$ 
TABLE 23

REACTIVIT Y REQUIREMENTS

(\$)

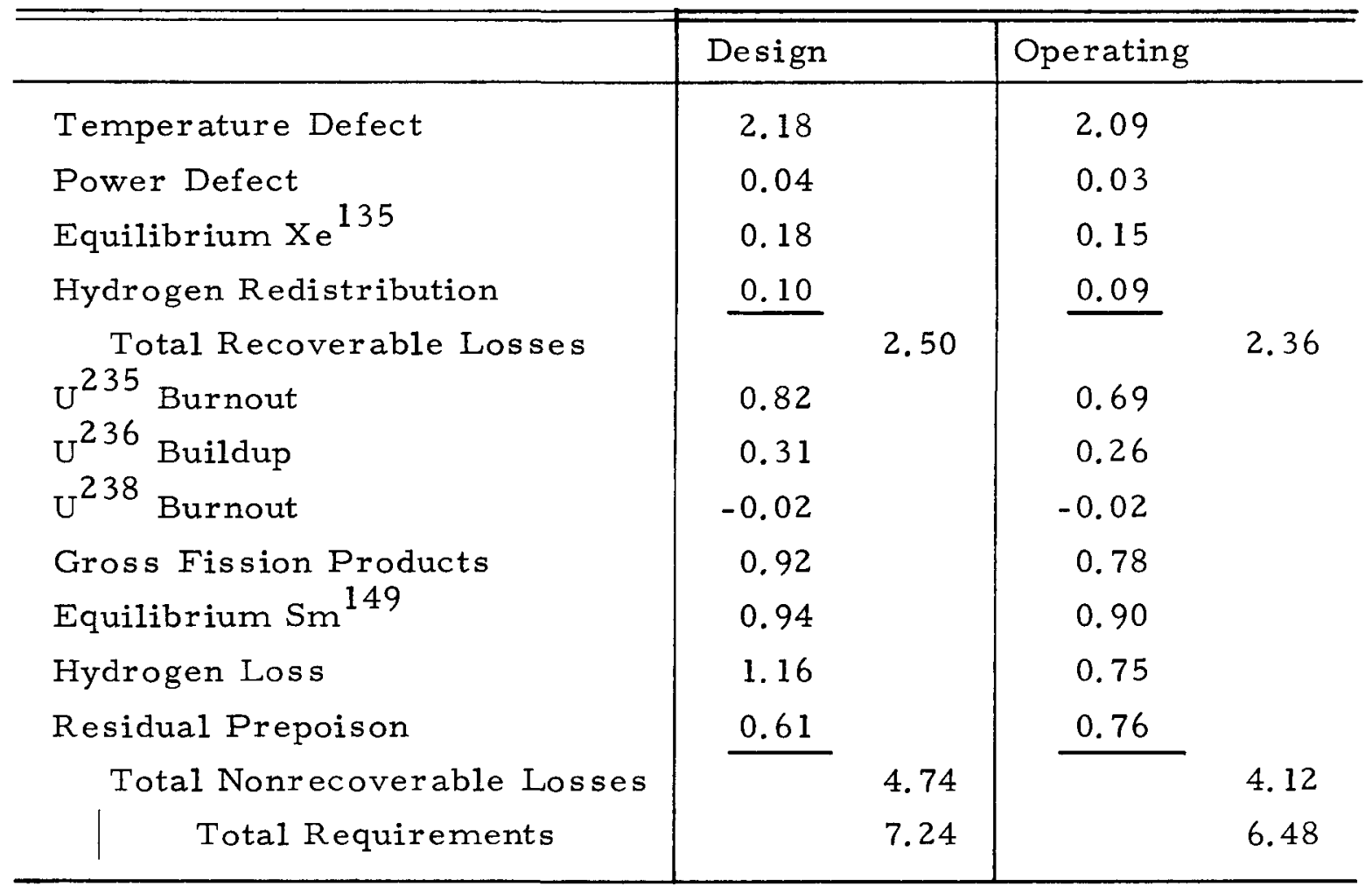

TABLE 24

NUCLEAR CHARACTERISTICS

(\$)

\begin{tabular}{l|c|c}
\hline \hline & Design & Operating \\
\hline Cold, Unpoisoned Reactivity & 7.74 & 7.74 \\
Hot Prepoison Loading & 3.00 & 3.00 \\
Recoverable Losses & 2.50 & 2.36 \\
Hot, Poisoned Reactivity & 2.24 & 2.38 \\
Nonrecoverable Losses & 4.74 & 4.12 \\
Prepoison Burnout & 2.39 & 2.24 \\
EOL Reactivity Margin & 0.50 & 1.26 \\
Control Worth & 7.74 & 7.74 \\
BOL Shutdown Margin & 3.00 & 3.00 \\
\hline
\end{tabular}




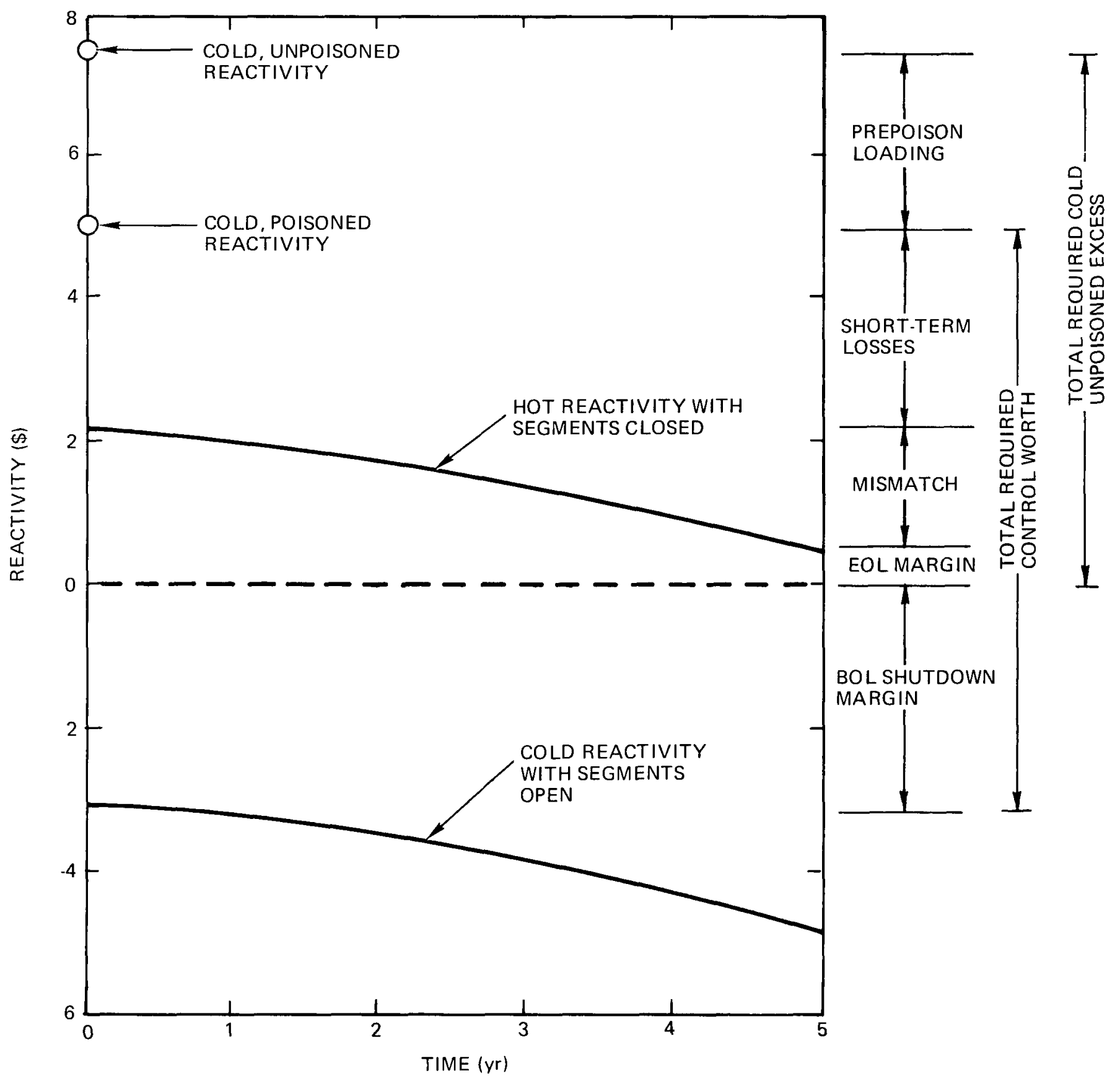

6531-4615

Figure 45. Reactivity vs Time, 5-kwe Reactor, Design-To Conditions 
with a $\$ 0.50$ end-of-life reactivity margin. At the operating power level, the EOL reactivity margin increases to $\$ 1.26$. The reactivity as a function of time at the design power level is shown in Figure 45. Also shown is the cold, shutdown reactivity with the control segments fully open.

\section{Prepoison Selection and Loading}

The nuclear parameters which influence the selection of a prepoison material are the burnout rate, the effect on the prompt temperature coefficient, and the specific worth $(\$ / \mathrm{gm})$. The nonnuclear parameters are the compatibility of the poison with other core materials, the availability and cost of the poison, and the method of depositing the poison in the core.

The reason for including a prepoison in the reactor is to reduce the control requirements by reducing the reactivity loss over life. The burnout of the prepoison helps to offset the losses from fuel depletion, fission product buildup, and hydrogen loss.

The poisons which have both nuclear and physical properties which make them suitable for use in SNAP reactors are samarium, gadolinium, gadolinium enriched in $\mathrm{Gd}^{155}$, europium enriched in $\mathrm{Eu}^{151}$, and erbium. The properties of the se poisons are as follows:

\section{a. Samarium}

This is the only poison which has been used in operating SNAP reactors. Its burnout rate is suitable for 5 -kwe reactor application. It has a positive effect on the prompt temperature coefficient but not as great as gadolinium. Natural samarium may be used because only one high cross section isotope, $\mathrm{Sm}^{149}$, occurs naturally; therefore, the cost and availability are favorable. In previous SNAP reactor use, samarium oxide was mixed with the ceramic hydrogen barrier. Post-irradiation examination of fuel elements indicated some deterioration of the ceramic.

\section{b. Gadolinium}

The burnout rate of natural gadolinium is very similar to that of samarium. The naturally occurring material contains two high cross section isotopes, Gd 155 and $\mathrm{Gd}^{157}$. The effect on the prompt temperature coefficient of natural gadolinium 
has not been measured, but calculations indicate that the effect is about the same as that of $\mathrm{Gd}^{155}$ which has been measured. Nonnuclear testing of gadolinium oxide vapor deposited on the fuel surface indicated that it is a very stable material. (12) The availability and cost of natural gadolinium are favorable.

\section{c. Gadolinium-155}

The burnout rate of $\mathrm{Gd}^{155}$ is too slow for 5-kwe reactor application. It is more suitable for higher power level reactors. The availability and cost are not favorable. The other properties are similar to those of natural gadolinium. d. Europium-151

The burnout rate of $\mathrm{Eu}^{151}$ is slow due to its low cross section and the buildup of the daughter product $\mathrm{Eu}^{152}$. Eu ${ }^{151}$ has a strong negative effect on the prompt temperature coefficient which is the only reason for considering its use. It may be used to offset the positive temperature coefficient effect of samarium and gadolinium. Natural europium must be enriched in $\mathrm{Eu}^{151}$ because of the presence of $\mathrm{Eu}^{153}$ which is unsuitable as a burnable poison. Its availability and cost, therefore, are not favorable. Nonnuclear testing of europium oxide vapor deposited on the fuel surface indicated it to be an unstable material.

e. Erbium

The burnout rate of erbium is slow. The main function of erbium is to alter the temperature coefficient; therefore, its use is in conjunction with samarium or gadolinium. Natural erbium may be used since all isotopes except Er 167 have negligible cross sections. The availability and cost of natural erbium are favorable. Erbium oxide is compatible with $\mathrm{ZrH}$ fuel.

Natural gadolinium oxide was selected for the 5-kwe reactor because of its chemical stability and because the required loading of $\$ 3$ did not reduce the temperature coefficient below an acceptable value.

A total loading of $13.25 \mathrm{gm}$ of gadolinium oxide is required to give a hot worth of $\$ 3$. Assuming that the poison will be deposited on 15 in. out of the total fuel length of $16 \mathrm{in.}$, the surface density is $0.547 \mathrm{mg} / \mathrm{cm}^{2}$. The calculated room temperature worth is $\$ 3.73$. 


\section{Control Worth}

Reactivity control is provided by two sliding reflector segments. The movable segments subtend $235^{\circ}$ of the reactor circumference and they open 4 -in. windows about the vertical center of the core. The sliding segments move along the $8.5^{\circ}$ taper angle rather than parallel to the core vessel surface. This also opens gaps between the reflector and core vessel, and between the sliding segment and fixed reflector which enhance the control worth.

A reliability analysis indicated that more than two segments did not yield a significant increase in reliability. Two segments were selected from the standpoint of simplicity and cost.

A total control worth of $\$ 7.74$ was determined from two-dimensional DOT calculations in $\mathrm{R}, \mathrm{Z}$ geometry. In the DOT calculations, it was necessary to assume that the segments subtend the full $360^{\circ} \mathrm{F}$. The worth obtained from the DOT calculations was multiplied by $235 / 360$ to obtain the worth of the $235^{\circ} \mathrm{seg}-$ ments. Calculations were made with the segments closed, 2 in. open, and $4 \mathrm{in.}$ open. The worth of the first 2 -in. opening was $\$ 3.95$, and the worth from 2 to 4 in. open was $\$ 3.79$. This indicates that the control worth is very nearly linear over the 4 -in. stroke.

\section{Temperature Coefficients}

Partial temperature coefficients of reactivity are shown in Table 25. The fuel coefficient is made up of the spectral, Doppler, and axial fuel expansion coefficients. The isothermal coefficient is the sum of the fuel, grid, and reflector coefficients. The isothermal coefficient is used to determine the reactivity loss in going from ambient to operating temperatures. The partial temperature coefficients are used to predict the kinetic behavior of the reactor.

The coefficients were determined using the $k$-difference method. The various effects which cause the reactivity to change with temperature, such as Doppler broadening of cross sections and thermal expansion of the different reactor components, were evaluated individually using the APC code. (14) The calculations were performed at beginning-of-life conditions. As mentioned in Section V-C-2, the gadolinium prepoison loading has a positive effect on the spectral component 


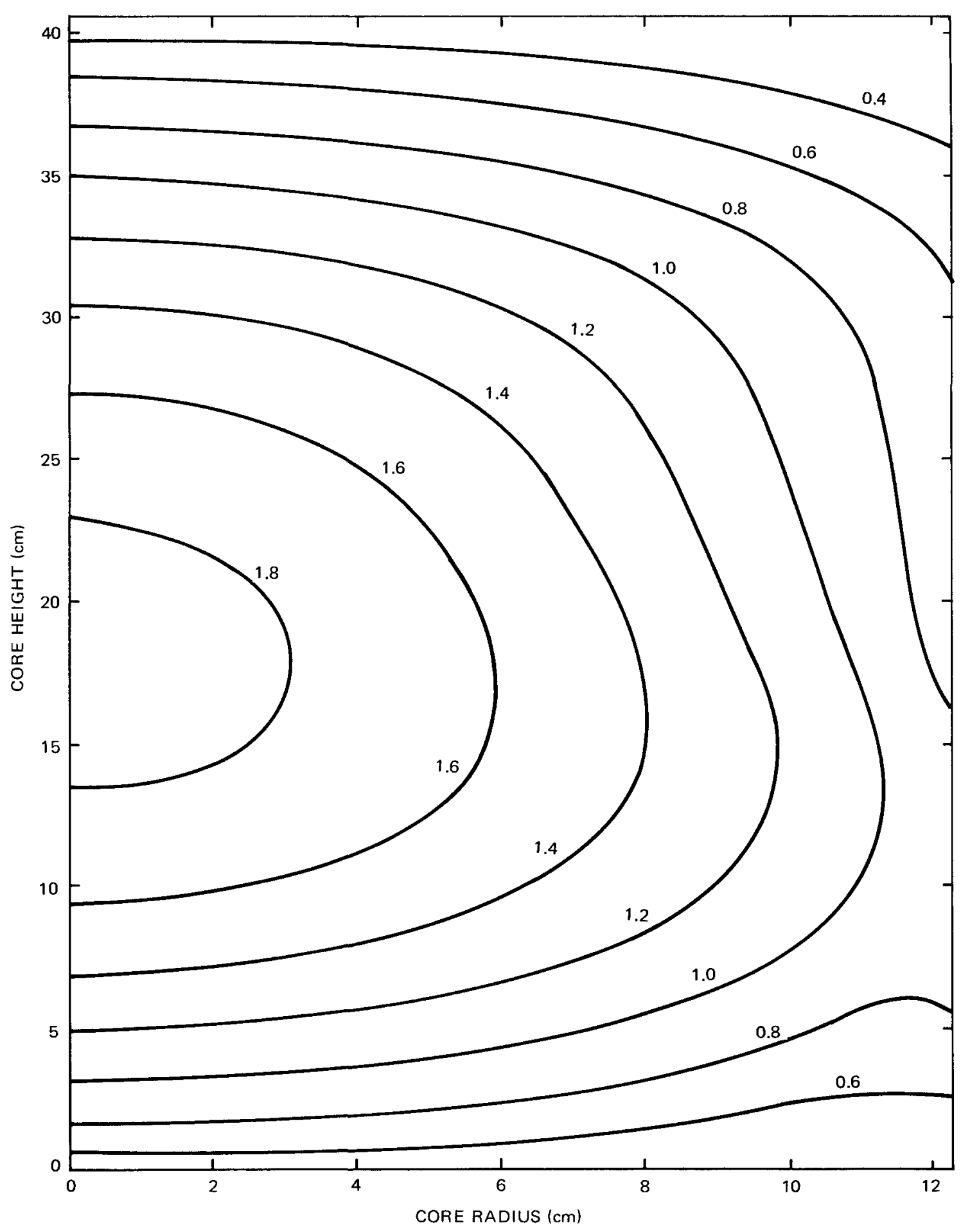

$6531-4616$

Figure 46. BOL Power Contours, Segments in Normal Position 
TABLE 25

PARTIAL TEMPERATURE COEFFICIENTS

$\left(\notin^{\circ} \mathrm{F}\right)$

\begin{tabular}{l|l}
\hline \hline Spectral & +0.007 \\
Doppler & -0.022 \\
Fuel Axial Expansion & -0.051 \\
\cline { 2 - 2 } Fuel Coefficient & -0.066 \\
Inlet Grid & -0.060 \\
Outlet Grid & -0.020 \\
Reflector Heating & -0.034 \\
Isothermal & -0.18 \\
\hline
\end{tabular}

of the fuel coefficient. As the gadolinium burns out over life, the fuel coefficient becomes more negative. The effect of the burnout of gadolinium is partially offset by the buildup of $\mathrm{Sm}^{149}$ fission product. The fuel coefficient at end-of-life was evaluated to be $-0.108 \not /^{\circ} \mathrm{F}$.

\section{Power Distributions}

Two-dimensional power profiles were generated from the DOT calculations in $\mathrm{R}, \mathrm{Z}$ geometry from which the control worth was obtained. The power profiles were generated for segments closed, 2 in. open, and 4 in. open. Figure 46 shows the profiles with segments 2 in. open which is representative of beginningof-life conditions. Figure 47 shows the profiles with segments fully closed which is representative of end-of-life conditions.

In the $\mathrm{R}, \mathrm{Z}$ geometry calculations, it was not possible to represent the fixed reflector between the two sliding segments. The segment opening in the calculations encompassed the full $360^{\circ}$ of the reactor circumference. In order to account for the azimuthal variation in the power, a power distribution was synthesized from two $R, Z$ calculations. The power distributions from the calculations with segments closed and 2 in. open were combined using a sinusoidal azimuthal variation. A timeshare computer program was written for this purpose. Figure 48 shows the resultant peak power relative to the core average for each fuel element in a quadrant. Due to symmetry, the power distribution is the same in all four quadrants. 


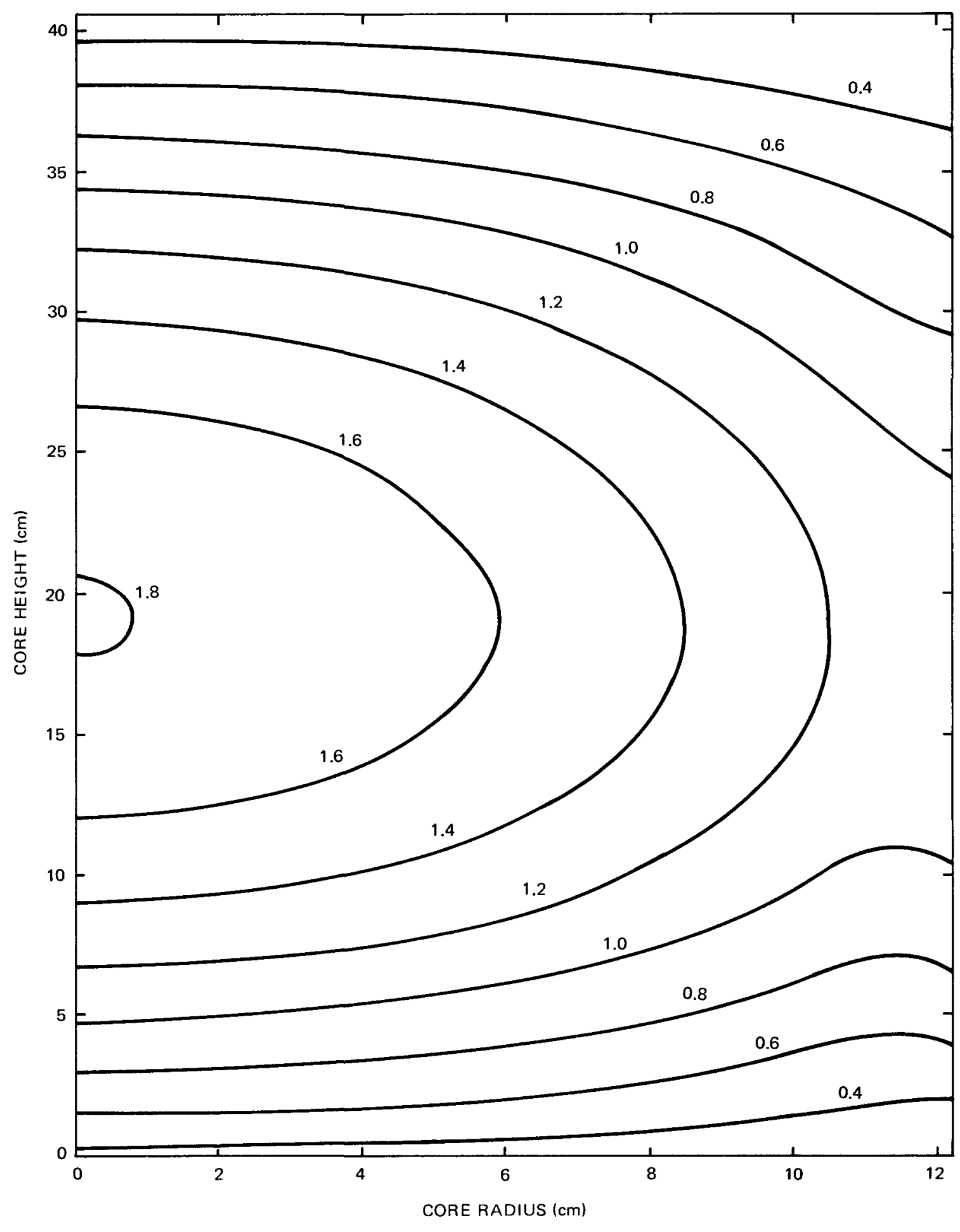

6531.4517

Figure 47. EOL Power Contours, Segments Fully Closed 


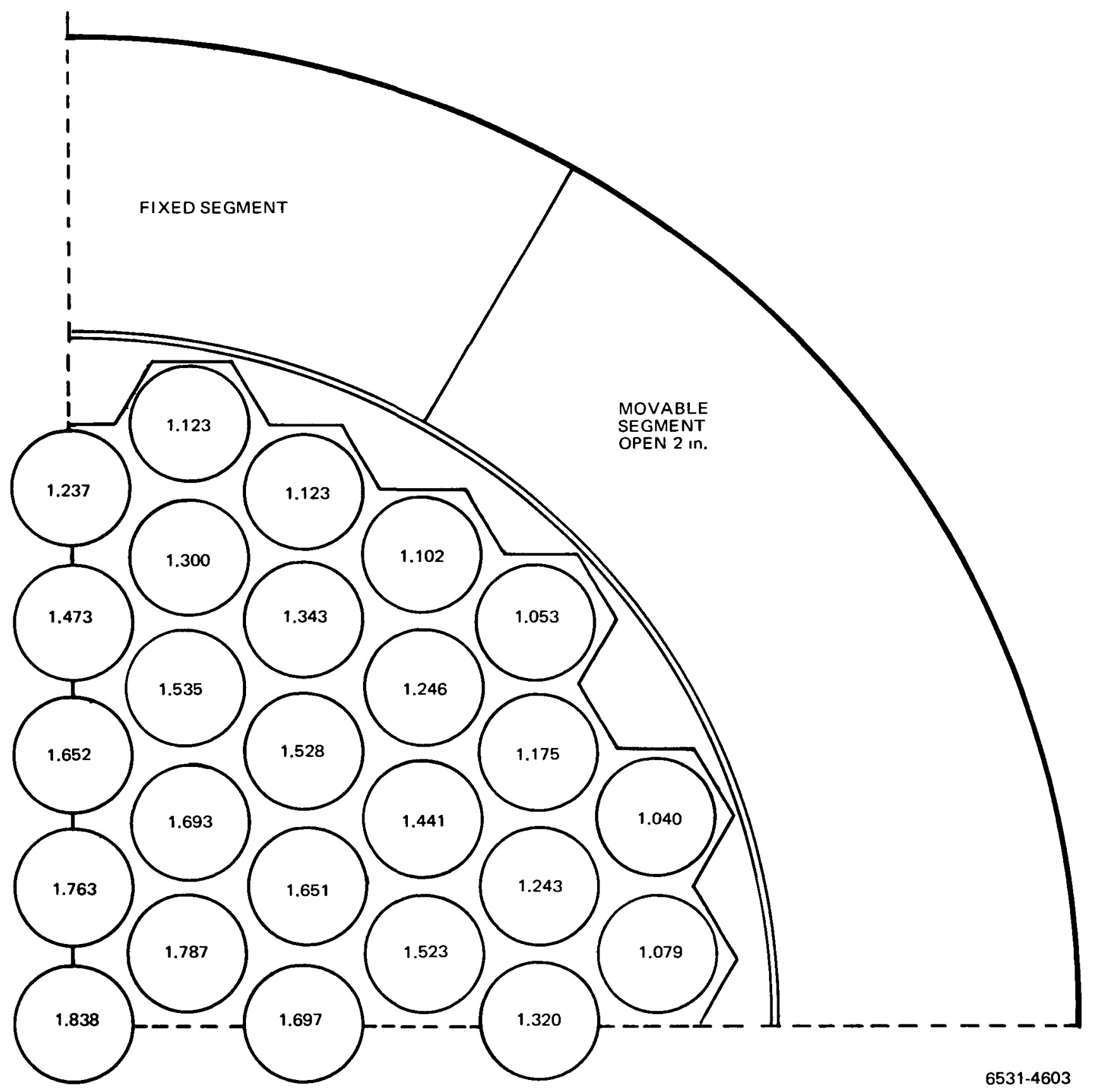

Figure 48. Peak Power Per Element Relative to Core Average 
TABLE 26

COMPARISON OF CALCULATED AND EXPERIMENTAL

REACTIVITIES OF SNAP REACTORS

\begin{tabular}{|c|c|c|c|}
\hline & \multicolumn{2}{|c|}{$\begin{array}{l}\text { Reactivity } \\
(\$)\end{array}$} & \multirow[b]{2}{*}{ Error } \\
\hline & Measured & Calculated & \\
\hline \multicolumn{4}{|l|}{ Near Critical Reactivities } \\
\hline $\begin{array}{l}\text { S8DR-165 Elements } \\
\text { Full Shims }\end{array}$ & 0.16 & 1.35 & 1.19 \\
\hline $\begin{array}{l}\text { SCA-4A-37 Elements } \\
1.25 \text {-in. Reflector }\end{array}$ & -0.25 & -0.73 & -0.48 \\
\hline $\begin{array}{l}\text { S8ER-211 Elements } \\
\text { No Shims }\end{array}$ & -0.28 & -0.88 & -0.60 \\
\hline $\begin{array}{l}\text { S8ER-186 Elements } \\
\text { A Shims }\end{array}$ & 0.14 & 0.40 & 0.26 \\
\hline $\begin{array}{l}\text { S8ER-173 Elements } \\
A+B \text { Shims }\end{array}$ & 0.10 & 0.60 & 0.50 \\
\hline $\begin{array}{l}\text { Average Error and Standard } \\
\text { Deviation }\end{array}$ & & & $0.17 \pm 0.74$ \\
\hline \multicolumn{4}{|l|}{ Supercritical Reactivities } \\
\hline $\begin{array}{l}\text { S8DR - } 169 \text { Elements } \\
\text { Full Shims }\end{array}$ & 1.40 & 2.37 & 0.97 \\
\hline $\begin{array}{l}\text { S8DR-211 Elements } \\
\text { Full Shims }\end{array}$ & 13.62 & 12.14 & -1.48 \\
\hline $\begin{array}{l}\text { SCA-4A-37 Elements } \\
2.25-\text { in. Reflector }\end{array}$ & 6.55 & 5.33 & -1.22 \\
\hline $\begin{array}{l}\text { SCA-4A-37 Elements } \\
3.25-\text { in. Reflector }\end{array}$ & 10.45 & 8.68 & -1.77 \\
\hline $\begin{array}{l}\text { S8ER-211 Elements } \\
\text { Full Shims }\end{array}$ & 10.09 & 7.36 & -2.73 \\
\hline $\begin{array}{l}\text { Average Error and Standard } \\
\text { Deviation }\end{array}$ & & & $-1.25 \pm 1.36$ \\
\hline $\begin{array}{l}\text { Overall Average Error and } \\
\text { Standard Deviation }\end{array}$ & & & $-0.54 \pm 1.28$ \\
\hline
\end{tabular}


6. Uncertainties and Shim Capabilities

The 28-group cross section library ${ }^{(15)}$ and transport theory method used in the analysis of the 5-kwe reactor were tested against several SNAP reactor experiments. The reactivity of a variety of coreloadings and shim configurations was measured on SCA-4A, S8ER, and S8DR. Reactivities near critical and significantly supercritical reactivities were measured. Table 26 contains a comparison between calculation and experiment of ten of the se configurations. In general, critical cores were calculated accurately and the large excess reactivities were underestimated. Part of the error in the supercritical reactivities may be due to the difficulty involved in their measurement. All of the supercritical reactivities were obtained from control drum calibrations and large variations in these calibrations were obtained due to interaction with neighboring drums. When these individual drum calibrations are added to obtain large excess reactivities, considerable uncertainty may result. Most of the near critical reactivities were obtained from inverse multiplication with all control drums full in.

The estimated uncertainty in the reactivity requirements for 5 years of full power operation are shown in Table 27. The overall uncertainty was obtained by adding the burnup, fission product, and prepoison burnout uncertainties and combining their total by root sum square with the remaining uncertainties. This method was used because it was felt that the long-term burnup effects are not independent of each other but are independent of the remaining uncertainties.

The uncertainty in control worth is based on calculations and measurements of sliding reflector worth on SCA-4A. (16) The R, Z geometry calculational method underpredicted by $18 \%$ the worth of two $90^{\circ}$ segments open 3.5 in. on SCA-4A. This means that the 5-kwe reactor control worth is underpredicted by about $\$ 1.4$.

Because of the uncertainty in reactivity predictions, the 5 -kwe reactor will contain provisions for reactivity shimming. To increase reactivity, provision is made for adding beryllium shims to the fixed portion of the reflector. To decrease reactivity, provision is made for increasing the gap between the reflector and core vessel by adding shims beneath reflector bearing pads. 
TABLE 27

REACTIVITY LIFETIME UNCERTAINTIES

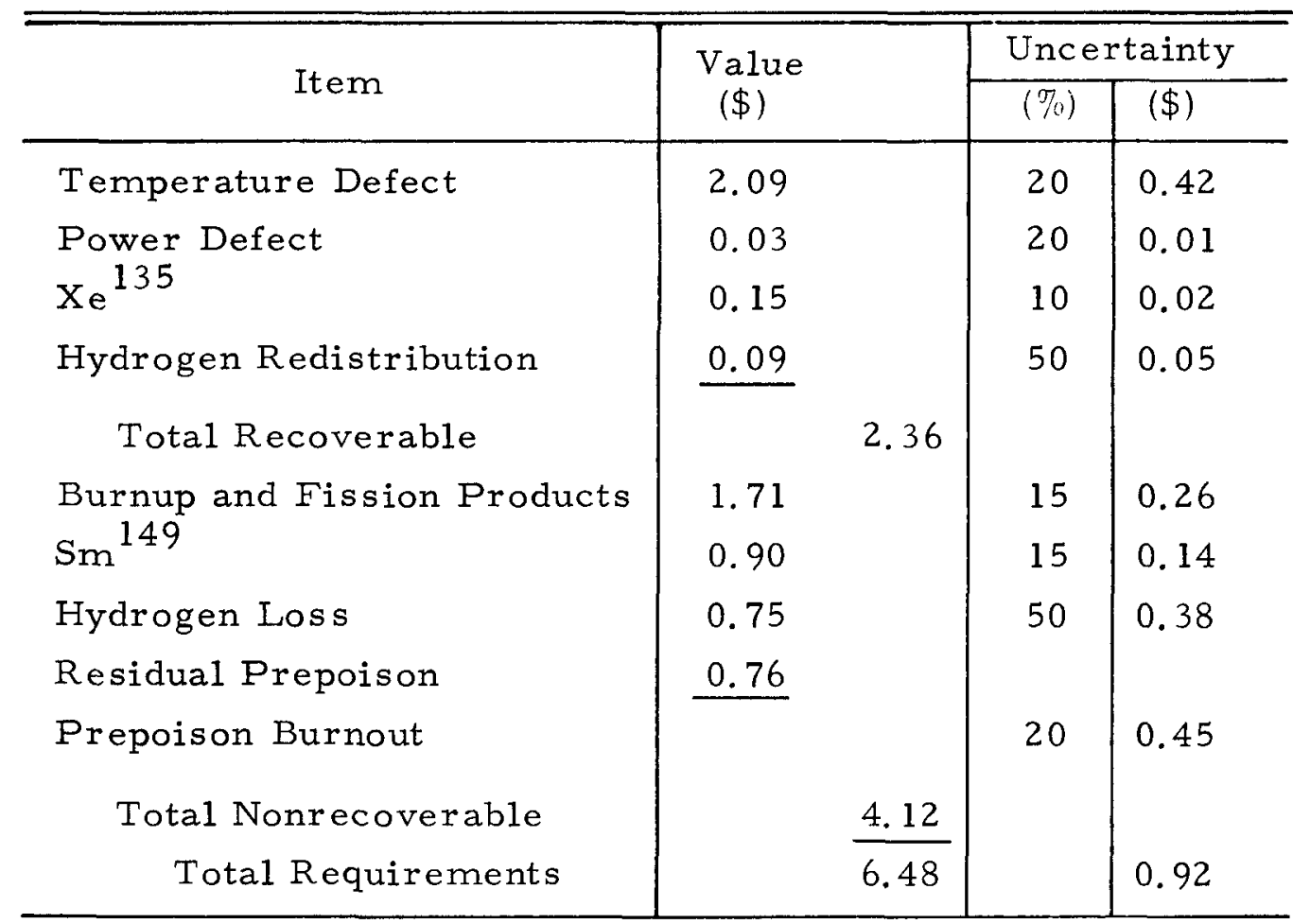

\section{METHODS OF NUCLEAR ANALYSIS USED}

\section{Nuclear Codes}

SNAP reactors are quite small from a nuclear standpoint. In order to accurately predict the nuclear performance of these reactors, transport theory (not diffusion theory) must be used. The one- and two-dimensional codes that have been developed for this purpose are as follows:

a. APC and APC II

$A P C$ and APC II are both buckling $\left(B^{2}\right)$ or leakage $\left(D B^{2}\right)$ iteration codes for reactor calculations based on the one-dimensional transport theory code, ANISN. ${ }^{(17,18)}$ In APC, ${ }^{(14)}$ a uniform composition (single material) must be specified for all core zones. In APC II, the composition in core zones may be different and options for flux and importance weighting of the different compositions are provided. 
In both codes, two complete ANISN problems are specified. These two problems make up a case. The two problems are processed alternately transferring $\mathrm{B}^{2}$ or $\mathrm{DB}^{2}$ from each to the other until the results are mutually consistent. Termination of a case is controlled by convergence criterion on $\mathrm{k}_{\mathrm{eff}}$ and leakage or by limiting the number of times the problems are processed (number of passes). Maximum execution time (CPU time) may also be used to terminate each problem or the case.

Although $\mathrm{a} \mathrm{B}^{2}$ or $\mathrm{DB}^{2}$ iteration case must be a k calculation, $\mathrm{APC}$ and APC II may both be used to run single ANISN type problems. These codes are the main production tools for SNAP nuclear analysis, since explicit twodimensional calculations are too expensive and time consuming to use for parametric studies.

b. DOT

$\operatorname{DOT}^{(13)}$ is a Fortran IV program which solves the linear, energy-dependent, Boltzmann neutron and/or photon transport equation for two-dimensional $\mathrm{R}-\mathrm{Z}$, $\mathrm{X}-\mathrm{Y}$, and $\mathrm{R}-\theta$ geometries. The gradient or convection term in the Boltzmann equation is approximated by a finite difference technique known as discrete ordinates or Carlson's $\mathrm{S}_{\mathrm{n}}$ method. The inscatter integral is approximated by expanding the differential cross-section in a Legendre series which allows the integral to be computed by quadrature. DOT will solve forward or adjoint, homogeneous or inhomogeneous problems. The inhomogeneous problems may have a volume-distributed source or a specified angular flux at the right or top boundaries; fissions may be included for a subcritical system. Homogeneous (eigenvalue) problems will determine the following: (1) static multiplication factor, "k;" (2) time adsorption, "Rossi $\alpha$;"(3) concentration for a specified $k$, and (4) zone thickness for a specified k.

DOT is a successor to the Los Alamos codes TDC, DDK, and DDF. The latest version of this code (from ORNL) is DOT III. Cross sections can be input on cards from an ANISN-type, nuclide-organized data set, or from a special group-organized data set which is valuable for very large cross section sets. 
c. $\quad$ COMPOZ

COMPOZ ${ }^{(19)}$ is a transport theory perturbation code designed to be used in conjunction with the multigroup transport code, APC. The code calculates the reactivity worth of cross section perturbations of materials which are included in the APC case or for materials from a library tape. The perturbation which is made to the cross section is equal to the value of the cross section. This makes it unnecessary to input any specific perturbation of a cross section or number density.

The majority of the input to a COMPOZ case is obtained from data sets created by APC; therefore, most of the COMPOZ input is control parameters. To run a COMPOZ case, it is necessary to have previously run both direct and adjoint APC cases." The data set created by the direct APC case contains fluxes, cross sections, number densities, and geometry data. The data set from the adjoint APC case contains only the adjoint fluxes.

The COMPOZ perturbation worths in units of $\triangle \mathrm{K} / \mathrm{K}$ per atom $/ \mathrm{cm}$. barn are given for each type of reaction (capture, fission, leakage, etc.) by interval and by zone. Integrals of the worth over a given range of intervals may be obtained by group as well as the total over all groups. The worth in dollars of the materials appearing in the APC case is given for all zones in which they appear. In this instance, the worth is calculated for the total amount of the material appearing in the zone.

COMPOZ calculates the transverse leakage worth of a material which the effect a perturbation in the total cross section of that material has on the $\mathrm{DB}^{2}$ term. Group-dependent $\mathrm{DB}^{2}$ terms are only given for core zones by $\mathrm{APC}$; therefore, the transverse leakage worth for noncore zones is inaccurate.

In addition to material worths, COMPOZ also calculates the effective delayed neutron fraction and neutron lifetime. The option is also available for performing a group-collapse to obtain importance weighted few-group cross sections.

*APC is designed so that two dimensions ( $R$ and $Z$ ) can be calculated in one run. 


\section{d. BUFRN}

This code solves the nuclear reactor burnup problem for SNAP reactors with a quasi-two-dimensional approach. By coupling the APC-II buckling iteration code and the NUCY burnup equations, ${ }^{(20)}$ axial and radial nuclide burnup effects are both taken into account. Therefore, a single nuclear case may be run to simultaneously obtain nuclear results for the beginning-of-life (BOL) and end-of-life (EOL) compositions of a SNAP reactor.

This code is useful for determining the impact of burnup on any reactor. However, it is a one-shot burnup code; that is, it does not contain fuel management provisions.

e. $\underline{\text { ZIP }}$

$\mathrm{ZIP}^{(11)}$ is a timeshare program for performing SNAP reactor parametric studies at nominal cost. ZIP calculates reactivity, reactivity requirements, and control worth for a specified reactor design. At the user's option, it searches on lattice pitch to determine a reactor which has a specified end-oflife (EOL) reactivity margin. ZIP also calculates hydrogen loss, fuel swelling, shadow shield requirements, and reactor and shield weights.

The program is written in FORTRAN for use on the Honeywell 440 computer. Input data are contained in " $Z$ " files numbered from $Z 1$ through $Z 40$. A maximum of four cases may be run simultaneously. The output data are written in a file named "OUTPUT" for later listing. Some of the pertinent information is printed on line so that a rapid evaluation of the cases being run can be made. f. $\mathrm{APCTC}$

This code is written to facilitate the analysis of nonisothermal temperature reactivity coefficient measurements such as those that were made on the SNAPTRAN reactor. ${ }^{(8)}$ Earlier studies which utilized isothermal calculations did not agree very well with the experimental measurements. Since the temperature distribution of the SNAPTRAN reactor was quite nonuniform during many of the temperature coefficient measurements, a nuclear code was needed which would handle these nonuniformities. 
APCTC calculates the spatial distribution of the fuel's temperature. This information is combined with temperature-dependent cell calculations from APC-II and adjoint fluxes from COMPOZ to determine temperature coefficients for the reactor. This calculational procedure produced temperature coefficients which were about $40 \%$ higher than temperature coefficients that were calculated with flat temperature distributions. Comparisons with experimental measurements were considerably improved with this procedure.

\section{Cross Sections}

A multigroup library of 28 groups is presently used for the nuclear analysis of SNAP reactors. The energy breakpoints used in this library were designed to provide detail both at high energies, in order to accurately calculate the significant fast leakage from SNAP cores, and around the thermal peak, in order to accurately calculate multiplication factors, prepoison reactivities, and temperature effects. This library provides for downscattering to 17 groups and upscattering to 12 groups. Half of the energy groups have been placed below $3 \mathrm{ev}$ since much of the flux in these reactors is near thermal energies and the median fission energy is about $0.2 \mathrm{ev}$.

While the flux spectrum in the SNAP reactors is essentially thermal, it cannot be accurately characterized by a typical Maxwellian thermal-neutron energy spectrum. This is a consequence of the zirconium-bound hydrogen in the uranium zirconium-hydride fuel matrix. Using the neutron-scattering kernel based on the SUMMIT II code, a 28 -group set of cross sections was prepared for use in calculations of the SNAP reactor cores. A calculated neutron spectrum for the $S 8 D R$ reactor core operating at $68^{\circ} \mathrm{F}$ had a peak in its thermal flux spectrum at $0.1 \mathrm{ev}$.

The SNAP library has been periodically updated in order to utilize the best data possible.

The 28-group library contains about 100 files of cross sections. These include all of the elements necessary for SNAP reactor analysis. The library also contains cross sections for various reactor operating temperatures and as a function of Legendre coefficient expansions (modified $\mathrm{P}_{0}, \mathrm{P}_{1}, \mathrm{P}_{2}$, and $\mathrm{P}_{3}$ ). A complete description of this library is given in Reference 15.

$\mathrm{AI}-\mathrm{AEC}-13075$ 


\section{Geometric Modeling}

SNAP reactors are generally quite small. The active core is a right circular cylinder about $1 \mathrm{ft}$ high, with a diameter of about 9 to 11 in. Since these reactors have a substantial leakage of neutrons, they can be adequately cantrolled by movable radial reflectors. The fuel elements for these reactors are clad rods of hydrided uranium-zirconium with an $O D$ of $1 / 2$ to $l \mathrm{in}$. The coolant is a sodium-potas sium alloy.

Although all of the geometric detail of SNAP reactors could be represented in a three-dimensional Monte Carlo calculation, this is not generally desirable from an engineering standpoint. In order to rapidly (and inexpensively) assess the impact of various design modifications, one-dimensional calculations are used extensively. Some two-dimensional calculations are used, but only for the calculation of nuclear parameters that cannot be adequately studied with $1-D$ methods (such as the worth of radial reflector drums).

The calculation of these reactors starts with an equivalent cylindrical (Wigner-Seitz) fuel cell. This cell typically contains a central fuel rod surrounded by annuli of cladding and coolant. Then cross sections are flux-weighted to spatially averaged cross sections for the active core.

These reactors are most commonly analyzed in a quasi-two-dimensional manner by iterating radial and axial one-dimensional, multigroup transport calculations (APC code). The radial geometrical model consists of the active core surrounded by annuli of the internal reflector region ( $\approx 1 \mathrm{~cm}$ thick), the reactor vessel $(0.1$ to $0.2 \mathrm{~cm}$ thick), and the outer reflectors which contain the control drums (5 to $14 \mathrm{~cm}$ thick depending upon the amount of reflection desired). The axial geometrical model contains the active core (30 to $35 \mathrm{~cm}$ high), upper and lower grid plates (each about $0.5 \mathrm{~cm}$ thick), and upper and lower coolant plena that contain 6 to $8 \mathrm{~cm}$ of $\mathrm{NaK}$.

The iterative APC technique is generally adequate for producing material sensitivity coefficients and studying the performance of the active core. $(24,25)$ However, the accurate calculation of quantities such as reflector control drum worth frequently require two-dimensional transport calculations ( $\mathrm{sing}$ the $\mathrm{X}-\mathrm{Y}$ version of DOT). 


\section{BLANK}

$\bullet$ 


\section{REACTOR PERFORMANCE MARGINS}

\section{A. INTRODUCTION}

In the design of any mechanical, electrical, or nuclear system, it is necessary to build into the system sufficient margin to ensure the design objectives will be achieved with a high degree of probability. On the other hand, it is usually desirable to limit the amount of margin in order to avoid excessive cost, weight, or other undesirable characteristics. The overall 5-kwe Reactor Thermoelectric System margins and their allocation to each subsystem, of which the reactor is one, are described in Reference 21.

From past experience as well as the results of the studies of Reference 21 , it is particularly important to examine in detail the reactor performance margins, since the reactor is the most complex component in the system, and has a large number of potential modes of performance degradation.

The primary way the reactor could cause the system to fail to achieve its design goal of $5 \mathrm{kwe}$ for 5 years is by becoming subcritical before the mission is completed. There are a number of ways that this could happen; the se may be grouped into three broad categories. First, the nuclear calculations of the required BOL reactivity, or the reactivity requirements over life could be in error, and reactivity could become zero before the 5 -year mission is completed. Second, the stress level in the fuel element cladding or glass hydrogen barrier could exceed the yield point and hydrogen leakage could, as a consequence, be significantly larger than predicted. This also could result in insufficient reactivity to operate for 5 years at $5 \mathrm{kwe}$. Third, the reflector control system could fail, thereby possibly causing the reactivity addition capability of the control system to be inadequate to achieve the mission objectives. In order for the reactor to have a high probability of achieving its design goals, sufficient margin must exist in each of these three areas. This was a design objective in the conceptual design of the reactor presented in this report.

\section{B. REACTIVITY LIFETIME MARGINS}

The reactor is designed for continuous 5-year operation at $110 \mathrm{kwt}, 1200^{\circ} \mathrm{F}$ outlet temperature, and $100^{\circ} \mathrm{F}$ core temperature rise. The reactivity margin under these conditions is $\$ 0.50$ which is sufficient for 1 year additional operation.

$$
\text { AI-AEC-13075 }
$$




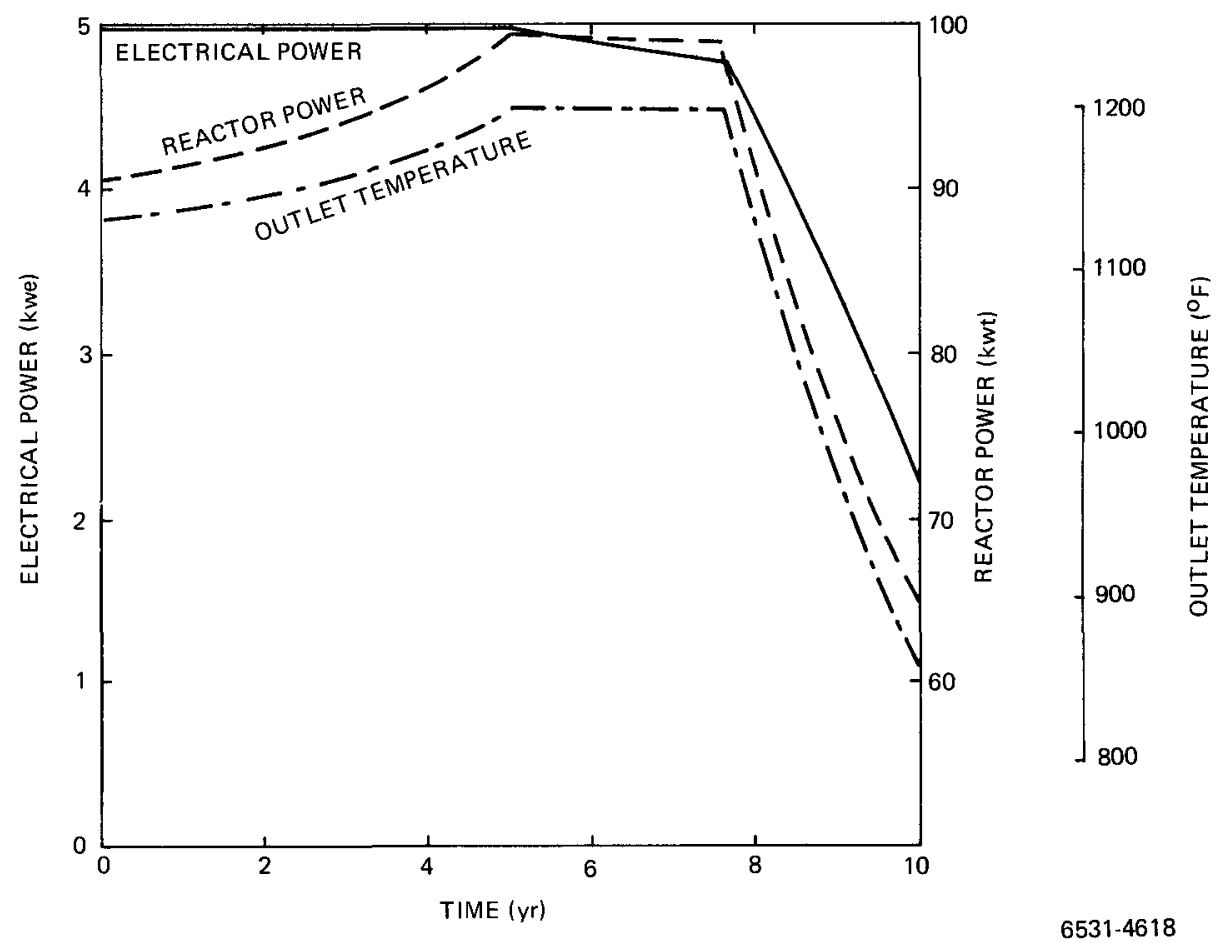

Figure 49. 5-kwe System, Extended Life Characteristics

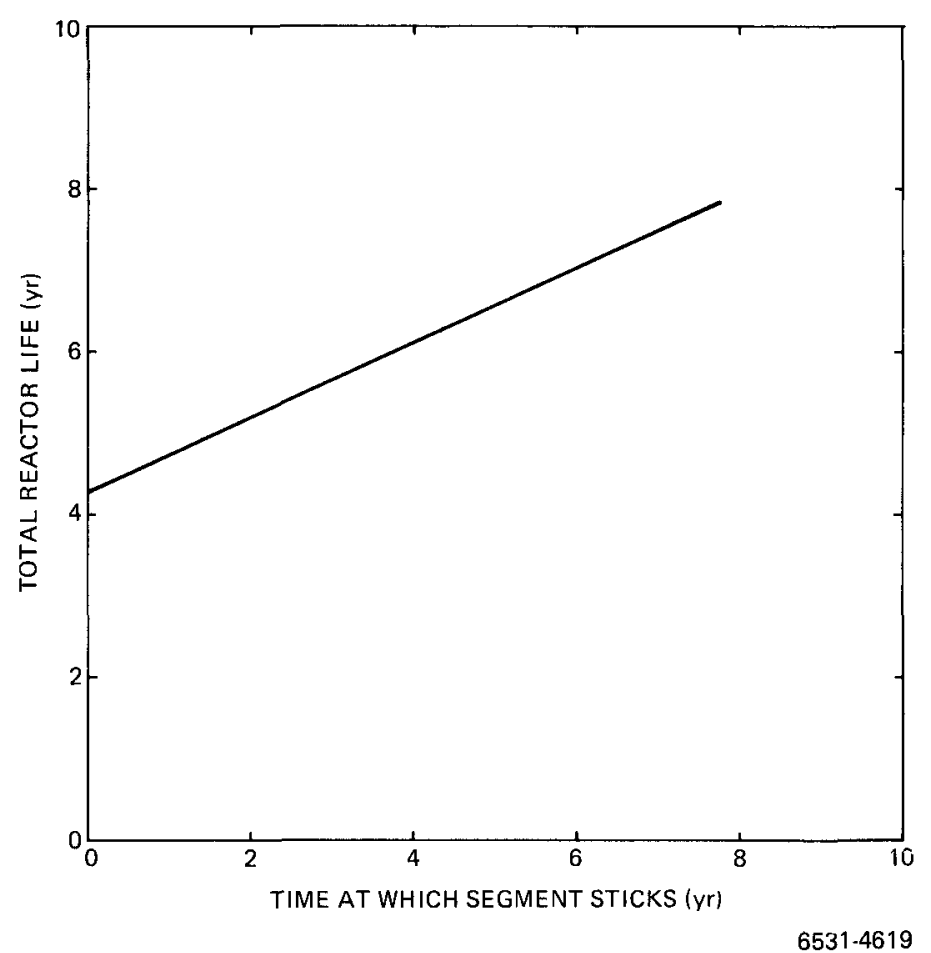

Figure 50. Reactor Lifetime Capability with One Stuck Control Segment

$\mathrm{AI}-\mathrm{AEC}-13075$ 
In actual operation, the thermoelectric system demands are less severe than the design conditions. The reactor power level from beginning of life (BOL) to end of life (EOL) varies from 91 to $99 \mathrm{kwt}$. The outlet temperature varies from $1135^{\circ} \mathrm{F}$ at $\mathrm{BOL}$ to $1200^{\circ} \mathrm{F}$ at EOL and the core temperature rise varies from $87^{\circ} \mathrm{F}$ at $\mathrm{BOL}$ to $95^{\circ} \mathrm{F}$ at EOL. There is sufficient reactivity at the actual (most probable) operating conditions to provide an additional 22 months operation.

After approximately 8 years at full power, it is possible to use temperature drift-down for continued operation at reduced power. This is illustrated in Figure 49.

An estimate of uncertainties in reactivity lifetime was given in Table 27. A total uncertainty of $\$ 0.92$ in the 5 -year reactivity requirement is shown. The reactivity margin at operating conditions is $\$ 1.26$.

In the event of failure of one control segment, the reactor may still attain a significant fraction of its design life. Figure 50 shows the reactor life attainable as a function of the time at which one control segment sticks at its operating position. If one segment sticks in the full-out position at startup, it is still possible to attain about 4.3 years operation with the remaining segment. The minimum time at which one segment can stick and the reactor still achieve its design life is 1.6 years.

\section{FUEL ELEMENT PERFORMANCE MARGINS}

The reactor fuel element is manufactured with a 12-mil (diametral) gap inside the cladding to allow for fuel swelling, bowing, manufacturing tolerances, etc. Based upon the design operating conditions and the current fuel growth data, the predicted fuel growth in the peak rated element ${ }^{(22)}$ is 6.3 mils (diametral), 4.7 mils at offset with an additional 1.6 mils occurring during the 5-year lifetime. This allows a 5.7-mil margin for fuel segment bowing and swelling uncertainty.

The hydrogen retention capabilities of the SCB (ceramic) hydrogen barrier, attached to the internal surface of the cladding, are described by the dimensionless parameter, ${ }^{A} D$. This parameter defines the fractional internal surface 
area of the cladding which is effectively bare metal. The leak rate is, typically, made up of about $75 \%$ due to leakage through defects in the glass (essentially leakage through bare metal) and $25 \%$ due to leakage through the glass and the metal, so the magnitude and timewise variation of $A_{D}$ pretty much determines the hydrogen retention characteristics of a fuel element. Evaluation of available test data ${ }^{(22)}$ indicates that $A_{D}$ for the 5 -kwe system will be of the order of $0.15 \%$ and will remain constant throughout the life of the core. The integral hydrogen loss over the design life of the reactor core results in a reactivity loss of $\$ 0.75$.

The fuel element stress study is discussed in Section IV-B. The margin of safety for the cladding stresses is always greater than one, except for cases where the element manufacturing bow was assumed to be much greater than the expected 6 mils. Even for an assumed 10-mil manufacturing bow the margin is based on that stress at which hydrogen leakage from the fuel element increases significantly.

\section{AUTOMATIC CONTROL SYSTEM RELIABILITY}

The purpose of the automatic control system for the flight reactor is to start up the reactor in orbit and maintain reactor power so as to generate electrical power at $5 \mathrm{kw}$ within narrow limits for 5 years.

Estimates of the reliability of the automatic control system can be made from the preliminary and conceptual designs of this system. More precise calculation of reliability must wait for the final design; reliability analysis would serve as a tool in developing the final design. The estimates derived here are approximations of what may be achieved.

The criterion of failure taken for this analysis is that if any component failure results in the inability of the control system to start up the reactor and maintain the thermoelectric power at $5 \mathrm{kw}$ for 5 years, the system has failed. This criterion is applied only to the automatic controller subsystem and does not include the segment drive system and actuators or the power supplies for the electronic components and actuators.

The automatic controller subsystem is shown in Figure 51, divided into functional blocks. During startup, pulses from the oscillators are passed by 


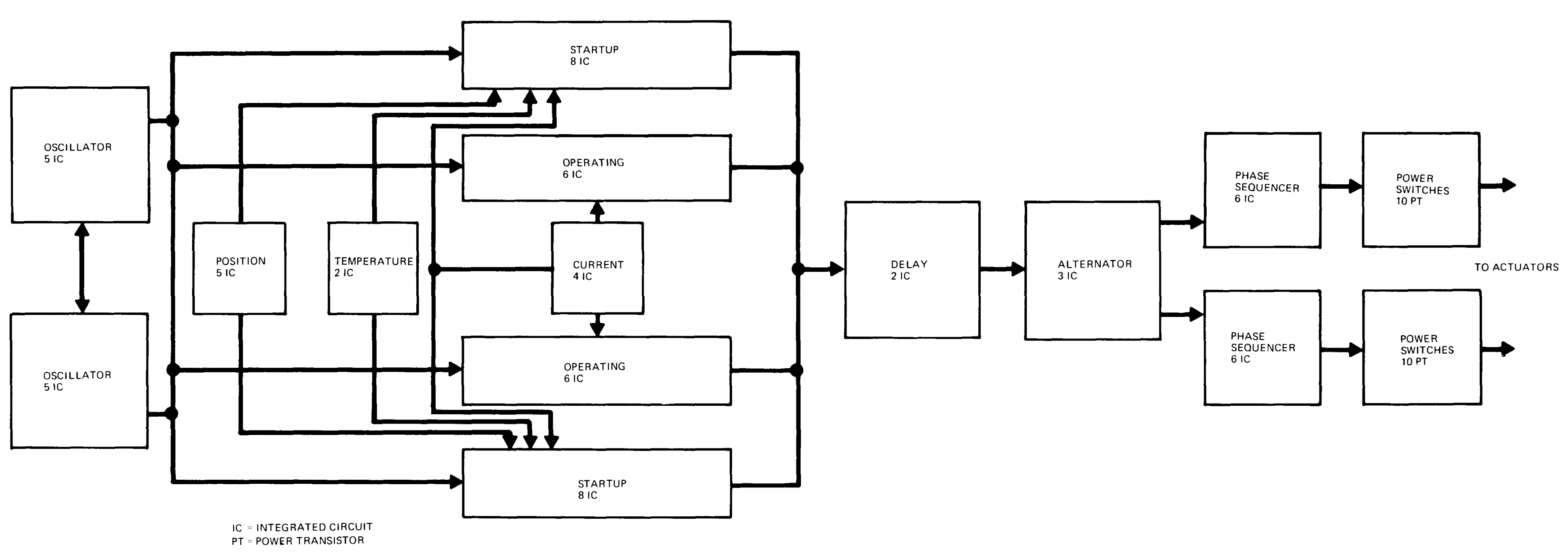

Figure 51. Functional Block Diagram Automatic
Controller 


\section{BLANK}


the startup blocks, subject to conditions established by the position, temperature, and current indicators, to the delay block and then to the alternator, where the pulses are alternately passed to one or the other of the phase sequencers. The active phase sequencer turns on five pairs of power transistors in sequence to release the actuator brake and step the actuator through a cycle, resetting the brake at the end of the cycle.

Preliminary and conceptual designs have established approximate active element part counts as indicated on the figure. Only integrated circuits and power transistors have been identified as necessary active elements at this stage.

Representative component failure rates at $25^{\circ} \mathrm{C}$ of 0.05 failures per million hours for the integrated circuits and 1.32 failures per million hours for the power transistors have been used. These rates do not include adjustments that should be made to reflect differences in temperature, humidity, and pressure from the nominal, the effects of launch and orbit insertion, derating in the design, and degradation due to radiation damage.

The failure probabilities for the startup phase and the operating phase were calculated separately from the individual functional block failure probabilities. These, in turn, were derived from the quantity of components and the components failure rate.

For startup, the subsystem failure probability is the sum of probabilities for disabling failures:

$$
\begin{aligned}
Q(\text { startup ) } & =Q_{\text {osc }}^{2}+Q_{\text {start }}^{2}+Q_{\text {pos }}+\frac{1}{2} Q_{\text {temp }}+\frac{1}{2} Q_{\text {cur }} \\
& +\frac{1}{2} Q_{\text {delay }}+\frac{1}{2} Q_{\text {alt }}+Q_{p h}^{2}+Q_{p s}^{2}+2 Q_{p h} Q_{p s}
\end{aligned}
$$

where obvious abbreviations of the block names have been used to identify the failure probabilities.

Since both the oscillators and the startup blocks are in parallel and fully interconnected, both oscillators must fail or both startup blocks must fail in order to produce a disabling failure. The delay and alternator blocks can fail 
in such a manner that the startup can still proceed. This is reflected by the factor of one-half for these probabilities. The phase sequencer and power switch blocks form parallel action paths but are not fully interconnected. It is possible to complete the startup phase using only one segment drive system. This is represented by the final three terms.

For the operating phase, the sum of failure probabilities is:

$$
Q \text { (operating) }=Q_{\text {osc }}^{2}+Q_{\text {op }}^{2}+Q_{\text {cur }}+\frac{1}{2} Q_{\text {delay }}+\frac{1}{2} Q_{\text {alt }}+2 Q_{p h}+2 Q_{p s}
$$

Changes from the startup failure probability are due to elimination of some of the functional blocks and the requirement that (except very near end of life) both segments must be driven correctly to satisfy the power requirement.

The block failure rates (per hour) are:

$$
\begin{aligned}
& Q_{\text {osc }}=5 \times 0.05 \times 10^{-6}=0.25 \times 10^{-6} \\
& Q_{\text {start }}=8 \times 0.05 \times 10^{-6}=0.40 \times 10^{-6} \\
& Q_{\text {op }}=6 \times 0.05 \times 10^{-6}=0.30 \times 10^{-6} \\
& Q_{\text {pos }}=5 \times 0.05 \times 10^{-6}=0.25 \times 10^{-6} \\
& Q_{\text {temp }}=2 \times 0.05 \times 10^{-6}=0.10 \times 10^{-6} \\
& Q_{\text {cur }}=4 \times 0.05 \times 10^{-6}=0.20 \times 10^{-6} \\
& Q_{\text {delay }}=2 \times 0.05 \times 10^{-6}=0.10 \times 10^{-6} \\
& Q_{\text {alt }}=3 \times 0.05 \times 10^{-6}=0.15 \times 10^{-6} \\
& Q_{\text {ph }}=6 \times 0.05 \times 10^{-6}=0.30 \times 10^{-6} \\
& Q_{\text {ps }}=5 \times\left(1.32 \times 10^{-6}\right)^{2}=8.7 \times 10^{-12}
\end{aligned}
$$

The last failure rate involves a square since two power transistors are used in parallel for each of the current switches. Using these failure rates, the failure probability for the startup phase ( 3 hours) is $1.6 \times 10^{-6}$ while for the operating phase $\left(44,000\right.$ hours) it is $41 \times 10^{-3}$. The corresponding success probabilities are 0.999998 for startup and 0.959 for full life operation. The phase sequencer blocks contribute over half of the failure probability while the current and alternator blocks account for most of the remainder. Improvements in design should concentrate on these functions with the aim to increase the full life reliability.

$$
\text { AI - AEC- } 13075
$$




\section{REFERENCES}

1. R. J. Tuttle, "Scram Controller and Automatic Controller, 5-kwe Reactor Thermoelectric System," AI-AEC-13073, May 25, 1973

2. L. D. Felten and E. Moody, "Fuel Element and Core Bundle, 5-kwe Reactor Thermoelectric System," AI-AEC-13077, June 22, 1973

3. J. D. Sutherland, "SNAP 10A Reactor Structure," NAA-SR-9899, August 1, 1964

4. J. R. Licht, "Design of 2 DRM Reactor Assembly," NAA-SR-TDR-11137, March 9, 1965

5. P. H. Horton, "ZrH Reactor Control Reflector Systems Summary Report," AI-AEC-13078, June 1973

6. A. H. Lillie and V. L. Rooney, Jr., "Findings of the SNAP 8 Developmental Reactor (S8DR) Post-Test Examination," AI-AEC-13003, June 30, 1971

7. B. J. Ostermier, "ZrH Reactor Core Hydraulic Studies Summary Report," AI-AEC-13087, June 1973

8. O. G. Feil, "Vane Systems for Very Wide Angle Diffusers," J. Basic Engineering, V. 86, p. 759, December 1964

9. L. R. Reneau, J. P. Johnston, and S. J. Kline, "Performance and Design of Straight, Two-Dimensional Diffusers," J. Basic Engineering, V. 89, p. 141, March 1967

10. E. Moody, "GEOM, A Thermal-Hydraulic-Stress Code," AI-AEC-13065, May 10, 1973

11. H. Rood, "Selected Computer Codes and Libraries, Volume I. ZIP, A Timeshare Program for SNAP Reactor Parametric Studies," AI-AEC-13076, Vol. I, June 21, 1973

12. R. VanHouten, "Burnable Poison Deposition on ZrH Fuel - Process Development and Evaluation," AI-AEC-13085, June 1973

13. F. R. Mynatt, "A User's Manual for DOT - A Two-Dimensional Discrete Ordinates Transport Code with Anisotropic Scattering," K-1694, January 1967

14. D. S. Bost, "Selected Computer Codes and Libraries, Volume II. APC A Multigroup Transport Buckling Iteration Code," AI-AEC-13076, Vol. II, May 2, 1973 
15. J. M. Otter, "Selected Computer Codes and Libraries, Volume IV. A 28Group Cross Section Library for SNAP Reactor Analysis," AI-AEC-13076, Vol. IV, May 31, 1973

16. D. S. Bost, "Control Worth of Sliding Reflectors for ZrH Reactors," AIAEC-13086, June 1973

17. Ward W. Engle, Jr., "A User's Manual for ANISN - A One-Dimensional Discrete Ordinates Transport Code with Anisotropic Scattering," K-1693, March 30, 1967

18. M. A. Boling and W. A. Rhoades, "ANISN/DTF II," AI-66-Memo-171, 1966

19. V. S. Lekach, "Selected Computer Codes and Libraries, Volume III. COMPOZ - A Multigroup Transport Perturbation Code," AI-AEC-13076, Vol. III, May 22, 1973

20. D. R. Vondy, "Development of a General Method of Explicit Solution of the Nuclide Chain Equations for Digital Machine Calculations," ORNL-TM-361, October 17, 1962

21. V. S. Lekach and H. Rood, "System Statistical Reliability Model and Analysis," AI-AEC-13098, June 8, 1973

22. A. H. Lillie, "ZrH Fuel Element Performance Characteristics," AI-AEC13084 , June 19, 1973

23. J. Bell, "Summit, An IBM-7090 Program for the Computations of Crystalline Scattering Kernals," GA-2492, February 1, 1962

24. L. D. Swenson, "SNAP 8 Development Reactor Nuclear Analysis," AI-AEC12864, October 31, 1969

25. B. J. Dray, et al, "Reactivity Effects of Gadolinium-155 on a SNAP Reactor," AI-AEC-12909, April 15, 1970 


\title{
APPENDIX. SELECTED LAYOUT DRAWINGS
}

\author{
$R-N 652200001$ \\ Reactor Layout - Conceptual, Rev. A, \\ March 26, 1973 \\ $R-N 652210001$ \\ Core Layout - Conceptual, Rev. A, \\ March 26, 1973 \\ $R-N 652240031$ \\ Fuel Element Layout - Conceptual Rev. NC, \\ October 9, 1972 \\ $\mathrm{R}-\mathrm{N} 652210002$ \\ Internal Reflector Layout - Conceptual, \\ Rev. A, March 26, 1973 \\ $R-N 652220032$ \\ Control Reflector and Drive Layout - \\ Conceptual, Rev. B, February 26, 1973 \\ $R-N 652220095$ \\ Reflector Drive Actuator - Conceptual, \\ Rev. NC, October 12, 1972 \\ $R-N 652220033$ \\ Ground Test Backup Shutdown Relatch \\ Mechanism - Conceptual, Rev. A, \\ February 26, 1973
}


BLANK

$\bullet$ 


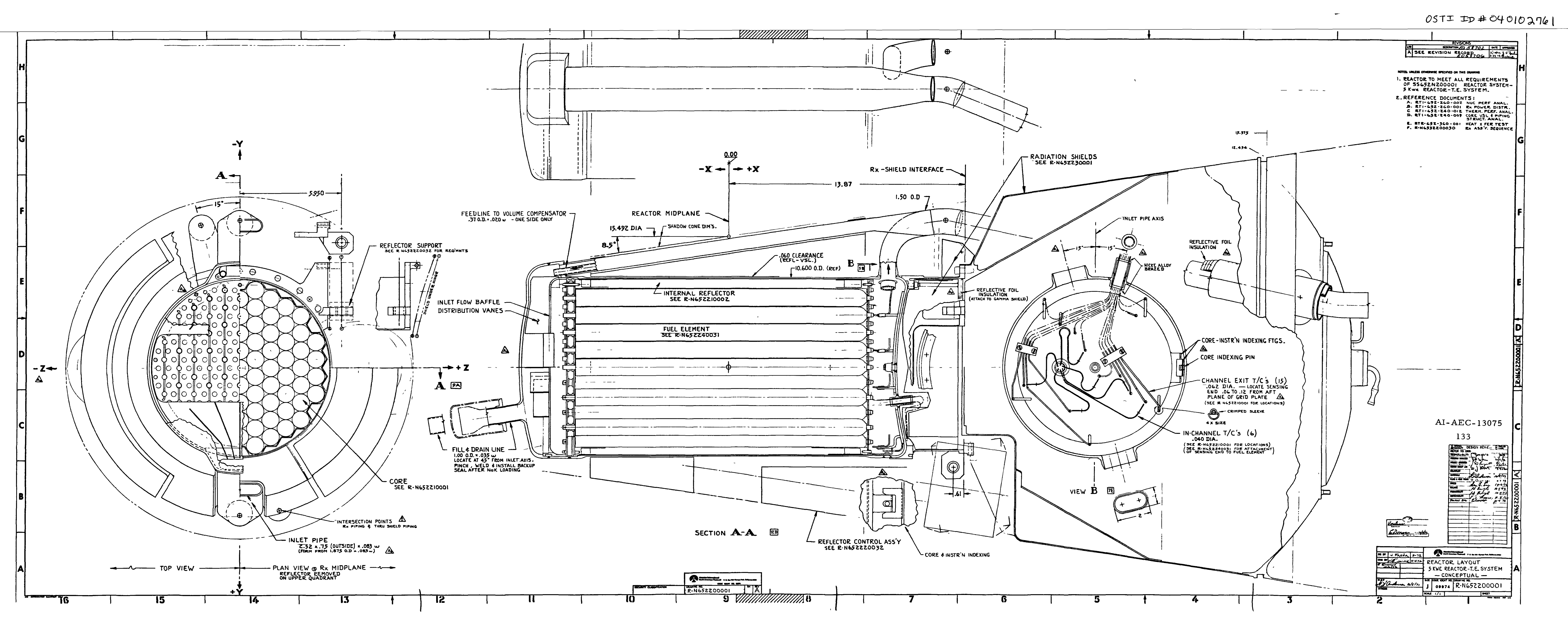




\section{BLANK}




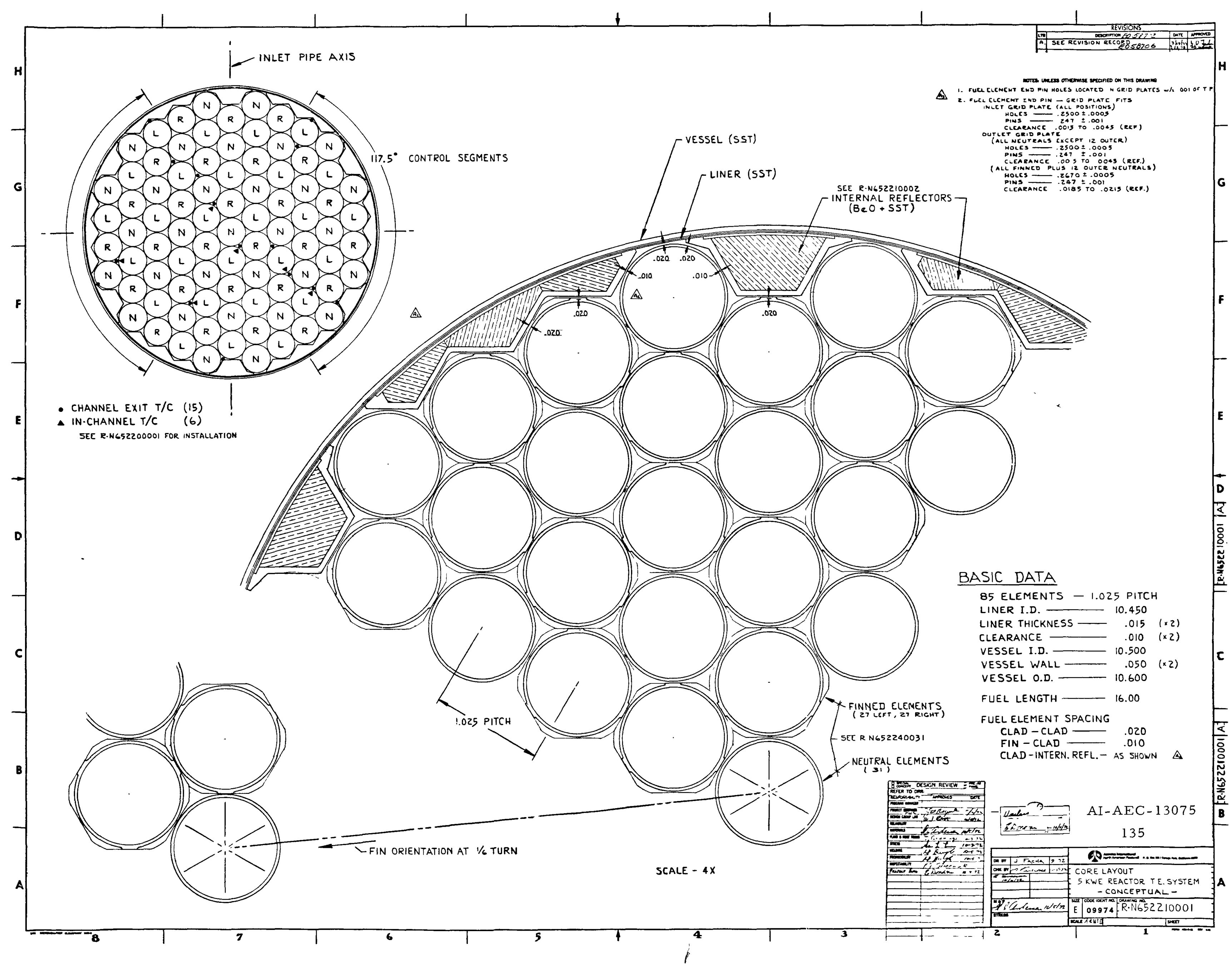




\section{BLANK}




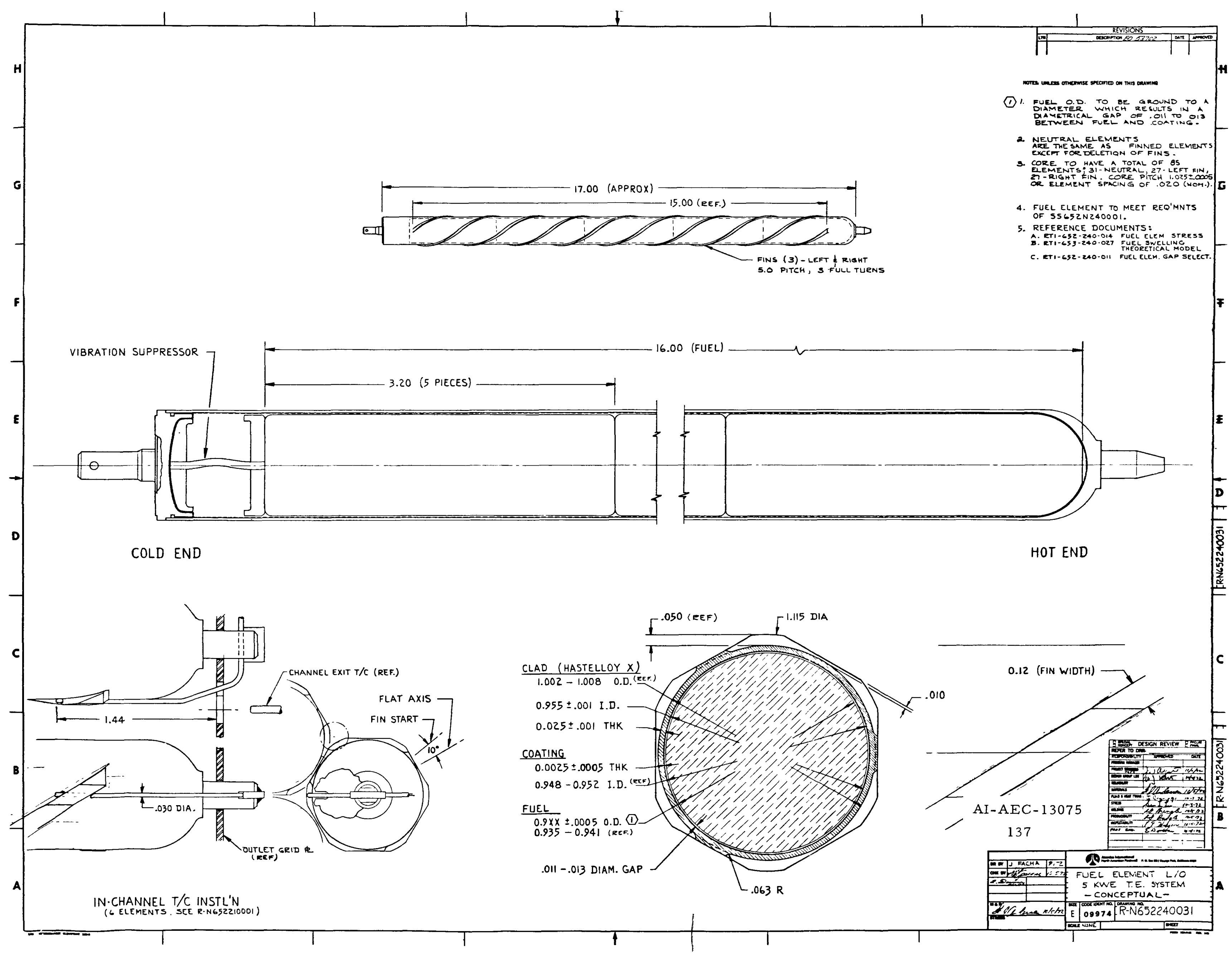




\section{BLANK}


There was no Page 139 located in original document. 
There was no Page 140 located in original document. 
There was no Page 141 located in original document. 
There was no Page 142 located in original document. 


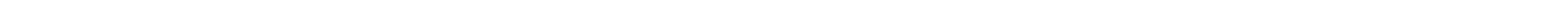




\section{BLANK}




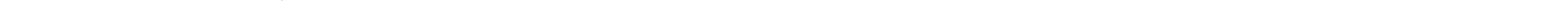

